Universidade de São Paulo

Faculdade de Filosofia, Ciências e Letras de Ribeirão Preto

Departamento de Química

Programa de Pós-Graduação em Química

\title{
Correlação da estrutura-função das Anexinas A5 e A6 no processo
}

\section{de biomineralização}

Ekeveliny Amabile Veschi

Tese apresentada à Faculdade de

Filosofia, Ciências e Letras de Ribeirão Preto da Universidade de São Paulo, como parte das exigências para a obtenção do título de Doutor em Ciências, Área: Química

RIBEIRÃO PRETO -SP 


\section{Universidade de São Paulo}

Faculdade de Filosofia, Ciências e Letras de Ribeirão Preto

Departamento de Química

Programa de Pós-Graduação em Química

\section{Correlação da estrutura-função das Anexinas A5 e A6 no processo}

\section{de biomineralização}

Ekeveliny Amabile Veschi

Orientador: Prof Dr. Pietro Ciancaglini

Co-orientador: Profa. Dra. Maytê Bolean

Tese apresentada à Faculdade de Filosofia, Ciências e Letras de Ribeirão Preto da Universidade de São Paulo, como parte das exigências para a obtenção do título de Doutor em Ciências, Área: Química

RIBEIRÃO PRETO -SP 


\section{FICHA CATALOGRÁFICA}

\section{Veschi, Ekeveliny Amabile}

Correlação da estrutura-função das Anexinas A5 e A6 no processo de biomineralização. Ribeirão Preto, 2021 p. 106

Tese de doutorado apresentada à Faculdade de Filosofia, Ciências e Letras de Ribeirão Preto/ USP - Área de Concentração: Química

Orientador: Ciancaglini, Pietro

Co-orientador: Bolean, Maytê

1.Anexina A6. 2. Lipossomos. 3. Proteolipossomos 4. Biomineralização 


\section{Agradecimentos Especiais}

De nada valeria esse momento se não existissem pessoas especiais com quem partilhar essa grande conquista, pois ninguém e nada crescer sozinho, sempre é preciso uma palavra de incentivo, um gesto de compreensão e uma atitude de amor. Sou grata por estar cercada de pessoas especiais, e a elas dedico essa Tese.

\section{À minha mãe Silvana,}

que nunca mediu esforços para que eu pudesse seguir meu sonhos e planos. Obrigada por todo carinho, atenção e apoio nos momentos dificeis. Obrigada por sempre me incentivar a ir mais longe, por me fazer enxergar a importância de se dedicar para conquistar nossos objetivos.

\section{Ao meu namorado, noivo e marido Bruno,}

Vivemos todos esses estágios durante a realização desse projeto, sendo você meu maior incentivador, se não fosse você eu não estaria escrevendo essa Tese hoje, e nem seria química! Palavras não conseguem mensurar o tamanho da gratidão que tenho por ter você ao meu lado. Então, em singelas palavras muito obrigada por ser meu porto seguro, meu apoio, meu amigo, meu companheiro de vida! Essa conquista também é sua!

Vó Irene, Tia Rosana, Tio Marcos, Má, Tio Kaká, Lindomar, Evandro e Maira,

Vocês acompanharam todo longo e árduo caminho até aqui, obrigada por todas as palavras de afeto e incentivo. Cada um ao seu modo, sempre me deu muita força para continuar.

Obrigada por vocês fazerem parte da minha vida!

\section{Manu, Nina e Vivi}

Minha afilhada Manuela, presente que ganhei durante o doutorado e que trouxe um brilho especial para os dias mais cinzas, obrigada por me alegrar com seu sorriso travesso! Nina, minha pequena dog, mesmo sem entender nada sempre foi a melhor ouvinte para as minhas apresentações e a companhia mais acolhedora em todos os momentos! Vivi, minha pequena grande irmã, obrigada por todo amor e carinho dedicado a mim, mesmo nos momentos que tive que fazer meu papel de irmã mais velha! 


\section{Pietro,}

Humildade, sabedoria, ética, generosidade, compreensão e amizade para mim são algumas das melhores palavras para tentar descrever o que aprendi nos últimos anos tendo você como orientador.

Admiro muito seu lado humano e profissional, e me sinto extremamente privilegiada por ter sido orientada por uma pessoa como você, e por ter feito parte do seu grupo de pesquisa.

Então, só tenho a agradecer pela oportunidade que me foi dada de aprender tanto ao seu lado, obrigada pelo incentivo, pela paciência e pela confiança concedida a mim.

Enfim, obrigada por tudo! 


\section{Agradecimentos}

À Coordenação de Aperfeiçoamento de Pessoal de Nível Superior (CAPES) pela Bolsa de Doutorado.

Ao Prof. Dr. Rene Buchet, pela colaboração neste projeto enviando amostras de Anexina A6 para a realização dos experimentos.

À prof ${ }^{a}$ Dra. Ana Paula Ramos por disponibilizar os equipamentos de seu laboratório, como também todas as discussões de resultados e análises de FTIR realizadas.

José Luís Millán, Massimo Bottini, Saida Mebarek e Thierry Granjon pela colaboração e apoio científico.

Aos amigos do laboratório de Sistemas Miméticos de Membrana: Bruno Favarin, Bruno Molero, Cláudio, Fábio, Heitor, Luiz e Maytê. Obrigada pela amizade, por todo conhecimento compartilhado, por todos os bolos, risadas e momentos agradáveis que vivemos juntos.

À Maytê obrigada por ter visto algo em mim e ter acreditado que eu era capaz de fazer esse doutorado direto. Sou muito agradecida pelo apoio e por todos os ensinamentos.

Aos queridos amigos Luiz e Cláudio, que viveram cada momento dessa caminhada ao meu lado. Obrigada por tudo que vocês fizeram para me ajudar, obrigada por cada momento único e especial que vivemos juntos no laboratório, por todas conversas, risadas, aprendizagens e cookies! Vocês são muito especiais para mim!

À Ana Maria, por ter sido a primeira pessoa que tive contato no laboratório e que com toda sua experiência e paciência me ensinou muito do que levo comigo hoje. Muito obrigada por esses ensinamentos e pela amizade demonstrada!

Ao laboratório da Prof a $^{a}$ Dra Ana Paula Ramos, muito obrigada a todos os alunos que me auxiliaram em diversos experimentos, em especial ao Marcos que sempre foi solicito e pronto a me ajudar.

À Dra . Ivana Aparecida Borin, obrigada pela paciência e ajuda com as análises de AFM.

À Janaina, pelo apoio no laboratório.

À Cinthia Moraes pela ajuda com inglês.

Aos docentes, técnicos, funcionários e demais pessoas do Departamento de Química da Faculdade de Filosofia, Ciências e Letras de Ribeirão Preto - USP.

À FAPESP, CAPES e CNPq, pela bolsa e auxílios concedidos ao laboratório.

Enfim, agradeço a todos que torceram por mim e que, de alguma forma, contribuíram para o desenvolvimento deste trabalho. 
A única pessoa que você está destinado a se tornar é a pessoa que você decide ser.

Ralph Waldo Emerson 
A persistência é o menor caminho do êxito.

Charles Chaplin 


\section{SUMÁRIO}

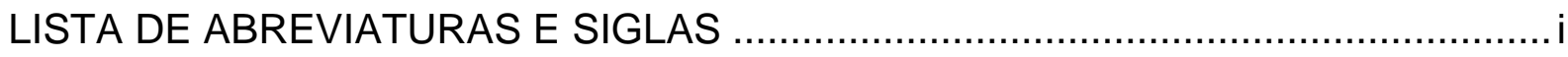

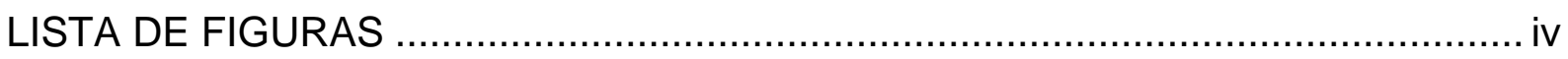

LISTA DE TABELA ......................................................................................

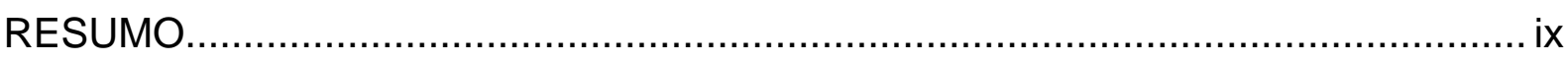

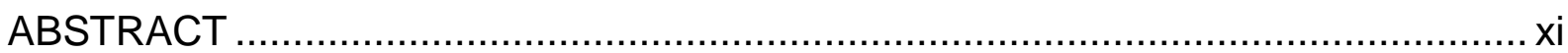

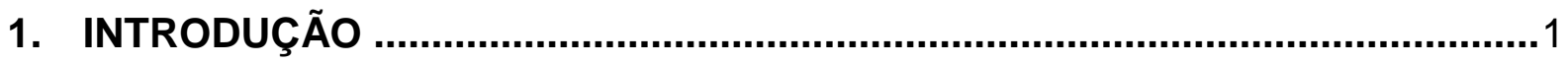

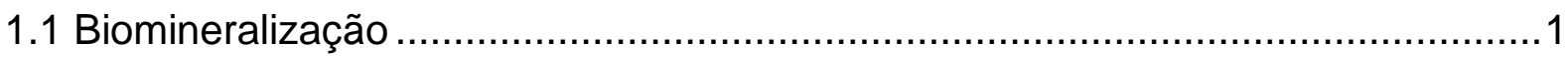

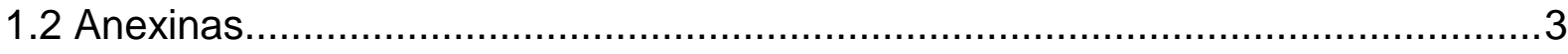

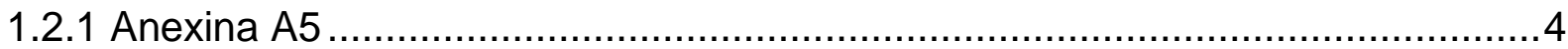

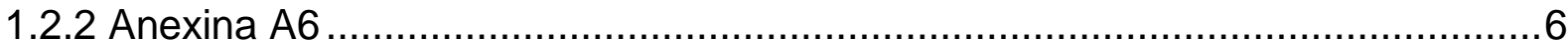

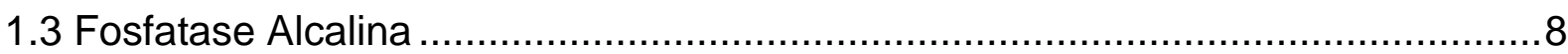

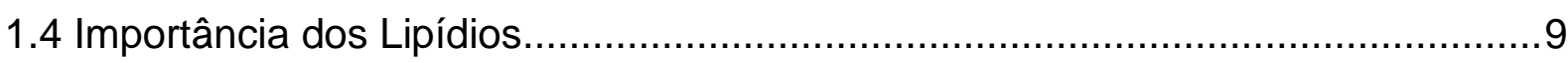

1.5 Principais Técnicas Bioquímicas e Biofísicas .............................................11

1.5.1 Calorimetria Diferencial de Varredura (DSC) .......................................11

1.5.2 Espectroscopia de Dicroísmo Circular (CD) ...........................................13

1.5.3 Espalhamento de Luz Dinâmico (DLS) ............................................... 14

1.5.4 Microscopia de Força Atômica (AFM) ................................................15

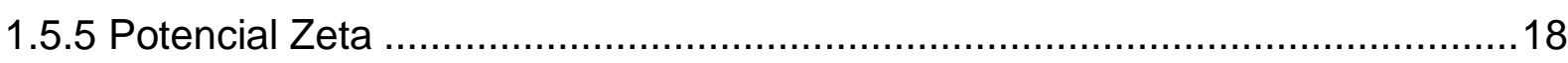

1.5.6 Sistemas Miméticos de Membranas - Monocamadas e Lipossomos ..............20

1.5.7 Tensão Superficial - Método da Gota Pendente ........................................21

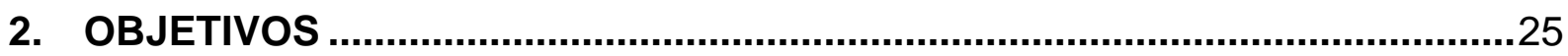

3. MATERIAL E MÉTODOS.............................................................................27

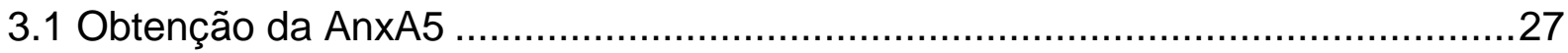

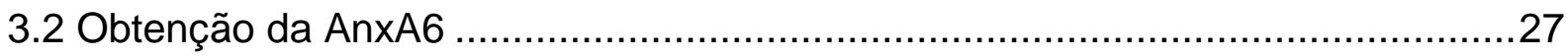

3.3 Caracterização estrutural das Anexinas A5 e A6 por Dicroísmo Circular ............27

3.4 Cálculo da elipticidade e estimativa de $\alpha$-hélices .......................................28

3.6 Análise da tensão superficial pelo método da gota pendente ..........................29

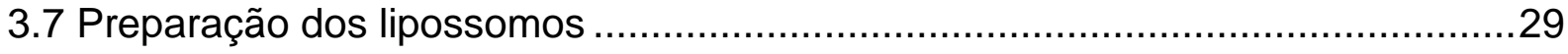




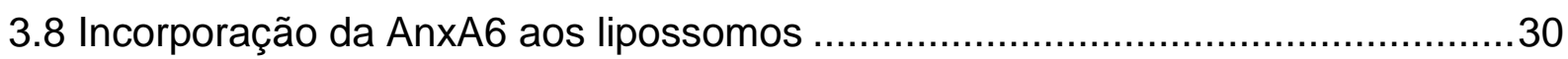

3.9 Medidas de espalhamento de luz dos lipossomos e proteolipossomos ...............30

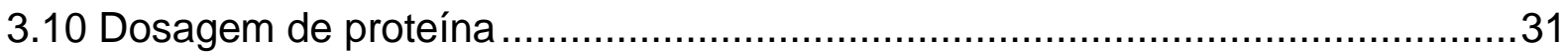

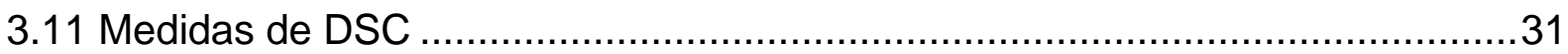

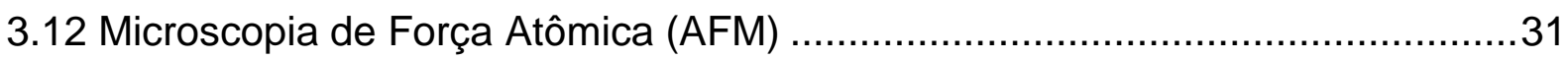

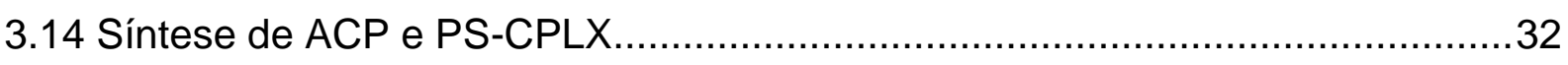

3.13 Ensaio de mineralização em microplacas com proteolipossomos......................33

3.14 Espectroscopia de infravermelho com transformada de Fourier (FTIR) ............33

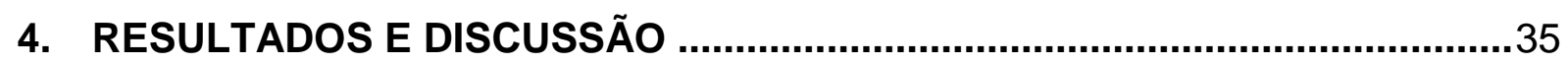

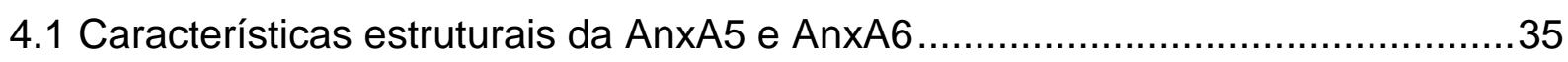

4.1.1 Caracterização estrutural das Anexinas A5 e A6 por Dicroísmo Circular .........35

4.1.2 Determinação do ponto isoelétrico da AnxA6 por medidas de potencial zeta ..39 4.2 Interação da AnxA6 com monocamadas lipídicas pelo método de gota pendente

4.3 Interação e caracterização da AnxA6 em lipossomos 45

4.3.1 Interação e Caracterização termodinâmica dos lipossomos e proteolipossomos de AnxA6

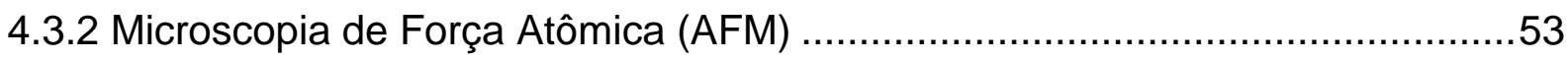

4.3.3 Estabilidade das vesículas utilizando o espalhamento de luz dinâmico ...........60

4.4 Ensaio de mineralização em microplacas com proteolipossomos.......................65

4.4.1 Espectroscopia de infravermelho com transformada de Fourier (FTIR) ...........77

5. CONCLUSÃO

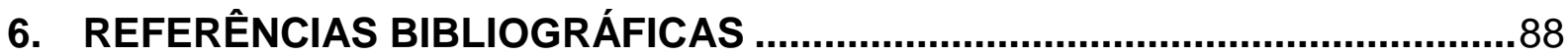

7. APÊNDICE 


\section{LISTA DE ABREVIATURAS E SIGLAS}

A 340 - Absorbância em 340nm

ACP - Fosfato de Calcio amorfo

AFM - Microscopia de Força Atômica

AMP - Adenosina-5'-monofosfato

AMPOL: 2-amino-2-metil-1-propanol

AnxA5 - Anexina A5

AnxA6 - Anexina A6

ATP - Adenosina-5'-trifosfato

ATR - Acessório de Reflectância Total

BSA: Albumina de Soro Bovino

CD - Dicroísmo Circular

Chol - Colesterol

$\mathrm{Cp}$ - Capacidade calorífica

Cpmax - Capacidade calorífica máxima

$\Delta \mathrm{T}_{1 / 2}$ - Cooperatividade de transição de Fase

$\Delta \mathrm{H}$ - Variação de Entalpia de transição de Fase

$\Delta \mathrm{P}$ - Variação da Pressão da Interface

Da - Dalton

DLS - Espalhamento de Luz Dinâmico

DPPC - Dipalmitoil fosfatidilcolina

DPPS - Dipalmitoil fosfatidilserina

DSC - Calorimetria Diferencial de Varredura

ECM - Matriz Extracelular

EGTA - Ácido etilenodiaminotetracético 
$f_{H}$-Quantidade de $\alpha$-hélice

FTIR - Espectroscopia de infravermelho com transformada de Fourier

$\gamma$ - Tensão Superficial

HA - Hidroxiapatita

$\mathrm{HCl}$ - Ácido Clorídrico

ICP - Fosfato Intracelular

IP - Índice de Polidispersão

Lo - Fase líquido-ordenada

La - Fase líquido-cristalina

$\mathrm{MgCl}_{2}$ - Cloreto de Magnésio

$\mathrm{MgSO}_{4}$ - Sulfato de Magnésio

MRW - Massa Molecular Média

MVs - Vesículas da Matriz

$\mathrm{NaOH}$ - Hidróxido de Sódio

PA - Ácido Fosfatídico

$\mathrm{PC}$ - fosfocolina

PE - fosfoetanolamina

PI - Fosfatidilinositol

$\mathrm{Pi}$ - Fosfato inorgânico

$\mathrm{pl}$ - Ponto Isoelétrico

PPi - Pirofosfato inorgânico

PS-CPLX - Nucleador (Emulsão de PS, Tampão ICP, $\mathrm{CaCl}_{2}$ )

SCL - Tampão linfa de cartilagem sintética

SM - Esfingomielina

SUV - Vesículas unilamelares pequenas

Tc - Temperatura crítica de transição

TNAP - Fosfatase Alcalina Tecido não Específica 
Tris - Tris(hidroximetil)aminometano

$\theta_{\text {obs }}$ - Elipticidade observada

$\theta_{\lambda}-$ Elipticidade molar

$\lambda$ - comprimento de onda

$\pi$ - Pressão Superficial

Texc - Pressão de Exclusão 


\section{LISTA DE FIGURAS}

Figura 1. Representação esquemática das moléculas envolvidas na calcificação mediada pelas vesículas da matriz, incluindo as reações enzimáticas mais favorecidas dos substratos fisiológicos. Adaptado de Simão et al. (2010a)

Figura 2. Estrutura cristalina da AnxA5 humana. Os 4 domínios estão representados pelas diferentes cores e os íons cálcio estão representados pelas esferas amarelas. Domínio I: verde, Domínio II: azul escuro, Domínio III: azul e rosa e Domínio IV: vermelho (Liemann e Huber, 1997)......

Figura 3. Estrutura da AnxA6 bovina. A parte $\mathrm{N}$-terminal da AnxA6 correspondente aos resíduos 2-342 (AnxA6a) é mostrada em verde, enquanto que a parte C-terminal associada aos resíduos 348-673 (AnxA6b) é mostrada em azul. A caixa com uma dimensão limitada no centro de AnxA6 indica a suposta localização do sítio de ligação de nucleotídeos. Adaptado de Pikula et al. (2003)....

Figura 4. Características dos parâmetros termodinâmicos de uma curva de DSC, utilizando no esquema lipossomos constituídos de DPPC $\left(10 \mathrm{mgmL}^{-1}\right)$. Adaptado de Demetzos et al. (2008)

Figura 5. Perfis de espectros de dicroísmo circular característicos de peptídeos em conformação em $\alpha$-hélice (círculos a cheio), em conformação em folha- $\beta$ (círculos vazios) e sem conformação preferencial (losangos) (Fändrich e Dobson, 2002) ....

Figura 6. Ilustração simplificada de um Microscópio de Força Atômica. Adaptado de Mironov, (2004).

Figura 7. Representação da distribuição de íons em torno de uma partícula esférica negativamente carregada dispersa num liquido ionizado. Adaptado de Zetasizer Nano Series, (2004)

Figura 8. Representação de uma monocamada, A - formada em uma interface água - ar; B - técnica de deposição com substrato sólido denominado filmes de Langmuir - Blodgett (LB). Adpatado de Oliveira et al. (2018)...

Figura 9. Representação de um lipossomo evidenciando sua estrutura interna constituída de um núcleo polar cercado por uma bicamada de fosfolipídios. Adaptado de Lehninger, (2014).

Figura 10. Configuração experimental de um instrumento de gota pendente. Adaptado de Maldonado-Valderrama et al. (2015).

Figura 11. Espectros de Dicroísmo Circular para AnxA5 $\left(2 \mu \mathrm{g} \cdot \mathrm{mL}^{-1}\right)$ para diferentes valores de $\mathrm{pH}$. Inserção: Elipticidade relativa molar em função da variação de $\mathrm{pH}$ com as respectivas estimativas percentuais de estruturas a-hélices. Preto - $\mathrm{pH} 3,0$; Vermelho - $\mathrm{pH}$ 5,0; Azul $\mathrm{pH}$ 8,0 e Rosa - pH 11,0. 
Figura 12. Espectros de Dicroísmo Circular para AnxA6 $\left(2 \mu \mathrm{g} \cdot \mathrm{mL}^{-1}\right)$ para diferentes valores de $\mathrm{pH}$. Inserção: Elipticidade relativa molar em função da variação de $\mathrm{pH}$ com as respectivas estimativas percentuais de estruturas $\alpha$-hélices. Preto - $\mathrm{pH} 2,0$; Vermelho - $\mathrm{pH} 3,0$; Azul $\mathrm{pH}$ 4,4; e Rosa - pH 7,0; Verde - pH 8,0 e Roxo - pH 10,0.

Figura 13. Potencial zeta da AnxA6 em função do pH para obtenção do ponto isoelétrico (pl)

Figura 14. Mudanças na pressão superficial $(\Delta \pi)$ devido à injeção de AnxA6 em função da pressão superficial inicial $\left(\pi_{0}\right)$ das monocamadas de Langmuir na ausência de $2 \mathrm{mM}$ de $\mathrm{Ca}^{2+}$. A interceptação com a abscissa é a pressão de exclusão $\left(\pi_{\text {exc }}\right)$. As análises foram ajustadas para $\pi_{0}$ próximo a 10, 15 e $20 \mathrm{mN} / \mathrm{m}$.

Figura 15. Mudanças na pressão superficial $(\Delta \pi)$ devido à injeção de AnxA6 em função da pressão superficial inicial $\left(\pi_{0}\right)$ das monocamadas de Langmuir na presença de $2 \mathrm{mM}$ de $\mathrm{Ca}^{2+}$. A interceptação com a abscissa é a pressão de exclusão ( $\left.\Pi_{\mathrm{exc}}\right)$. As análises foram ajustadas para $\pi_{0}$ próximo a 10, 15 e $20 \mathrm{mN} / \mathrm{m}$.

Figura 16. Termogramas de calorimetria de varredura diferencial (DSC) dos lipossomos de DPPC na ausência (A) e na presença de $2 \mathrm{mM}$ de $\mathrm{Ca}^{2+}(B)\left(10 \mathrm{mg} \cdot \mathrm{mL}^{-1}\right.$, concentração total de lipídios). Os termogramas de DSC foram processados em excesso de capacidade de calor (Cp) (kcal. $\left.\mathrm{K}^{-1} \cdot \mathrm{mol}^{-1}\right)$ em função da temperatura $\left({ }^{\circ} \mathrm{C}\right)$ dos lipossomos (linha preta) e proteolipossomos (linha vermelha).

Figura 17. Termogramas de calorimetria de varredura diferencial (DSC) dos lipossomos de DPPC:DPPS (9:1 - razão molar) na ausência (A) e na presença de $2 \mathrm{mM}$ de $\mathrm{Ca}^{2+}(\mathrm{B})$ (10 $\mathrm{mg} \cdot \mathrm{mL}^{-1}$ concentração total de lipídios). Os termogramas de DSC foram processados em excesso de capacidade de calor $(\mathrm{Cp})\left(\mathrm{kcal}^{\mathrm{K}} \mathrm{K}^{-1} \cdot \mathrm{mol}^{-1}\right)$ em função da temperatura $\left({ }^{\circ} \mathrm{C}\right)$ dos lipossomos (linha preta) e proteolipossomos (linha vermelha)....

Figura 18. Termogramas de calorimetria de varredura diferencial (DSC) dos lipossomos de DPPC:Chol (6:4 - razão molar) na ausência $(A)$ e na presença de $2 \mathrm{mM}$ de $\mathrm{Ca}^{2+}(B)$ (10 $\mathrm{mg} \cdot \mathrm{mL}^{-1}$, concentração total de lipídios). Os termogramas de DSC foram processados em excesso de capacidade de calor $(\mathrm{Cp})\left(\mathrm{kcal}^{\mathrm{K}} \mathrm{K}^{-1} \cdot \mathrm{mol}^{-1}\right)$ em função da temperatura $\left({ }^{\circ} \mathrm{C}\right)$ dos lipossomos (linha preta) e proteolipossomos (linha vermelha).

Figura 19. Termogramas de calorimetria de varredura diferencial (DSC) dos lipossomos de DPPC:Chol:DPPS (6:4:1 - razão molar) na ausência $(A)$ e na presença de $2 \mathrm{mM}$ de $\mathrm{Ca}^{2+}(B)$ (10 mg. $\mathrm{mL}^{-1}$, concentração total de lipídios). Os termogramas de DSC foram processados em excesso de capacidade de calor (Cp) $\left(\mathrm{kcal}^{\mathrm{K}} \mathrm{K}^{-1} \cdot \mathrm{mol}^{-1}\right)$ em função da temperatura $\left({ }^{\circ} \mathrm{C}\right)$ dos lipossomos (linha preta) e proteolipossomos (linha vermelha). 50

Figura 20. Análise de AFM dos lipossomos de DPPC $\left(1,5 \mathrm{mg} \cdot \mathrm{mL}^{-1}\right)$ : imagem de fase $(A)$, perfis topográficos $3 \mathrm{D}(\mathrm{B})$ e estrutura química do DPPC e representação esquemática dos lipossomos (C). 55

Figura 21. Análise de AFM dos lipossomos de 5:4:1 DPPC:Chol:DPPS (1,5 mg. $\left.\mathrm{mL}^{-1}\right)$ : imagem de fase $(A)$, perfis topográficos 3D (B) e estrutura química do DPPS e colesterol com representação esquemática dos lipossomos $(\mathrm{C})$. 
Figura 22. Análise de AFM dos proteolipossomos de DPPC contendo AnxA6: (A) imagem de fase, (B) imagem de altura, (C) perfil topográfico 3D (D) Zoom (146,48 nm x 146,48 nm) da superfície do proteolipossomo mostrando domínios de proteína; (E) Análise de linha simultânea de fase e altura (linhas azuis e vermelhas) dos domínios AnxA6 inseridos em proteolipossomos, e $(F)$ Perfis de altura e análise derivada de fase de linhas azuis e vermelhas no proteolipossomo DPPC-AnxA6, a sombra cinza destaca as saliências. A Figura E foi preparada usando o software WSxM 4.0 Beta 9.1 desenvolvido por Horcas et al. (2007).

Figura 23. Análise de AFM dos proteolipossomos de 5:4:1 DPPC:Chol:DPPS contendo AnxA6: (A) imagem de fase, (B) imagem de altura, (C) perfil topográfico 3D (D) Zoom $(109,83 \mathrm{~nm} \times 109,83 \mathrm{~nm})$ da superfície do proteolipossomo mostrando domínios de proteína; (E) Análise de linha simultânea de fase e altura (linhas azuis e vermelhas) dos domínios AnxA6 inseridos nos proteolipossomos, e (F) Perfis de altura e análise derivada de fase de linhas azuis e vermelhas no proteolipossomo DPPC:Chol:DPPS-AnxA6, a sombra cinza destaca as saliências. A Figura E foi preparada usando o software WSxM 4.0 Beta 9.1 desenvolvido por Horcas et al. (2007).

Figura 24. DLS de lipossomos $\left(10 \mathrm{mg} \cdot \mathrm{mL}^{-1}\right)$ na ausência de $\mathrm{Ca}^{2+}$. (A) Diâmetro médio das vesículas; (B) Índice de polidispersão. Azul - DPPC; Cinza - 9:1 DPPC:DPPS; Laranja - 6:4 DPPC:Chol e amarelo - DPPC:Chol:DPPS (6:4:1), razões molares. Os gráficos de dispersão de luz diferencial foram registrados usando o N5 Submicron Particle Size Analyzer. $O$ valor médio $(n=5)$ dos diâmetros dos lipossomas foi obtido a $25^{\circ} \mathrm{C}$ por distribuição unimodal, previamente filtrado $(0,8 \mu \mathrm{m})$. 61

Figura 25. DLS de proteolipossomos $\left(4,6 \mathrm{mg}^{-1}\right)$ na ausência de $\mathrm{Ca}^{2+}$. (A) Diâmetro médio das vesículas; (B) Índice de polidispersão. Azul - DPPC; Cinza - 9:1 DPPC:DPPS; Laranja - 6:4 DPPC:Chol e Amarelo - DPPC:Chol:DPPS (6:4:1), razões molares. Os gráficos de dispersão de luz diferencial foram registrados usando o N5 Submicron Particle Size Analyzer. O valor médio $(n=5)$ dos diâmetros dos lipossomas foi obtido a $25^{\circ} \mathrm{C}$ por distribuição unimodal, previamente filtrado $(0,8 \mu \mathrm{m})$. 62

Figura 26. DLS de lipossomos $\left(10 \mathrm{mg}^{\mathrm{mL}} \mathrm{m}^{-1}\right)$ na presença de $\mathrm{Ca}^{2+}$. (A) Diâmetro médio das vesículas; (B) Índice de polidispersão. Azul - DPPC; Cinza - 9:1 DPPC:DPPS; Laranja - 6:4 DPPC:Chol e Amarelo - DPPC:Chol:DPPS (6:4:1), razões molares. Os gráficos de dispersão de luz diferencial foram registrados usando o N5 Submicron Particle Size Analyzer. $O$ valor médio $(n=5)$ dos diâmetros dos lipossomas foi obtido a $25^{\circ} \mathrm{C}$ por distribuição unimodal, previamente filtrado $(0,8 \mu \mathrm{m})$.

Figura 27. DLS de proteolipossomos $\left(4,6 \mathrm{mg} \cdot \mathrm{mL}^{-1}\right)$ na presença de $\mathrm{Ca}^{2+}$. (A) Diâmetro médio das vesículas; (B) Índice de polidispersão. Azul - DPPC; Cinza - 9:1 DPPC:DPPS; Laranja - 6:4 DPPC:Chol e Amarelo - DPPC:Chol:DPPS (6:4:1), razões molares. Os gráficos de dispersão de luz diferencial foram registrados usando o N5 Submicron Particle Size Analyzer. $O$ valor médio $(n=5)$ dos diâmetros dos lipossomas foi obtido a $25^{\circ} \mathrm{C}$ por distribuição unimodal, previamente filtrado $(0,8 \mu \mathrm{m})$.

Figura 28. Teste de mineralização in vitro empregando formulações de DPPC. (A) Nucleador ACP; (B) Nucleador PS-CPLX. Vermelho - Proteolipossomo; Preto - somente Lipossomo; Rosa - AnxA6 (em solução) + nucleador; Azul - somente o Nucleador e Verde AnxA6 sozinha (em solução). 
Figura 29. Teste de mineralização in vitro empregando formulações de 9:1 DPPC:DPPS. (A) Nucleador ACP; (B) Nucleador PS-CPLX. Vermelho - Proteolipossomo; Preto - somente Lipossomo; Rosa - AnxA6 (em solução) + nucleador; Azul - somente o Nucleador e Verde AnxA6 sozinha (em solução).

Figura 30. Teste de mineralização in vitro empregando formulações de 5:4:1 DPPC:Chol:DPPS. (A) Nucleador ACP; (B) Nucleador PS-CPLX. Vermelho Proteolipossomo; Preto - somente Lipossomo; Rosa - AnxA6 (em solução) + nucleador; Azul - somente o Nucleador e Verde - AnxA6 sozinha (em solução). 69

Figura 31. Teste de mineralização in vitro empregando formulações de DPPC na presença de colágeno tipo I. (A) Nucleador ACP; (B) Nucleador PS-CPLX. Vermelho Proteolipossomo; Preto - somente Lipossomo; Rosa - AnxA6 (em solução) + nucleador; Azul - somente o Nucleador e Verde - AnxA6 sozinha (em solução).

Figura 32. Teste de mineralização in vitro empregando formulações de 9:1 DPPC:DPPS na presença de colágeno tipo I. (A) Nucleador ACP; (B) Nucleador PS-CPLX. Vermelho Proteolipossomo; Preto - somente Lipossomo; Rosa - AnxA6 (em solução) + nucleador; Azul - somente o Nucleador e Verde - AnxA6 sozinha (em solução).

Figura 33. Teste de mineralização in vitro empregando formulações de 5:4:1 DPPC:Chol:DPPS na presença de colágeno tipo I. (A) Nucleador ACP; (B) Nucleador PSCPLX. Vermelho - Proteolipossomo; Preto - somente Lipossomo; Rosa - AnxA6 (em solução) + nucleador; Azul - somente o Nucleador e Verde - AnxA6 sozinha (em solução).

Figura 34. Espectros de FTIR de proteolipossomos com o nucleador PS CPLX. (A) ausência de colágeno; (B) presença de colágeno. Azul - DPPC; Verde - 9:1 DPPC:DPPS; Vermelho - 5:4:1 DPPC:Chol:DPPS e Rosa - AnxA6, em solução, + nucleador

Figura 35. Mecanismo de translocação da AnxA6 em vesículas de matriz durante a mineralização e suas funções. (A) Em baixa concentração de cálcio, a AnxA6 está localizada no lúmen das MVs. (B) $O$ acúmulo de cálcio dentro das MVs favorece a ligação da AnxA6, onde sua afinidade de ligação para $\mathrm{Ca}^{2+}$ está na faixa de $\mathrm{mM}$, então a AnxA6 liga-se a lamela interna das MVs, contendo fosfatidilserina (PS), de uma maneira dependente de cálcio, formando um núcleo nucleacional, iniciando a formação de apatita. (C) Durante a formação da apatita, ocorre a liberação de prótons $\left(\mathrm{H}^{+}\right)$, induzindo a protonação da AnxA6, tornando-a mais hidrofóbica devido ao seu potencial de ionização em torno de 5,5. Uma parte da AnxA6 pode ser inserida na bicamada das MVs, onde pode formar um poro de íon. (D) O pH externo corresponde ao da matriz extracelular e é neutro, (E) AnxA6 pode ser desprotonada e liberada para a superfície externa das MVs ricas em fosfatidilcolina (PC). (F) Sua ligação a fosfolipídios neutros não depende do cálcio. O AnxA6 ou AnxA5 podem se ligar às fibras de colágeno, contribuindo para fixar as MVs às fibras de colágeno (Veschi et al., 2020). 


\section{LISTA DE TABELA}

Tabela 1. Valores de $\pi_{\text {exc }}$ para cada composição lipídica estudada na monocamada.

Tabela 2. Efeito da composição lipídica e da presença dos íons $\mathrm{Ca}^{2+}$ na incorporação de AnxA6 em proteolipossomos.

Tabela 3. Parâmetros termodinâmicos de diferentes composições de lipossomos (10 mg. $\mathrm{mL}^{-1}$ ) e proteolipossomas contendo AnxA6 por meio de DSC, na presença e ausência de $\mathrm{Ca}^{2+}(2 \mathrm{mM})$

Tabela 4. Porcentagem de formação mineral estimada em (\%), conforme descrito por Warner e colaboradores (1983). Cada amostra utilizada no ensaio (lipossomos e proteolipossomos) com os nucleadores ACP e PS-CPLX na ausência ou na

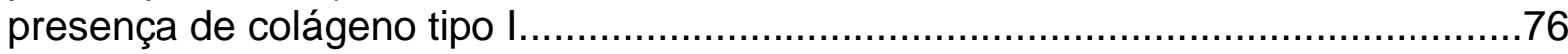

Tabela 5. Razões entre as áreas das bandas em $1032\left(\mathrm{PO}_{4}{ }^{3-}\right)$ e $1740(\mathrm{C}=\mathrm{O}) \mathrm{cm}^{-1}$ obtidas por FTIR para as diferentes amostras de proteolipossomos. 


\section{RESUMO}

O tecido ósseo é constituído pela combinação de uma matriz de colágeno e uma matriz mineral, que é formada por cristais de fosfato de cálcio, sob a estrutura de hidroxiapatita. Este processo de acúmulo de mineral no tecido ósseo é denominado biomineralização e é realizado por células chamadas osteoblastos, por intermédio da liberação de vesículas da matriz (MVs). Estas vesículas surgem por brotamento das superfícies das células e são secretadas no local específico do início da biomineralização na matriz do tecido ósseo. MVs contém altas concentrações de íon $\mathrm{Ca}^{2+}$ e fosfato inorgânico ( $\mathrm{Pi}$ ), proporcionando um microambiente adequado para a formação inicial e propagação dos cristais de hidroxiapatita. Para que isso ocorra corretamente são necessárias várias proteínas/enzimas, bem como microambientes com condições bastante particulares. Uma atenção especial deve ser dada a algumas proteínas presentes nas MVs: Anexina A5 (AnxA5) e Anexina A6 (AnxA6) e a Fosfatase Alcalina de tecido não especifica (TNAP). A AnxA6, foco de estudo desta tese, é o maior membro da família das anexinas presentes nas MVs, com aproximadamente $68 \mathrm{kDa}$. Análises bioquímicas revelaram que ela está presente em três regiões distintas nas $M V s$, indicando diversas funções durante o processo de mineralização. Buscamos neste estudo, compreender características e possíveis funções da AnxA6, comparando muitos de nossos achados com o que temos disponível na literatura em relação a AnxA5. O estudo revelou que em pH 6,5, 86\% da estrutura da AnxA6 está na conformação a-hélice enquanto que a AnxA5 apresentou maior quantidade de $\alpha$-hélice em pH 8 ( $50 \%)$. Utilizando-se medidas de potencial zeta, foi possível determinar o ponto isoelétrico de 4,2 para a AnxA6. Os demais estudos foram realizados utilizando monocamadas e proteolipossomos composto de dipalmitoil fosfatidilcolina (DPPC) para mimetizar a lamela externa da bicamada de MV e eventualmente para imitar a lamela interna utilizou-se uma mistura de 9:1 DPPC:dipalmitoil fosfatidilserina (DPPS) com e sem $\mathrm{Ca}^{2+}$. Confirmamos que, de acordo com os dados bioquímicos, a AnxA6 interage de forma diferente com a membrana da MV. Análises termodinâmicas baseadas em medidas de pressão de exclusão superficial (mexc), entalpia $(\Delta \mathrm{H})$ e cooperatividade de transição de fase $\left(\Delta T_{1 / 2}\right)$ mostraram que a AnxA6 interage com DPPC e 9:1 DPPC:DPPS, sendo que esta interação se tornou maior na presença de colesterol (Chol) (6:4 DPPC:Chol e 5:4:1 DPPC:Chol:DPPS). A interação AnxA6-lipídio também se mostrou $\mathrm{Ca}^{2+}$-dependente, conforme evidenciado pelo aumento na $\pi_{e x c}$ 
em monocamadas carregadas negativamente de 9:1 DPPC:DPPS bem como, diminuição de $\Delta \mathrm{H}$ em proteolipossomos desta composição lipídica causada pela adição da AnxA6 na presença de $\mathrm{Ca}^{2+}$ em comparação às bicamadas zwitteriônicas de DPPC. A interação da AnxA6 com DPPC e 9:1 DPPC:DPPS foi distinta mesmo na ausência de $\mathrm{Ca}^{2+}$, conforme observado por uma maior alteração nos valores de $\Delta \mathrm{T}_{1 / 2}$ nas vesículas de 9:1 DPPC:DPPS em comparação com as vesículas DPPC. Imagens obtidas por microscopia de força atômica (AFM) revelaram protrusões na superfície dos proteolipossomos de DPPC e 5:4:1 DPPC:Chol:DPPS o que sugere que a AnxA6 oligomérica interagiu com a membrana das vesículas e que pode adotar conformações diferentes quando interage com a membrana lipídica. Estudos de mineralização in vitro foram realizados com a finalidade de verificar se a presença da AnxA6 (em solução ou associado a proteolipossomos) e Colágeno Tipo I levariam a propagação mineral. Foram utilizados como nucleadores o fosfato de cálcio amorfo (ACP) e sua forma mais estável associada à fosfatidilseria (PS-CPLX). Por meio de medidas de turbidez e análises de Espectroscopia de infravermelho com transformada de Fourier (FTIR), verificou-se a AnxA6, em solução, e proteolipossomos com o nucleador PS-CPLX na ausência de colágeno tipo I, apresentaram melhores indícios de propagação mineral. A AnxA6 mostrou baixa capacidade de propagação de nucleação incorporada superficialmente em lipossomos, tal fato sugere que seu melhor desempenho seja na nucleação mineral. 


\section{ABSTRACT}

The bone tissue consists of a collagen and mineral matrix combination formed by calcium phosphate crystals converted into a hydroxyapatite. This mineral accumulation process in the bone tissue is called biomineralization and it is performed by osteoblasts cells throughout matrix vesicles (MVs) release. MVs are a special class of extracellular vesicles that serve as a nucleation site during bone mineralization. MVs have high $\mathrm{Ca}^{2+}$ and inorganic phosphate $(\mathrm{Pi})$ concentration, thus, providing a suitable microenvironment for the initial mineral formation and propagation. Several proteins/enzymes are needed as well as microenvironments of MVs in very peculiar conditions in order to perform the correct biomineralization. Special attention must be given to some proteins present in MVs: Annexin A5 (AnxA5) and Annexin A6 (AnxA6) and the Tissue Non-specific Alkaline Phosphatase (TNAP), being, AnxA6 the focus of this study. AnxA6 is the largest member of the annexin family present in MVs, with $\sim 68 \mathrm{kDa}$. Biochemical analysis revealed that AnxA6 is present in three different positions of membrane MVs, which indicates it plays different roles in the mineralization process. In this study, we were able to understand its biochemical/biophysical characteristics and possible functions by comparing many of our findings with what we have found in the literature regarding AnxA5. At pH 6, AnxA6 has shown $86 \%$ of its structure in an a-helix conformation, whereas AnxA5 has shown $\sim 50 \%$ of its $\alpha$-helix content at $\mathrm{pH} 8$. Using zeta potential measurements, the isoelectric point was determined as 4.2 for AnxA6. Using monolayers and proteoliposomes composed of either dipalmitoylphosphatidylcholine (DPPC) to mimic the outer leaflet of the MV membrane bilayer or a 9:1 DPPC:dipalmitoylphosphatidylserine (DPPS) mixture to mimic the inner leaflet, with and without $\mathrm{Ca}^{2+}$, we confirmed that, in agreement with the biochemical data, AnxA6 interact differently with the MV membrane. Thermodynamic analyses based on the measurement of surface pressure exclusion (техс), enthalpy $(\Delta H)$, and phase transition cooperativity $\left(\Delta T_{1 / 2}\right)$ showed that AnxA6 interacted with DPPC and 9:1 DPPC:DPPS and that this interaction increased in the presence of cholesterol (Chol) (6:4 DPPC:Chol and 5:4:1 DPPC:Chol:DPPS). AnxA6-lipid interaction was also $\mathrm{Ca}^{2+}$ dependent, as evidenced by the increase in $\Pi_{e x c}$ in negatively charged 9:1 DPPC:DPPS monolayers and the decrease in $\triangle H$ in 9:1 DPPC:DPPS proteoliposomes caused by the addition of AnxA6 in the presence of $\mathrm{Ca}^{2+}$ compared to DPPC zwitterionic bilayers. The interaction of AnxA6 with DPPC and 9:1 DPPC:DPPS was distinct even in the absence of $\mathrm{Ca}^{2+}$ as observed by the larger 
change in $\Delta T_{1 / 2}$ in 9:1 DPPC:DPPS vesicles as compared to DPPC vesicles. Protrusions on the surface of DPPC and 5:4:1 DPPC:Chol:DPPS proteoliposomes observed by atomic force microscopy (AFM) suggested that oligomeric AnxA6 interacted with the vesicle membrane may adopt different conformations upon interaction with the lipid membrane. In vitro mineralization studies were carried out in order to verify if the presence of AnxA6 (in solution or associated to proteoliposomes) and Collagen Type I would lead to mineral propagation. Amorphous calcium phosphate nucleators (ACP) or along with its more stable form associated with phosphatidylserine (PS-CPLX) were used as nucleator. Turbidity and Fourier Transform Infrared Spectroscopy (FTIR) analyzes have presented that AnxA6 in solution as well as in proteoliposomes with the PS-CPLX nucleator in the absence of collagen type I, better mineral propagation evidences. AnxA6 lacks nucleation propagation capacity incorporated superficially into liposomes suggesting that it may play an important role in mineral nucleation. 


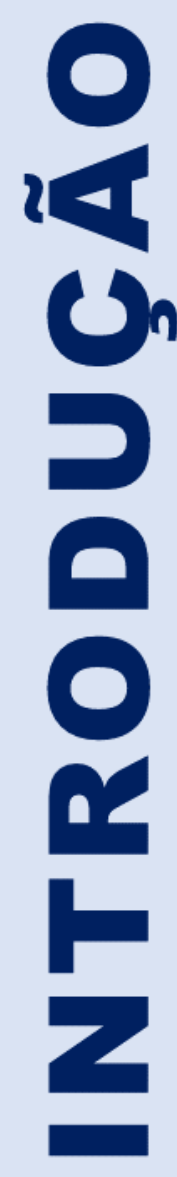




\section{INTRODUÇÃO}

\subsection{Biomineralização}

Uma das maneiras pelas quais muitos organismos se adaptam ao ambiente é por meio da criação de um sistema esquelético de tecido duro para proteção, digestão, suporte e locomoção. A criação desses elementos esqueléticos envolve a formação coordenada de uma fase mineral biogênica (Evans et al., 2019; Cruz et al., 2021).

Sendo assim, o processo de biomineralização consiste no acúmulo de mineral constituído principalmente por íons de fosfato e cálcio que formam um sal de fosfato de cálcio, cuja estrutura se transforma em hidroxiapatita $\left(\mathrm{Ca}_{10}\left(\mathrm{PO}_{4}\right)_{6}(\mathrm{OH})_{2}\right)$.

processo de ossificação mediado por osteoblastos (células responsáveis pela formação óssea) ou por odontoblastos (célula responsável pela síntese ou produção da dentina) é claramente distinto daquele que ocorre na calcificação da cartilagem epifisária (a partir de um modelo cartilaginoso), que é mediada por condrócitos hipertróficos. A mineralização de ossos e dentes depende de uma homeostase sistêmica de íons cálcio e fosfato, um adequado esqueleto proteico na matriz extracelular e ausência e/ou remoção de inibidores da mineralização (Wuthier e Lipscomb, 2011; Cruz et al., 2021). Em vertebrados, a biomineralização é uma característica considerada única para osteoblastos e odontoblastos maduros, pelos quais eles sintetizam a hidroxiapatita $(\mathrm{HA})$, que é depositada na matriz de colágeno para construir o endoesqueleto (Tian et al., 2020)

Estudos realizados no final dos anos de 1960 descobriram nanoestruturas extracelulares discretas, chamadas de vesículas da matriz - MVs (do inglês matrix vesicles). As MVs são vesículas com diâmetros que variam de 100 a 300 nm, que surgem por brotamento das superfícies laterais dos condrócitos e são secretadas no local específico do início da biomineralização da matriz do tecido ósseo (Anderson, 2004). Nos osteoblastos, as vesículas surgem da membrana plasmática adjacente à matriz óssea recentemente formada, e nos odontoblastos, na porção apical da célula que se encontra em contato com a matriz da pré-dentina (Golub, 2009; McKee et al., 2013; Bottini et al., 2018). 
Diferentes teorias são propostas para a formação e o crescimento de minerais, no entanto a mais aceita associa as MVs à formação dos primeiros cristais de HA, propondo que durante a fase inicial ou também chamada fase I da biomineralização, os íons $\mathrm{Ca}^{2+}$ são atraídos pelas moléculas ligadoras de cálcio que se encontram dentro das MVs. Na fase de propagação ou fase II, ocorre a liberação dos cristais de HA no fluído extracelular que são propagados entre fibrilas de colágeno. Essa fase é controlada pelo $\mathrm{pH}$ do fluido extracelular, pela concentração de íons $\mathrm{Ca}^{2+}$ e fosfato inorgânico $(\mathrm{Pi})$ como também pela presença de moléculas reguladoras, como colágeno dos tipos I e II (Anderson et al., 2005). Assim, as MVs apresentam a finalidade de nucleação dos íons que formarão os cristais de hidroxiapatita, como também proteção dos primeiros cristais amorfos formados e direcionamento do local específico do início da mineralização (Anderson, 1969, 2003; Bonucci, 1967, 1970), mas até hoje existem muitas dúvidas de como as MVs apresentam esta função (Wuthier e Lipscomb, 2011; McKee et al., 2013; Simão et al., 2019).

De acordo com Bottini e colaboradores (2018), as MVs contêm um complexo enzimático tanto no seu interior como na sua membrana, como mostrado na figura 1. Esse complexo atua principalmente na saturação local de íons $\mathrm{Ca}^{2+}$ e $\mathrm{Pi}$ durante o crescimento dos minerais, além de controlar a concentração de inibidores do processo, como o pirofosfato inorgânico (PPi).

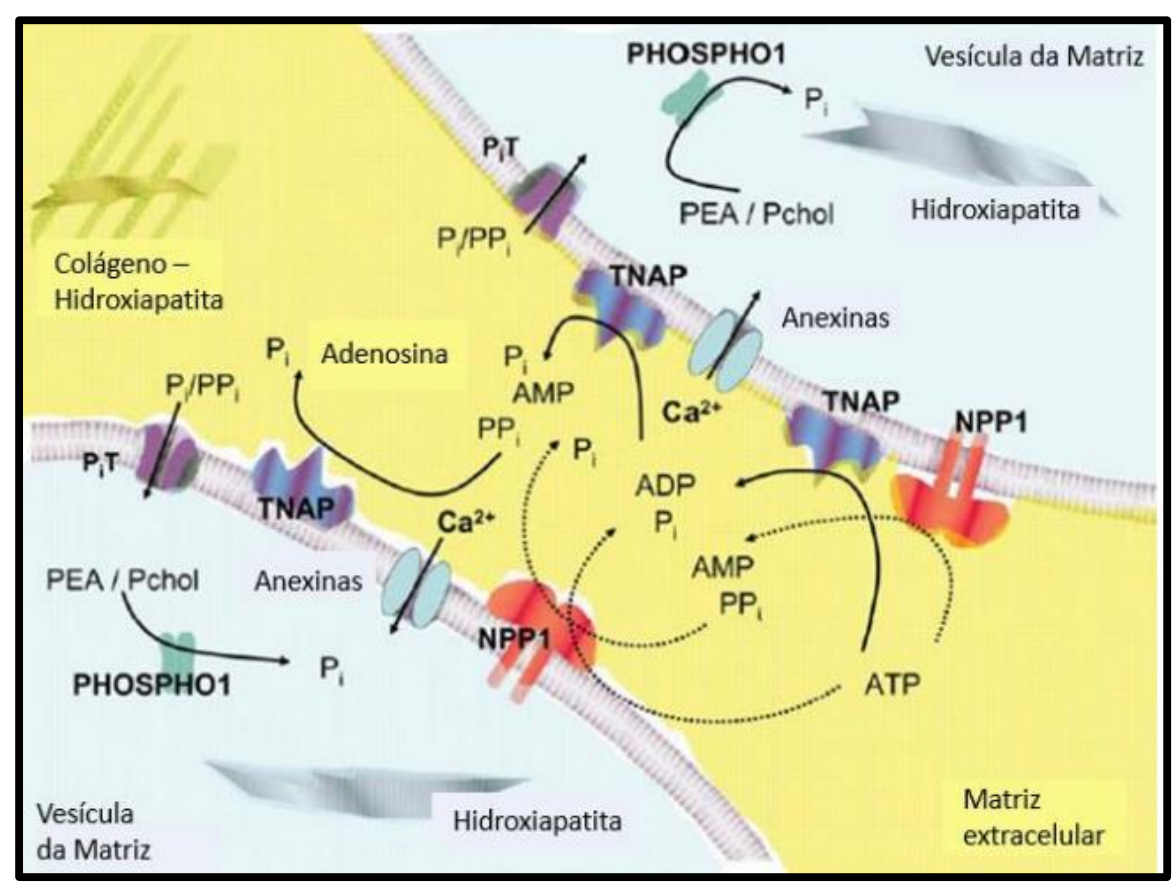

Figura 1. Representação esquemática das moléculas envolvidas na calcificação mediada pelas vesículas da matriz, incluindo as reações enzimáticas mais favorecidas dos substratos fisiológicos. Adaptado de Simão et al., (2010a) 
Estudos recentes também mostraram que tanto as anexinas quanto a fosfatase alcalina tecido não específica (TNAP), possuem capacidade de ligação ao colágeno, que é uma propriedade que pode ajudar a alinhar MVs ao longo das fibras de colágeno para promover a propagação de mineralização na ECM. Evidências experimentais ainda sugeriram que as anexinas, como proteínas de ligação ao cálcio e a fosfolipídios, estão envolvidas na homeostase do cálcio das células mineralizadoras e no influxo de $\mathrm{Ca}^{2+}$ para as MVs (Genetos et al., 2014; Strzelecka et al., 2019; Cruz et al., 2021).

Apesar de haver tantos estudos sobre a biomineralização óssea, ainda não se conhecem todas biomoléculas e os mecanismos envolvidos nesse processo extremamente complexo. Dentre essas biomoléculas, maior enfoque será dado às anexinas - AnxA5 e AnxA6.

\subsection{Anexinas}

A anexina foi descoberta pela primeira vez em 1978 e purificada por Creutz, desde a primeira clonagem humana de AnxA1 e AnxA2, mais de 1000 membros da subfamília da anexina foram relatados (Huang et al., 1986).

Segundo Crumpton, e Dedman (1990), as anexinas estão distribuídas em vários tecidos e células de animais e plantas. Por definição, uma anexina deve satisfazer dois critérios principais:

- Ser capaz de se ligar a fosfolipídios carregados negativamente de uma maneira dependente à $\mathrm{Ca}^{2+}$.

- Precisa conter as chamadas repetições de anexina como um elemento estrutural conservado, um segmento de cerca de 70 resíduos de aminoácidos.

De acordo com a estrutura, relação evolutiva e localização cromossômica dos genes, as anexinas podem ser divididas em cinco categorias: anexina A - expressa em células de vertebrados, anexina B - expressa em células de invertebrados, anexina $C$ - expressa em fungos e células eucarióticas de monócitos, anexina D expressa em células vegetais e anexina $\mathrm{E}$-expressa em células procarióticas (Moss e Morgan, 2004).

A anexina A é um tipo de proteína de ligação a fosfolipídios dependentes de cálcio, que contribui para a formação de membranas celulares e do citoesqueleto 
como também ajudam na estabilização da bicamada lipídica. Até agora, 12 tipos de anexinas (AnxA1-A11 e AnxA13) foram encontrados em células de vertebrados (Wei et al., 2015).

As anexinas de membrana são relativamente conservadoras na evolução. A maioria delas pertence a proteínas intracelulares, representando cerca de $2 \%$ do total de proteínas celulares. Elas podem existir em um estado livre na célula e também podem se ligar à membrana celular ou ao citoesqueleto (Chander et al., 2007; Mortimer et al., 2008). Visto que as anexinas têm a capacidade de se ligar ao $\mathrm{Ca}^{2+}$, elas podem participar de uma série de atividades biológicas da membrana dependente de $\mathrm{Ca}^{2+}$ (Lin et al., 2020). De forma geral, elas podem induzir a curvatura da membrana podendo ser uma propriedade importante para a sua função como também para sua interação com os componentes da bicamada lipídica das biomembranas (Kirsch et al., 1997; Wuthier e Lipscomb, 2011; Boye et al., 2018; Lin et al., 2020).

\subsubsection{Anexina A5}

Três proteínas da família das anexinas (AnxA2, AnxA5 e AnxA6) estão presentes nas MVs e poderiam ser as responsáveis pela formação de canais de $\mathrm{Ca}^{2+}$ (Genge et al., 1992; Cao et al., 1993; Wu et al., 1997, Bolean et al., 2015).

Dentre essas anexinas, a AnxA5 especificamente, é uma proteína de 35 $\mathrm{kDa}$, é responsável pela formação de canais de cálcio que se formam pela associação desta proteína tanto com a face externa quanto interna das membranas das MVs. 20 diferentes anexinas já foram isoladas e análises proteômicas mostram que as anexinas são as proteínas mais abundantes detectadas nas MVs (Wuthier e Lipscomb, 2011). A AnxA5 humana foi a primeira a ter sua estrutura tridimensional caracterizada (Huber et al., 1990a; Liemann e Huber, 1997), a qual revela uma molécula ligeiramente curva constituída por quatro repetições homólogas constituídas por cerca de 70 aminoácidos, formando domínios compactos de 5 ahélices como pode ser visto na figura 2 (Liemann e Huber, 1997). Estes domínios estão dispostos formando um poro hidrofílico no centro da proteína e esse poro apresenta função de canal de $\mathrm{Ca}^{2+}$ na membrana das MVs (Kirsch et al., 1997; Wuthier e Lipscomb, 2011; Bolean et al., 2020). 


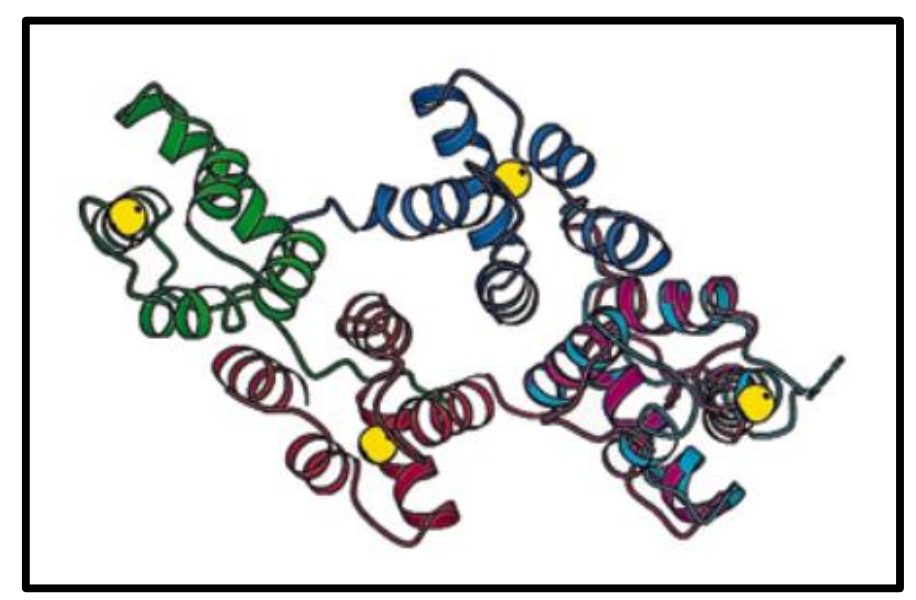

Figura 2. Estrutura cristalina da AnxA5 humana. Os 4 domínios estão representados pelas diferentes cores e os íons cálcio estão representados pelas esferas amarelas. Domínio I: verde, Domínio II: azul escuro, Domínio III: azul e rosa e Domínio IV: vermelho (Liemann e Huber, 1997)

Essa função de canal iônico em membranas reconstituídas foi semelhante à observada em MVs (Arispe et al., 1996). As adições de anticorpo anti-anexina específico ou de inibidor de canal de anexina K-201 (Kaneko, et al., 1997a; 1997b; Hofmann, et al., 1998), leva a uma diminuição do cálcio e uma redução da mineralização em MVs (Wang et al., 2005; Kirsch et al., 2000). Para entender como as anexinas podem mediar o influxo de $\mathrm{Ca}^{2+}$ nas $\mathrm{MVs}$, devem ser identificados todos os fatores que afetam a função das anexinas durante o processo de mineralização, tais como suas localizações e suas funções específicas dentro do processo de mineralização como um todo.

AnxA5 também é responsável por outros eventos fisiológicos como, por exemplo, inibição de coagulação sanguínea fosfolipídio-dependente (Hauptmann et al., 1989; Andree et al., 1992); modulação da proteína kinase C (Schlaepfer et al., 1992); inibição da atividade da fosfolipase A2 (Davidson et al., 1990), eventos de desorganização celular resultando em processos de apoptose. 


\subsubsection{Anexina A6}

AnxA6 é o maior membro da família das anexinas presentes nas MVs, com aproximadamente $68 \mathrm{kDa}$. Análises bioquímicas revelaram que a AnxA6 está presente em três regiões distintas nas MVs: (1) ligada à parte externa da membrana, na presença de cálcio; (2) localizada na superfície interna da monocamada das membranas e (3) inserida na bicamada hidrofóbica e co-localizada com regiões ricas em colesterol (Wu et al.; 1997). Essas diferentes localizações e formas de interação com a membrana das MVs indicam que a AnxA6 pode exercer funções distintas durante o processo de mineralização (Veschi et al., 2020).

Diferentemente dos demais membros da família das anexinas, que são estruturalmente caracterizados pela presença de um núcleo altamente conservado, composto por quatro domínios homólogos, AnxA6 possui oito domínios em seu núcleo (Huber et al., 1990b; Boye et al., 2018). Além disso, possui tamanho e estrutura incomuns dentre as anexinas, ocorrendo uma ligação com duas outras anexinas diferentes, a AnxA5 e a AnxA10. Acredita-se que essa duplicação da anexina seja o resultado de um evento evolutivo que fundiu seus genes, com domínios ligados por um circuito em forma de dobradiça (Benz et al., 1996; Kawasaki et al., 1996). 


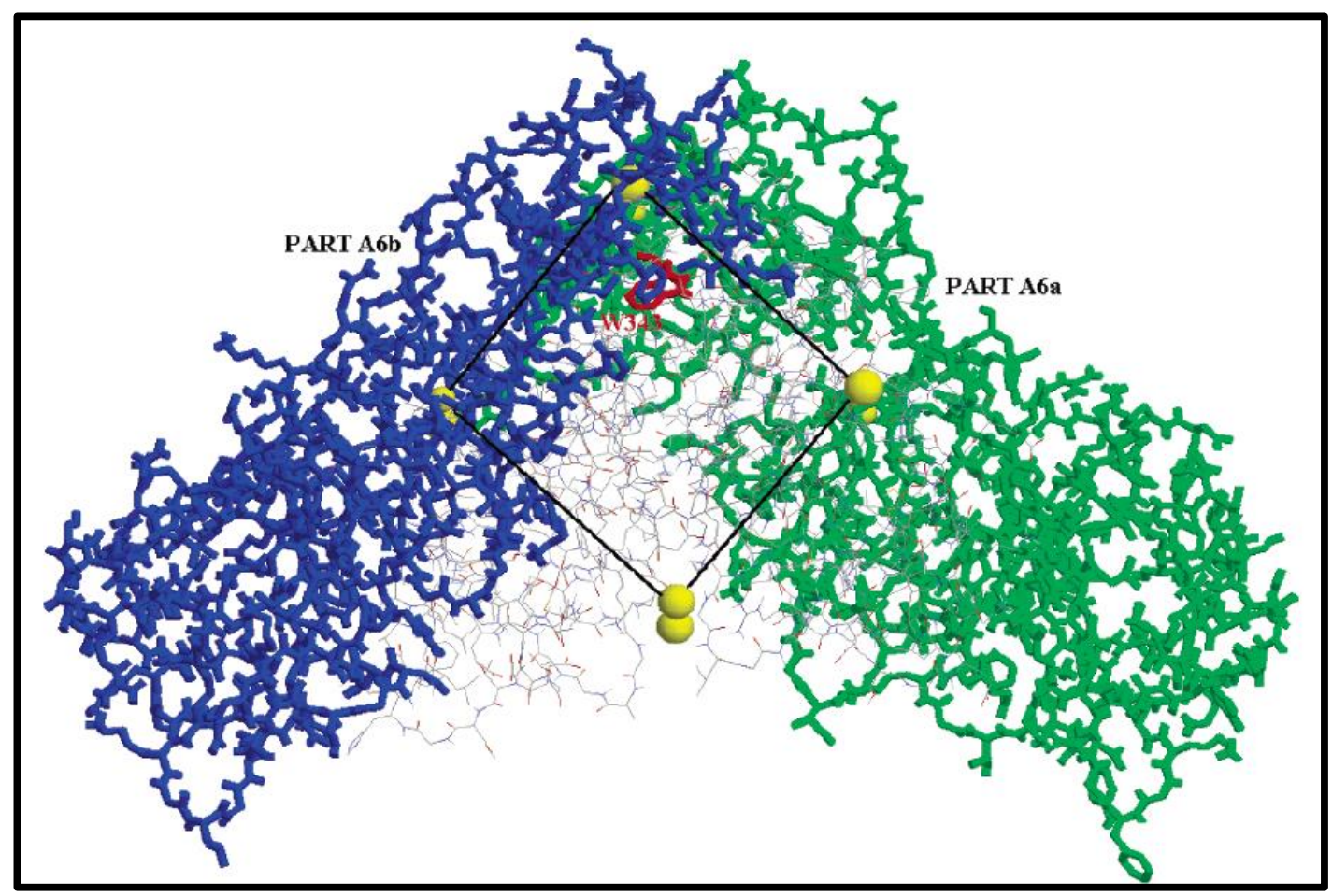

Figura 3. Estrutura da AnxA6 bovina. A parte N-terminal da AnxA6 correspondente aos resíduos 2-342 (AnxA6a) é mostrada em verde, enquanto que a parte C-terminal associada aos resíduos 348-673 (AnxA6b) é mostrada em azul. A caixa com uma dimensão limitada no centro de AnxA6 indica a suposta localização do sítio de ligação de nucleotídeos. Adaptado de Pikula et al. (2003)

AnxA6 está presente em muitos processos celulares, atuando como uma proteína multifuncional e capaz de recrutar um grande número de proteínas de sinalização, modula o transporte de colesterol e sua distribuição dentro da célula, e também regula o transporte de membrana através da dinâmica da actina, além de desempenhar um papel essencial na organização das membranas (Lin et al., 2020).

Essas atividades sugerem que a AnxA6 pode contribuir para a formação de complexos proteicos específicos e domínios de membrana relevantes na transdução de sinal, na homeostase do colesterol e na endocitose/exocitose (BandorowiczPikuła e Seliga, 2018; Grewal et al., 2017; Cairns et al., 2018 Garcia-Melero et al., 2016;).

Todas estas funções podem ser facilitadas por sua capacidade de ligar-se temporariamente a domínios de membrana distintos ao citoesqueleto. Apesar do mecanismo comum, AnxA6 parece estar envolvida em uma diversidade de tarefas em diferentes áreas da célula (Cornely et al., 2011) 
A AnxA6 também tem sido associada ao armazenamento de triglicerídeos em adipócitos (Cairns et al.; 2018).

Pouco se sabe sobre como as células controlam a distribuição intracelular topológica da AnxA6, embora a maior parte esteja provavelmente direcionada para membranas através da ligação dependente de $\mathrm{Ca}^{2+}$ a fosfolipídios carregados negativamente, estudos recentes sugerem que a localização intracelular da AnxA6 e a ligação à membrana em pH baixo são determinadas pelo colesterol, sendo então componentes como $\mathrm{pH}$ ácido e colesterol possíveis estimulantes da afinidade de ligação da AnxA6 à membrana (Bandorowicz-Pikuła e Seliga, 2018; Golczak et al., 2001).

Muitos outros estudos ainda são importantes para identificar, esclarecer e revelar completamente os processos fisiológicos e/ou patológicos envolvendo a capacidade da AnxA6 de alterar a permeabilidade da membrana a íons ou mecanismos de reparo da membrana (Bandorowicz-Pikuła e Seliga, 2018; Demonbreun et al., 2019; Croissant et al., 2020).

\subsection{Fosfatase Alcalina}

A fosfatase alcalina pertence a uma família de proteínas multigênicas na qual diferentes formas dessa enzima estão distribuídas em quase todos os tecidos. No homem e nos primatas superiores, três isoformas distintas têm sido identificadas: a da placenta, a do intestino e a do fígado-osso-rim (Lowe et al., 1990; Le Du e Millán, 2002).

As isoformas da placenta e do intestino são tecido-específicas e são expressas unicamente nessas regiões, enquanto a isoforma do fígado-osso-rim é encontrada em quase todos os tecidos, sendo também denominada por esta razão de fosfatase alcalina não específica de tecido (TNAP). Além disso, níveis elevados desta isoforma têm sido encontrados, também, nas membranas dos osteoblastos durante a formação e a mineralização do tecido ósseo (Wuthier and Register, 1985; Nakamura et al., 1988; Anderson, 1995; Hsu and Anderson, 1995).

Independentemente de sua origem, as fosfatases alcalinas são enzimas homodiméricas e cada sítio catalítico contém três íons metálicos (dois íons zinco e um íon magnésio), necessários para a atividade da enzima (Millán, 2006; Stec et al., 
2010). Um novo sítio não - catalítico que se liga a um metal e parece ser ocupado por cálcio foi descoberto após a resolução da estrutura tridimensional da fosfatase alcalina de placenta (Le Du et al., 2001).

A importância estrutural e funcional deste novo sítio metálico confirma estudos anteriores que indicavam que, em cartilagem, a fosfatase alcalina era uma glicoproteína ligadora de $\mathrm{Ca}^{2+}$ (De Bernard et al., 1986).

Já foi demonstrado que a TNAP também pode hidrolisar adenosina trifosfato (ATP), liberando o fosfato inorgânico $(\mathrm{Pi})$. A enzima é regulada alostericamente pelo ATP (Pizauro et al., 1993) e inibida competitivamente pelo produto da reação, o Pi (Pizauro et al., 1987), sugerindo que os níveis relativos de pirofosfato inorgânico (PPi), um inibidor da biomineralização, e de Pi, um inibidor da TNAP, presentes no fluído extracelular da matriz, também desempenham um papel importante na regulação do processo de mineralização biológica (Bolean et al., 2017a; Cruz et al., 2021).

\subsection{Importância dos Lipídios}

Irving (1959 e 1963) em seus estudos, mostrou pela primeira vez como os lipídios estavam associados histologicamente com os estágios iniciais da mineralização in vivo. Estudos bioquímicos subsequentes revelaram que uma fração química e metabolicamente distinta do lipídio presente nos tecidos estava fortemente ligada ao mineral e não poderia ser extraída até após a desmineralização (Irving, 1968; Wuthier, 1968). Posteriormente, foi relatado que as MVs eram ricas em lipídios, principalmente esfingomielina, fosfatidilserina e colesterol, quando comparadas a células isoladas de uma mesma cartilagem (Peress et al., 1974; Wuthier, 1975)

Descobertas mais detalhadas vieram de um estudo de Thouverey e colaboradores (2009), onde a composição lipídica das MVs foi comparada com a das membranas basolaterais das células Saos-2 e microvilosidades, chegando à conclusão que as MVs e as microvilosidades apresentavam a mesma composição lipídica, com conteúdo mais alto de colesterol, esfingomielina e fosfatidilserina quando comparadas à membrana plasmática. Dessa forma, relataram-se valores aproximados de $36 \%$ de fosfatidiletanolamina (PE), $26,5 \%$ de fosfatidilcolina (PC), 
3,5\% de ácido fosfatídico (PA), 7\% de fosfatidilinositol (PI), 16,5\% de fosfatidilserina (PS) e $11 \%$ de esfingomielina (SM) para a composição de fosfolipídios das MVs (Thouverey et al., 2009; Bottini et al., 2018).

Roberts e colaboradores (2004) também demonstraram que fosfocolina e fosfoetanolamina podem ser hidrolisados pela proteína intracelular PHOSPHO 1 (Houston et al., 2004), sugerindo que a geração de $\mathrm{Pi}$ em células envolvidas no processo de biomineralização pode estar acoplada à degradação de fosfolipídios.

Os fosfolipídios ácidos que apresentam grande afinidade por cálcio, principalmente a fosfatidilserina, são geralmente encontrados nas membranas das vesículas extracelulares (Boyan et al., 1989) e são capazes de promover a formação de hidroxiapatita in vitro, mesmo na ausência de fosfatase alcalina (Eanes e Hailer, 1987). Este fato sugere uma possível associação dos fosfolipídios com o processo de mineralização. Além disso, eles podem atuar na regulação da biomineralização regulando o transporte de íons cálcio através da organização estrutural da membrana e também promovendo a nucleação de hidroxiapatita pela interação com íons cálcio e estabilização de associações de fosfato de cálcio amorfo (Wuthier et al., 1985; Boyan et al., 1989; Balcerzak et al., 2003; Blandford et al., 2003; Bolean et al., 2017a; Favarin et al., 2017; 2020).

Provavelmente, mudanças na atividade da fosfatase alcalina podem ser resultantes de alterações na composição lipídica da membrana celular, e também mediadas pela associação da enzima com a AnxA5 ou pela variação da concentração de íons cálcio na interface lipídica mediada pela própria AnxA5. Assim, alterações que podem ocorrer nas funções das vesículas podem representar um mecanismo de regulação da formação do mineral. Um problema que tem dificultado os estudos in vitro é que a reação de indução de deposição de minerais por complexos lipídio-cálcio-fosfato é lenta, necessitando frequentemente de vários dias para a obtenção significativa de mineral (Bolean et al., 2017a; Cruz et al., 2021).

Além disso, os níveis de íons minerais e/ou pH nas soluções metaestáveis de fosfato de cálcio geralmente usados nestes estudos são baixos. Em síntese, qualquer conclusão acerca da importância dos complexos de lipídios na mineralização mediada por MVs necessita de estudos mais aprofundados sobre a cinética da mineralização induzida por tais complexos, especialmente num 
sistema onde $\mathrm{o} \mathrm{pH}$ e os níveis de eletrólitos sejam semelhantes àqueles encontrados no interior das vesículas ou no fluido extracelular nativo (Simão et al., 2013). Empregando-se os sistemas vesiculares de lipossomos, cuja metodologia de obtenção foi padronizada em nosso laboratório (Camolezi et al., 2002; lerardi et al., 2002), o envolvimento das proteínas e dos lipídios durante o processo de mineralização se torna mais fácil de ser estudado, pois estes sistemas podem mimetizar a função das vesículas tanto em sistemas in vitro bem como in vivo (Bolean et al., 2017a e 2017b).

Estudos anteriores mostram a interação da AnxA5 com colágeno e como essa interação pode regular o processo de crescimento e mineralização de condrócitos de placa óssea. Relatos sugerem que as MVs se ligam fortemente a uma rede de fibras de colágeno, no espaço extracelular de placa óssea hipertrófica, através das anexinas e de lipídios como as fosfatidilserinas presentes na superfície das MVs. Entretanto, não existem resultados conclusivos que relacionem o papel da interação anexinas/colágeno na iniciação da mineralização de cartilagem de placa óssea (Wuthier e Lipscomb, 2011; Grskovic et al., 2012; Bolean et al., 2015, 2020).

\subsection{Principais Técnicas Bioquímicas e Biofísicas}

\subsubsection{Calorimetria Diferencial de Varredura (DSC)}

A calorimetria diferencial de varredura (DSC) é uma técnica altamente sensível usada para estudar as propriedades termodinâmicas de transições induzidas termicamente. Como essas propriedades podem ser afetadas pela ligação ao ligante, o DSC é particularmente útil para a caracterização de interações proteicas com membranas biomiméticas (Kleinschmidt, 2013).

Baseado nos valores fornecidos por essa técnica, a análise termodinâmica de enovelamento de uma proteína permite a elucidação de características da sua estrutura terciária e ainda a determinação das contribuições das interações que mantêm a estabilidade da estrutura nativa (Minetti e Remeta, 2006; Demetzos et al., 2008). 
Os lipídios podem adotar diferentes estados lamelares chamados fase gel ou semicristalina e estado fluido cristalino. O parâmetro determinante do comportamento físico-quimico da membrana é a temperatura critica (Tc) a qual é a temperatura de transição entre o estado gel e o estado fluido - cristalino: abaixo da Tc os lipídios os lipídios estão empacotados em um estado ordenado na fase gel, entretanto acima dessa temperatura eles estão mais desordenados em um estado fluido (fluido cristalino) (Tistram - Nagle e Nagle, 2004; Mannock et al., 2006). Esta transição ocorre em membranas biológicas produzindo sua funcionalidade.

No esquema ilustrado na figura 4 utilizaram-se lipossomos constituídos de DPPC (10 mg. $\mathrm{mL}^{-1}$ ) para a observação dos parâmetros termodinâmicos que podem ser extraídos de uma curva de DSC.

Fosfolipídios, especialmente glicerofosfolipídios, são grupos de lipídios que consistem em uma ampla variedade de moléculas, que tem habilidade de formar estruturas de bicamada. Em meio aquoso este sistema é muito semelhante às membranas biológicas e por isso é utilizado como modelo em estudos de calorimetria.

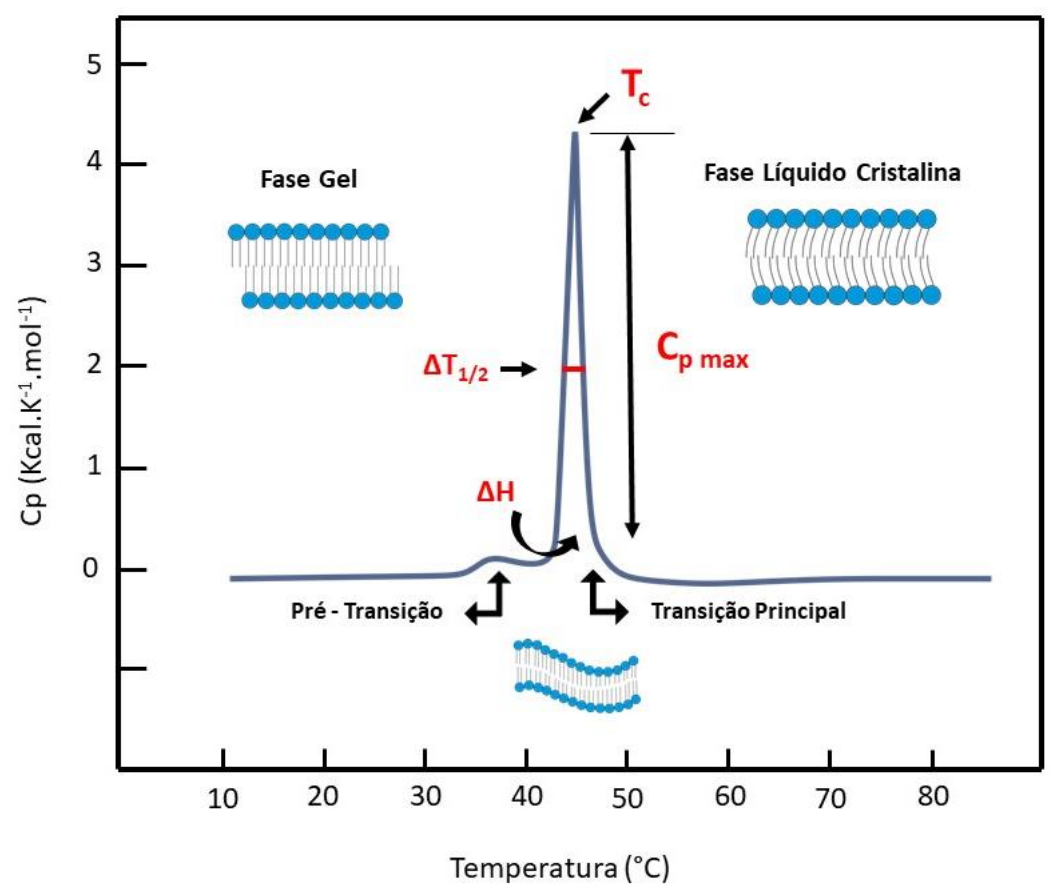

Figura 4. Características dos parâmetros termodinâmicos de uma curva de DSC, utilizando no esquema lipossomos constituídos de DPPC $\left(10 \mathrm{mg} \cdot \mathrm{mL}^{-1}\right)$. Adaptado de Demetzos et al. (2008) 
Nesse esquema pode-se obter a temperatura crítica de transição (Tc), temperaturas na qual a amostra apresenta máxima capacidade calorífica pontuando a transição da fase gel a fase fluido cristalino. A entalpia de transição $(\Delta H)$ é um parâmetro representado pela área total do pico, o qual está relacionado à estabilidade do sistema analisado. A cooperatividade das moléculas durante o processo de transição apresenta grande importância em relação ao comportamento termotrópico da amostra e pode ser definido como a largura que corresponde à meia altura do pico de transição $\left(\Delta \mathrm{T}_{1 / 2}\right)$. Na transição de fase do DPPC pode ser observado o aparecimento de um pico agudo e bem definido, devido às favoráveis interações de van der Waals entre as cadeias hidrocarbônicas do lipídio, resultando em uma alta cooperatividade de moléculas. Neste esquema podemos observar dois picos de transição: o primeiro ao redor de $33^{\circ} \mathrm{C}$ que corresponde à pré - transição de fase e o segundo pico que corresponde à transição principal em $41^{\circ} \mathrm{C}$ (Demetzos et al., 2008).

\subsubsection{Espectroscopia de Dicroísmo Circular (CD)}

A espectroscopia de dicroísmo circular (CD) se baseia na absorção preferencial da luz circularmente polarizada, sendo uma técnica valiosa para se estudar a formação de estrutura secundária de proteínas e peptídeos em solução, pois permite a determinação dos percentuais de estrutura secundária de peptídeos e proteínas.

Para isso, as amostras devem possuir unidades opticamente ativas, ou seja, que ao interagirem com a luz circularmente polarizada, provocam uma alteração na luz incidente. Na região do UV próximo (240-320 nm), o método é utilizado para identificar pequenas alterações estruturais, enquanto que, na região de UV distante (190-260 nm), o método é usado para caracterizar as alterações na estrutura secundária de peptídeos e proteínas (Karabencheva-Christova et al., 2013).

A análise dos dados de CD é feita por base no dicroísmo das ligações peptídicas e, dependendo da orientação destas ligações no esqueleto peptídico, as transições eletrônicas que podem dar origem ao sinal de CD são as $n \rightarrow \pi^{*}$ e $\pi \rightarrow$ $\pi^{*}$. Os comprimentos de onda e as intensidades das transições podem variar, devido à influência da geometria local dos esqueletos peptídicos. Como consequência, os 
motivos característicos de estrutura secundária, tais como $\alpha$-hélice e folhas- $\beta$, têm espectros de CD muito característicos (Figura 5) (Greenfield, 1996; Whitmore e Wallace, 2007).

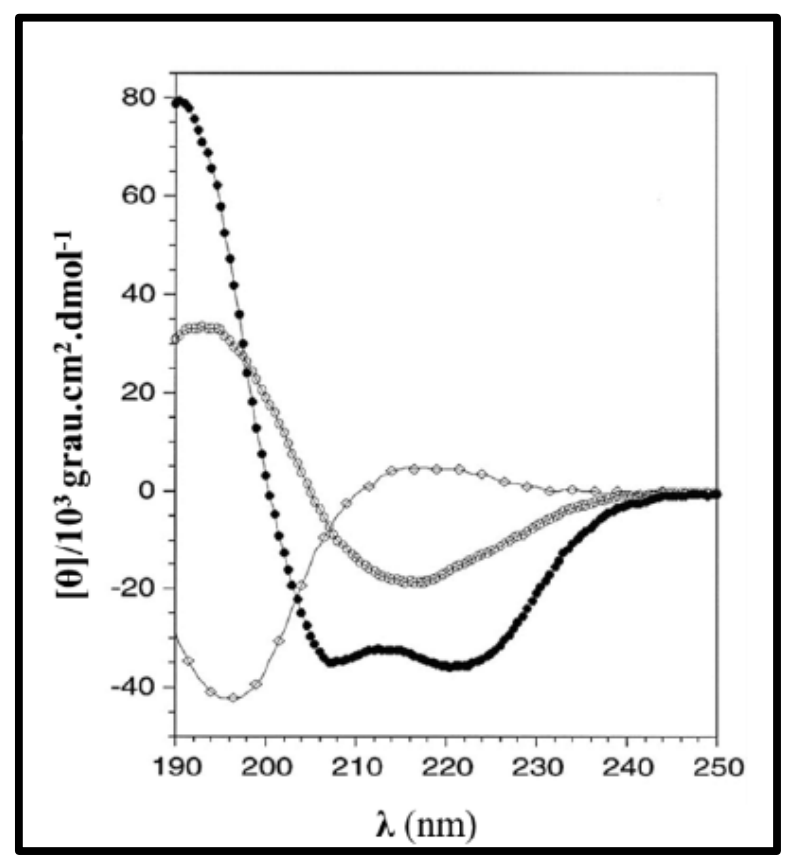

Figura 5. Perfis de espectros de dicroísmo circular característicos de peptídeos em conformação em $\alpha$-hélice (círculos a cheio), em conformação em folha- $\beta$ (círculos vazios) e sem conformação preferencial (losangos) (Fändrich e Dobson, 2002)

Para a determinação do perfil de estrutura secundária média foram desenvolvidas análises de desconvolução, para se quantificarem as contribuições provenientes dos diferentes motivos de estruturas secundárias presentes na estrutura tridimensional (Sreerama e Woody, 2000; 2004).

\subsubsection{Espalhamento de Luz Dinâmico (DLS)}

Espectroscopia de correlação de fótons, mais conhecida como Espalhamento de Luz Dinâmico (DLS), baseia-se nas pequenas variações de intensidade da luz espalhada, resultantes das flutuações do índice de refração da solução dentro do volume espalhado. As flutuações do índice de refração podem ser resultantes da difusão translacional das moléculas ou partículas em solução ou suspensão, o denominado movimento browniano. Essas flutuações podem ser correlacionadas e 
avaliadas em termos de vários processos de relaxação através de uma função de correlação temporal, obtida por um correlador (Pecora, 1985; 2000; Brown, 1993).

O DLS vem sendo extensamente utilizado em físico - química, química coloidal, ciências dos polímeros, bioquímica, biofísica, e ciências médicas (Izumi et al., 2011). Esta técnica é uma eficiente ferramenta para provar o processo de relaxação estimulado pelo movimento aleatório que ocorre em matéria condensada não cristalina (De Moraes et al., 2012).

As características fundamentais evidenciadas por esse método consistem em medidas de tamanho médio das partículas analisadas, como também a distribuição de tamanhos delas. Partículas menores são capazes de movimentarem mais rapidamente e causam rápidas modificações no espalhamento da luz. Por outro lado, partículas de maior diâmetro, as quais possuem menores coeficientes de difusão, resultam em menores flutuações na intensidade do espalhamento da luz (Haskell et al., 1998).

A extensão da variação de tamanhos também pode ser avaliada pelo valor do índice de polidispersão (IP). O mesmo está relacionado com a variação do raio hidrodinâmico representando a distribuição de tamanhos das vesículas em suspensão, sendo que o raio hidrodinâmico representa o raio médio de uma partícula dentro da sua dinâmica de difusão, considerando a camada de solvatação (Mikos e Peppas, 1989).

\subsubsection{Microscopia de Força Atômica (AFM)}

A técnica de Microscopia de Força Atômica baseia-se na varredura da superfície estudada por meio de sondas de dimensões muito reduzidas a distancias muito pequenas (da ordem de alguns $\AA$ ), proporcionando uma alta resolução espacial, tanto lateral como vertical, na visualização de superfícies em nível atômico de diferentes naturezas (metais, películas orgânicas, polímeros, amostras biológicas em sistemas condutores e isolantes) e em diversos meios (vácuo, pressão atmosférica, meios líquidos) (Ohnesorge e Binnig, 1993).

O princípio da técnica se baseia na varredura da superfície da amostra por uma ponta piramidal (ponteira) de alguns micras de comprimento (100 a $200 \mu \mathrm{m}$ ) e geralmente com menos de vinte nanômetros de diâmetro, integrada em um 
"cantilever" flexível. A sonda (ponteira + cantilever) é sempre o componente básico para alcançar resolução atômica. A força entre a ponteira e a superfície da amostra faz com que o "cantilever" se aproxime ou se afaste e essa deflexão é proporcional à força de interação.

Na parte superior da haste há um espelho que reflete a luz de um feixe de laser. Após a reflexão, o feixe de laser passa por uma lente e incide sobre um fotodetector (fotodiodo) de quatro quadrantes, que mede as variações de posição e de intensidade da luz produzidas pelas deflexões do cantilever. À medida que a ponteira varre a amostra, os diferentes tipos de "acidentes geográficos" encontrados sobre a superfície fazem com que a interação mude. As variações das interações são os fatores que provocam diferentes deflexões. Essas diferenças, captadas no detector, são armazenadas e processadas por um computador, que as transformam em imagens topográficas da superfície bi e tridimensionais. As forças interativas medidas pelo AFM podem ser explicadas qualitativamente considerando, as forças de van der Waals (Worcester et al., 1988; Morandat et al., 2013).

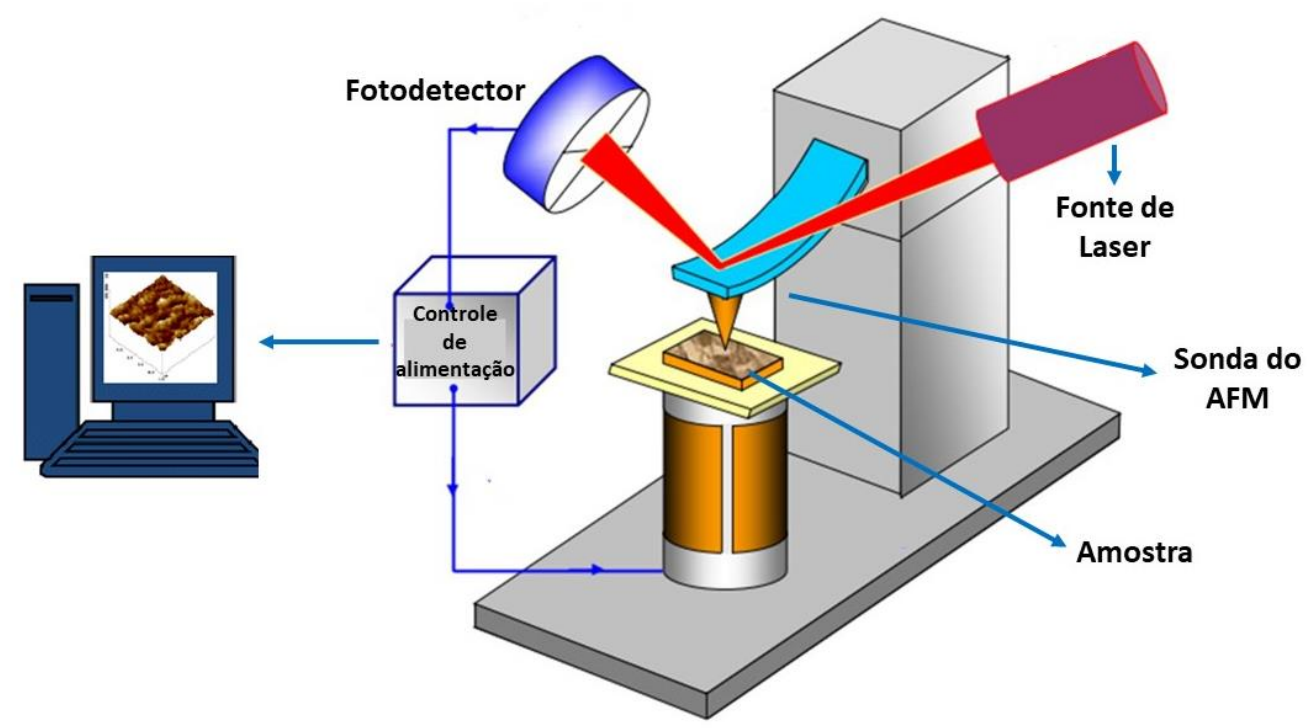

Figura 6. Ilustração simplificada de um Microscópio de Força Atômica. Adaptado de Mironov, (2004).

A técnica de AFM pode ser operada em três modos diferentes: contato, não contato, e contato intermitente ("tapping") (Ferreira, 2006; El Kirat et al., 2010; Morandat et al., 2013). 
No modo contato, o "cantilever" é mantido a poucos angstroms da superfície da amostra e a força interatômica entre a ponta e a amostra é repulsiva. Neste modo de operação, a ponta faz um leve "contato físico" com a amostra produzindo imagens com alta resolução, mas a compressão e as forças geradas, entre a ponteira e a superfície, podem causar danos à amostra, o que é especialmente prejudicial às amostras biológicas que são sensíveis e nem sempre fortemente aderidas ao substrato (Ferreira, 2006; El Kirat et al., 2010; Morandat et al., 2013).

No modo não - contato, o "cantilever" é mantido de dezenas a centenas de angstroms da superfície da amostra e a força interatômica entre a ponta e a amostra é atrativa. Neste caso a ponta oscila em alta frequência (100 kHz a $1 \mathrm{MHz}$ ), poucos nanômetros acima da superfície e a força total entre a ponta e a amostra é muito baixa, geralmente em torno de $10^{-12} \mathrm{~N}$. Esta oscilação aumenta consideravelmente a sensibilidade do microscópio, o que faz com que forças de van der Waals e forças eletrostáticas possam ser detectadas. O modo de não - contato não sofre os efeitos do atrito sobre a amostra, causada pela ponta, conforme é observado no modo contato após diversas varreduras. Por outro lado, este modo não tem encontrado aplicabilidade geral, devido à instabilidade entre a ponta e as forças adesivas da superfície e à resolução reduzida pela distância ponta - amostra que é relativamente grande. Esta limitação tem sido contornada com a utilização do modo intermitente (Ferreira, 2006; El Kirat et al., 2010; Morandat et al., 2013).

O modo de contato intermitente ("tapping") é similar ao não - contato, exceto pelo fato de que a ponta vibrante fica mais próxima da amostra, de forma que tenha um contato intermitente e é utilizado para contornar as limitações impostas pelo modo contato. A comparação das imagens nos modos contato e intermitente mostra que as superfícies são menos modificadas no modo intermitente (Ferreira, 2006; El Kirat et al., 2010; Morandat et al., 2013).

Devido às vantagens do modo contato intermitente, este foi escolhido para a realização das análises de varredura nos lipossomos e proteolipossomos estudados, com o intuito de verificar mudanças morfológicas e nas propriedades mecânicas das vesículas devido às composições lipídicas distintas e presença de proteínas nas vesículas. 


\subsubsection{Potencial Zeta}

A presença de uma carga superficial em partículas suspensas num líquido afeta a distribuição de íons que estão numa região muito próxima da partícula, ou seja, na interface entre a superfície da partícula e o meio de suspensão. O efeito resultante é um acúmulo de íons de carga oposta à carga da superfície, na região que cerca a partícula. Esses íons acabam formando uma "camada elétrica" que reveste a partícula e a mesma é dividida em duas partes (Figura 9): uma camada interna, onde os íons estão fortemente ligados à partícula, e uma camada externa, onde os íons difundem e estão fracamente ligados.

A camada externa representa uma barreira de proteção dentro da qual a partícula e os íons formam uma entidade com relativa estabilidade iônica. Quando a partícula difunde no líquido, sob ação de uma diferença de potencial na ordem de $150 \mathrm{~V}$, os íons contidos dentro dessa barreira difundem juntamente com a partícula, o que não acontece com os íons externos à barreira. O potencial que existe nesta barreira é denominado de potencial eletrocinético, mais conhecido como Potencial Zeta (Zetasizer Nano Series, 2013).

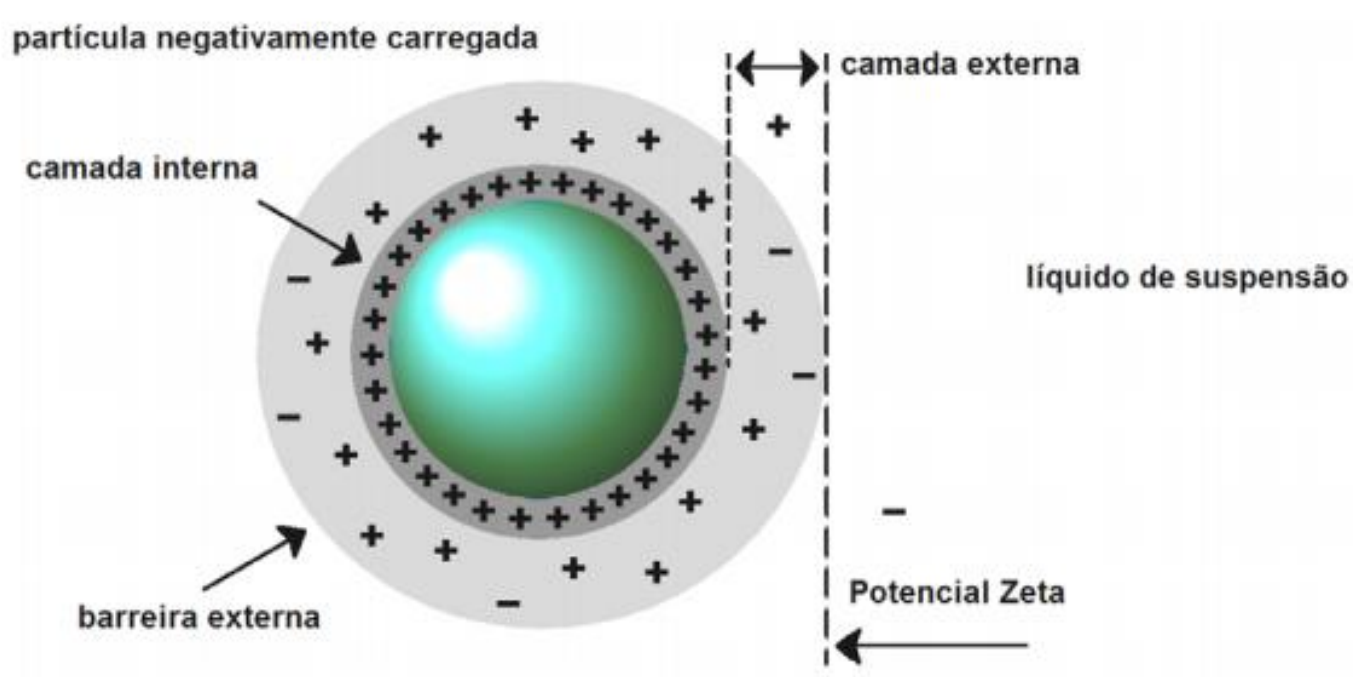

Figura 7. Representação da distribuição de íons em torno de uma partícula esférica negativamente carregada dispersa num liquido ionizado. Adaptado de Zetasizer Nano Series, (2004) 
Potencial Zeta é, portanto, a diferença de potencial entre o meio de dispersão e a camada externa. A magnitude deste potencial permite uma avaliação da estabilidade das partículas em suspensão considerando que, se todas as partículas apresentam um valor altamente positivo ou altamente negativo de Potencial Zeta, elas irão repelir umas às outras evitando a agregação. No caso de valores de Potencial Zeta muito baixos, próximos à zero, a ausência de carga superficial pode favorecer, em alguns casos, interações entre partículas o que promove processos de floculação ou agregação. De forma geral, a fronteira entre suspensões estáveis e não estáveis é considerada como sendo o valor de Potencial Zeta de $\pm 30 \mathrm{mV}$. Sendo assim, suspensões com valores acima de $+30 \mathrm{mV}$, bem como com valores inferiores a -30 mV, são consideradas estáveis. Já as suspensões com valores entre -30 e +30 $\mathrm{mV}$ são instáveis, sendo o valor de $0 \mathrm{mV}$ como o de maior instabilidade, o chamado ponto isoelétrico.

Evidentemente essa não é uma regra, considerando que partículas também podem ser preparadas com materiais que proporcionam um impedimento estérico que desfavorece fenômenos de agregação. Assim, as especificidades de cada sistema devem ser avaliadas para conclusões a respeito de estabilidade.

O parâmetro mais influente no Potencial Zeta é o $\mathrm{pH}$. Considerando que o pH do líquido de suspensão pode fornecer cargas positivas ou negativas que irão interagir com as partículas, o mesmo deve ser conhecido nas avaliações de estabilidade (Zetasizer Nano Series, 2004).

Se uma partícula está em suspensão e com um potencial zeta negativo, ao se adicionar uma base nessa suspensão as partículas tenderão a adquirir mais cargas negativas. Por outro lado, se for adicionado ácido a essa suspensão, as partículas irão adquirir cargas positivas até a neutralização. Logo a curva de potencial zeta versus $\mathrm{pH}$ será positiva para valores de $\mathrm{pH}$ mais baixos e negativa para valores de $\mathrm{pH}$ elevados (Zetasizer Nano Series, 2013). Além de interferir no potencial zeta, o $\mathrm{pH}$ afeta a estrutura das proteínas e o seu enovelamento depende de muitas variáveis tais como a temperatura, pressão e $\mathrm{pH}$. 


\subsubsection{Sistemas Miméticos de Membranas - Monocamadas e Lipossomos}

As membranas biológicas são sistemas muito complexos, não é fácil entender o comportamento físico-químico da bicamada lipídica ou explicar muitas de suas propriedades. Assim, os pesquisadores desenvolveram "modelos" de membranas biológicas que consistem em mono- ou bicamadas lipídicas simplificadas (Ciancaglini et al., 2012).

Esses sistemas miméticos podem ser constituídos por lipídios puros (mono componentes), misturas de mais de um tipo de lipídio e misturas reconstituídas de lipídios e uma única ou múltiplas proteínas podem ser preparados (Silvius 1992a; Rigaud et al., 1995).

As monocamadas, embora imitem metade de uma membrana biológica natural, podem ser facilmente obtidas pela dispersão de um composto anfifílico (como um lipídio) em uma interface água - ar (figura 8A). O sistema assim formado é um filme de espessura molecular em que a cabeça polar está em contato com a água e a cauda hidrofóbica se estende na direção do ar (monocamadas de Langmuir). Esses modelos de monocamadas são muito úteis para o estudo de lipídios e interações lipídicas, porém apresenta pouca aplicabilidade no estudo de interações com proteínas integrais. A partir de monocamadas, os sistemas modelos de bicamada podem ser facilmente preparados, por exemplo, imergindo substratos sólidos em monocamadas previamente formadas e obtendo o que é chamado de filmes de Langmuir - Blodgett (LB) (Figura 8B) (Dynarowicz-Latka et al., 2001a e b).

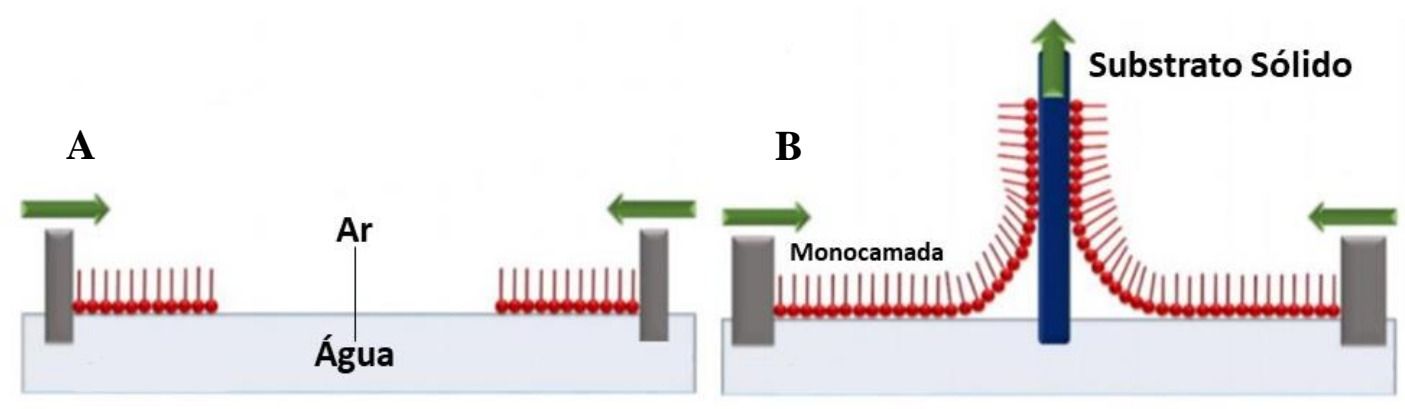

Figura 8. Representação de uma monocamada, A - formada em uma interface água - ar; B técnica de deposição com substrato sólido denominado filmes de Langmuir - Blodgett (LB). Adpatado de Oliveira et al. (2018) 
Os sistemas modelos de membrana mais estudados são os lipossomos ou vesículas (Figura 9), que podem ser obtidos em solução e não em suporte sólido, como os filmes LB. Em uma suspensão aquosa, a maioria dos lipídios (geralmente fosfolipídios) se organiza espontaneamente, formando sistemas com muitas bicamadas (multilamelares). Essa organização é impulsionada pela entropia das moléculas de água e pela interação entre as cadeias hidrofóbicas lipídicas (constituídas por ácidos graxos) (New 1990; Camolezi et al., 1999; 2002).

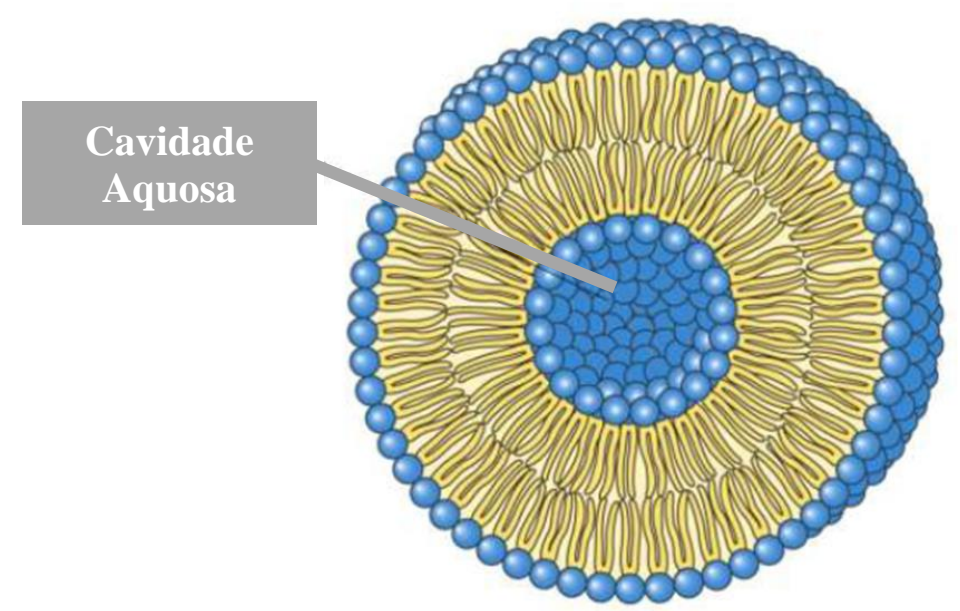

Figura 9. Representação de um lipossomo evidenciando sua estrutura interna constituída de um núcleo polar cercado por uma bicamada de fosfolipídios. Adaptado de Lehninger, (2014).

Esses sistemas multilamelares podem ser sonicados ou forçados a passar por poros (extrusão) de dimensões nanométricas, para formar sistemas unilamelares (com uma única bicamada concêntrica), muito semelhantes às membranas naturais. A sonicação e o processo de extrusão fornecem a energia necessária para romper as diferentes lamelas e reorganizar as bicamadas em vesículas uniformes e de tamanho controlado (lerardi et al., 2002; Daghastanli et al., 2004; dos Santos et al., 2002; Rigos et al., 2008).

\subsubsection{Tensão Superficial - Método da Gota Pendente}

A tensão superficial é a medida da quantidade de energia que é necessária para obter uma unidade de área de interface entre dois líquidos que não são 
miscíveis, e é dada em unidades de $\mathrm{J} / \mathrm{m}^{2}$ ou $\mathrm{N} / \mathrm{m}$ (Eggers, 1997; Eggers e Villermaux, 2008; Berry et al., 2015).

Em líquidos puros ou soluções, a tensão de superfície ( $(\mathrm{Y})$ pode ser medida de diferentes formas experimentais (Andrade et al., 2017). Os métodos mais utilizados na caracterização físico-química de misturas interfaciais são baseados na técnica que utiliza a cuba de Langmuir, onde a monocamada pode ser espalhada e uma nova solução pode ser injetada através da monocamada (Dynarowicz-Latka et al., 2001; Girard-Egrot et al., 2005; Stefaniu et al., 2014; Maldonado-Valderrama et al., 2015). Porém estes estudos são limitados pois, são necessários grandes volumes de amostra (Maldonado-Valderrama et al., 2015).

Dessa forma, o método da gota pendente também chamado de "análise do formato da gota assimétrica" (axisymmetric drop shape analysis - ADSA) mede a tensão de superfície na interface líquido - ar ou líquido - líquido. Esta técnica utiliza pequeno volume de amostra, na faixa de microlitros, o que é considerado uma vantagem, principalmente quando não se dispõem de grandes quantidades de amostra disponíveis (Rotenberg et al., 1983; Berry et al., 2015; Andrade et al., 2017). Além disso, ela permite o controle de condições experimentais como temperatura e pressão (Ferri et al., 2010; Wege et al., 2002; Maldonado-Valderrama et al., 2015).

A técnica consiste de 5 subsistemas fundamentais: luz, aquisição de imagem, controle ambiental, controle de fluxo de líquido e subsistemas antivibração (Figura 10) (Maldonado-Valderrama et al., 2015). 


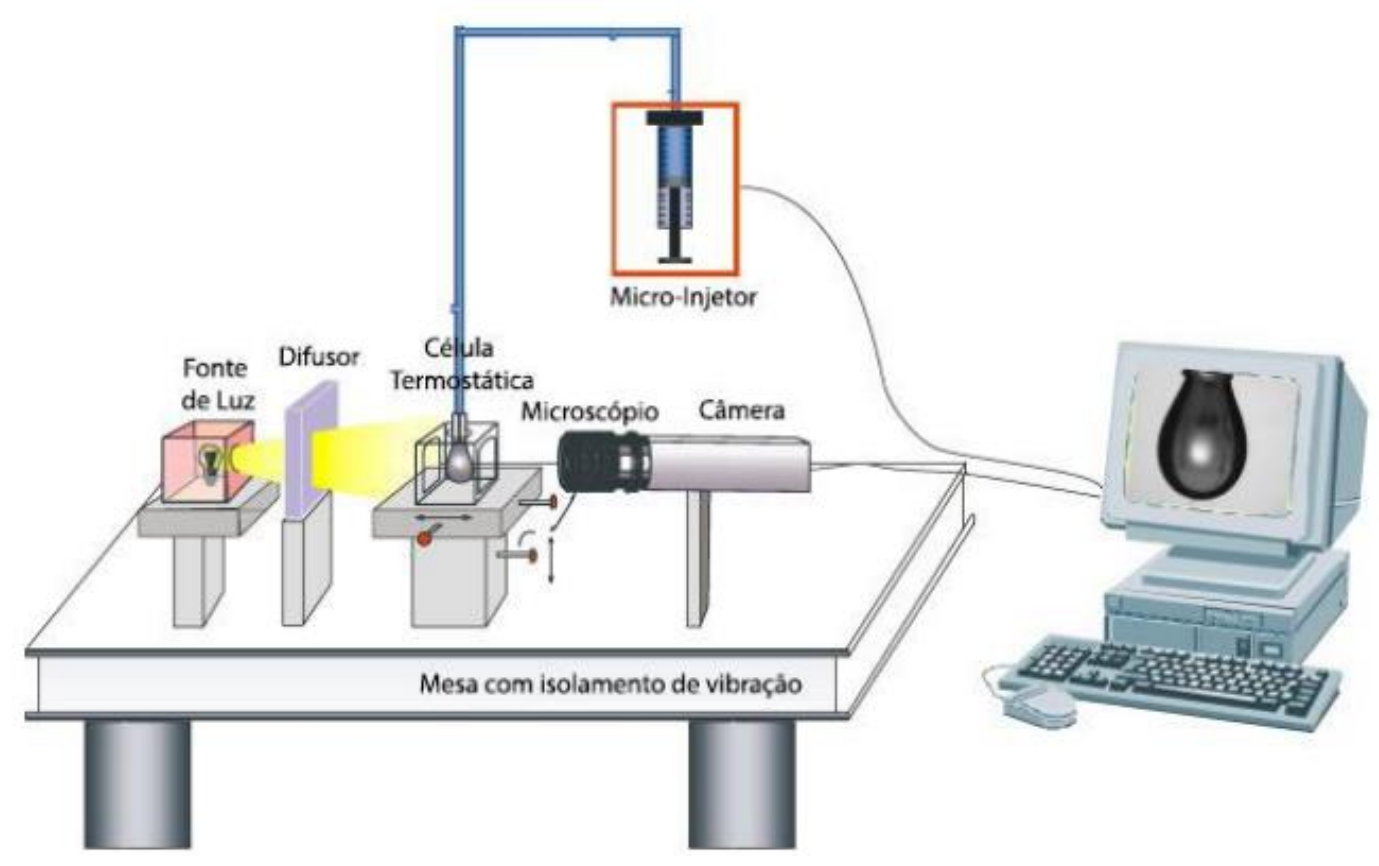

Figura 10. Configuração experimental de um instrumento de gota pendente. Adaptado de Maldonado-Valderrama et al. (2015).

A determinação da tensão superficial é baseada na equação de Laplace de capilaridade (Eq. 1), que relaciona a pressão através da interface $(\Delta P)$ com a tensão de superfície e o raio de curvatura principal $\left(R_{1}\right.$ e $\left.R_{2}\right)$ (Miller et al., 1993; Andrade et al., 2017):

$$
\Delta P=\gamma\left(\frac{1}{R_{1}}+\frac{1}{R_{2}}\right)
$$

Eq. 1

A tensão superficial depende da quantidade de surfactante que é adsorvida na área superficial da gota, portanto, valores diferentes de tensão superficial e pressão superficial serão encontrados para concentrações diferentes de surfactante. A pressão superficial $(\pi)$ corresponde à diminuição da y da solução aquosa pura ( $\left({ }_{0}\right)$ na presença do surfactante (Wege et al., 1999):

$$
\pi=\gamma_{0}-\gamma
$$

Eq. 2

A técnica de tensiometria da gota pendente é considerada uma solução simples para determinar a tensão de superfície e tensão interfacial de muitos sistemas coloidais, incluindo emulsões e espumas (Berry et al., 2015). 


\section{OBJETIVOS}

O objetivo principal deste projeto foi buscar compreender características até então pouco conhecidas da AnxA6 no processo de biomineralização. Assim, estudos de seu comportamento mediante diferentes composições lipídicas, verificando a intercorrência de interações da proteína com monocamadas e bicamadas lipídicas foram indispensáveis para poder traçar características comportamentais da proteína, como maiores afinidades lipídicas, parâmetros termodinâmicos dos proteolipossomos, bem como sua contribuição para a biomineralização óssea.

Para tanto, o projeto utilizou de estudos bioquímicos e biofísicos para a caracterização da AnxA6, compreendo os seguintes objetivos específicos:

A. Analisar as diferenças estruturais entre as anexinas A5 e A6;

B. Verificar se há associação da AnxA6 com diferentes composições lipídicas utilizando o método da gota pendente;

C. Estudar a incorporação da Anexina A6 em lipossomos compostos por diferentes composições lipídicas;

D. Avaliar os comportamentos de transição de fase por calorimetria.

E. Estudar agregação das proteínas por "light scaterring".

F. Avaliar os sistemas vesiculares por Microscopia de Força Atômica

G. Investigar a capacidade de formação de nódulos de mineralização da AnxA6 presente nos diferentes sistemas vesiculares obtidos. 
$\theta$ 0

.

(O)

ㄴ

$\Sigma$

U

$\square$

4

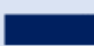

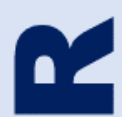

II

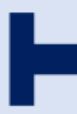

4

$\square$ 


\section{MATERIAL E MÉTODOS}

\subsection{Obtenção da AnxA5}

O plasmídeo para AnxA5 (pProEx.Htb.annexin V) foi gentilmente cedido pelo professor Seamus J. Martin de Dublin, Irlanda e foi expresso em E. coli com uma calda de histidina para facilitar a sua purificação, de acordo com o protocolo descrito por Logue e colaboradores (2009). Esta etapa do trabalho já foi padronizada no laboratório do Prof. Dr. José Luis Millán e atualmente, temos a metodologia implementada em nosso laboratório.

\subsection{Obtenção da AnxA6}

AnxA6 foi gentilmente cedida pelo laboratório do Prof. Rene Buchet (Department of Chemistry-Biochemistry, Universite Lyon, França). A proteína humana recombinante AnxA6 foi expressa e purificada pelo laboratório do Prof. Slawomir Pikula (Nencki Institute of Experimental Biology, Polônia) segundo descrito por Golczak et al. (2001).

\subsection{Caracterização estrutural das Anexinas A5 e A6 por Dicroísmo Circular}

Os estudos de dicroísmo circular (CD) foram realizados conforme descrito por Franzoni e colaboradores (1997) utilizando-se um equipamento Jasco 810 equipado com célula termostatizada do tipo Peltier. Os experimentos foram realizados a $25^{\circ} \mathrm{C}$, 190 a $250 \mathrm{~nm}$ submetendo as anexinas A5 e A6 $\left(2 \mu \mathrm{g} \cdot \mathrm{mL}^{-1}\right)$ a diferentes valores de $\mathrm{pH}$. A variação de $\mathrm{pH}$ utilizada foi de 3 - 11. Para acidificar o meio utilizou-se solução de ácido clorídrico $\left(\mathrm{HCl} 1\right.$ mol..-1 ${ }^{-1}$ e uma solução de hidróxido de sódio $(\mathrm{NaOH} 1$ mol. $\left.\mathrm{L}^{-1}\right)$ para alcalinizar o meio proteico. Todas as medidas foram realizadas em triplicata a fim de obter uma média entre elas. 


\subsection{Cálculo da elipticidade e estimativa de $\alpha$-hélices}

A elipticidade molar foi calculada de acordo com a equação:

$$
\theta_{\lambda}=\theta_{\text {obs }} x M R W / 10 x d x C
$$

Eq. 3

onde $\theta_{\lambda}=$ elipticidade molar em determinado comprimento de onda; $\theta_{\text {obs }}=$ elipticidade observada; $\mathrm{MRW}=$ média de peso molecular de resíduos de aminoácidos. O MRW usado para um grande grupo de proteínas é de aproximadamente 115); $d=$ comprimento da cubeta em $\mathrm{cm}$ e $\mathrm{C}=$ concentração de proteína em $\mathrm{g} \cdot \mathrm{mL}^{-1}$ (Adler, 1973).

A quantidade de estrutura em hélice $\alpha\left(f_{H}\right)$ das anexinas AnxA5 e AnxA6 foi estimada a partir da elipticidade por resíduo em $222 \mathrm{~nm}\left(\theta_{222}\right)$ determinada pelo espectro de CD em cada condição, conforme descrito por Chen e colaboradores (1972) pela equação:

$$
(f H)=-\left([\theta]_{222}+2340\right) / 30300
$$

Eq. 4

\subsection{Medidas de Potencial Zeta}

As análises foram realizadas no equipamento ZEN 1020 Surface Zeta Potential (Malvern Instrument), acessório do equipamento de espalhamento de luz Zetasizer Nano ZS - Malvern Instruments. Para análises zeta pontuais, a AnxA6 foi diluída em água na proporção de 1:100 para que a intensidade fosse atingida. Nas titulações, foram utilizadas as mesmas proporções, para $8 \mathrm{~mL}$ finais de amostra. $\mathrm{O}$ escaneamento foi iniciado em $\mathrm{pH} 7,0$ até o final em $\mathrm{pH} 3,0$. O HCl foi usado como padrão a $0,094 \pm 4,0 \times 10^{-4} \mathrm{~mol} \cdot \mathrm{L}^{-1}$. (Tovani, 2020) 


\subsection{Análise da tensão superficial pelo método da gota pendente}

Para os experimentos de tensão superficial ( $(\mathrm{Y})$ acoplando DRUV (Espectrofotometria UV-Vis por Reflectância Difusa) - ADSA (Análise do Formato da Gota Eixossimétrica), a fibra ótica foi colocada próxima à superfície lateral da gota (cerca de 2-3 mm), variando o volume adicionado entre 10 e $12 \mu \mathrm{L}$, com o auxílio de um tensiômetro automático do tipo OCA-20 (Dataphyics ${ }^{\circledR}$ ). A gota pendente foi um microambiente formado por tampão Tris-HCl $50 \mathrm{mM}, \mathrm{pH} 7,5$, contendo $\mathrm{MgCl}_{2} 2 \mathrm{mM}$ e EGTA $200 \mu \mathrm{M}$ e num segundo momento adicionando-se $2 \mathrm{mM}$ de cálcio $\left(\mathrm{Ca}^{2+}\right)$ ao tampão para a formação da gota. A tensão superficial $(\mathrm{Y})$ foi monitorada através da técnica de DRUV-ADSA, pela injeção de $0,5 \mu \mathrm{L}$ da solução proteica de AnxA6 (0,2 $\mathrm{mg} \cdot \mathrm{mL}^{-1}$ ) na gota.

As monocamadas foram formadas por injeção de alguns microlitros de diferentes composições lipídicas (baseando -se em Dipalmitoil fosfatidilcolina (DPPC), Dipalmitoil fosfatidilserina (DPPS) e Colesterol (Chol)), dentro da gota. Foi injetado cerca de $0,5 \mu \mathrm{L}$ da solução proteica e assim registrada as alterações na $Y$ da monocamada em consequência da interação da proteína. O tempo inicial foi baseado na injeção da proteína ao sistema. Os dados foram relatados como a média em triplicatas de diferentes preparações de gotas. (Andrade et al., 2017; Favarin et al., 2017).

\subsection{Preparação dos lipossomos}

Foram utilizadas diferentes composições lipídicas para a preparação dos lipossomos, assim como a presença de $\mathrm{Ca}^{2+}$ a fim de obter uma eficiente incorporação da AnxA6. Os lipídios utilizados foram dipalmitoil fosfatidilcolina (DPPC), dipalmitoil fosfatidilserina (DPPS) e colesterol (Chol) (Veschi et al., 2020).

A preparação dos lipossomos foi realizada a partir da pesagem da mistura de lipídios de acordo com as composições propostas. Os lipídios foram dissolvidos em clorofórmio, o qual foi removido através da passagem de uma corrente de nitrogênio pela solução, formando um filme nas paredes do tubo. Estes filmes foram mantidos em vácuo por 1 hora, para garantir a completa remoção do solvente. Em seguida, o filme lipídico foi ressuspenso em um volume apropriado de tampão Tris- $\mathrm{HCl} 50 \mathrm{mM}$, 
pH 7,5, contendo $\mathrm{MgCl}_{2} 2$ mM e EGTA $200 \mu \mathrm{M}$, a fim de se obter uma solução com a concentração final de $10 \mathrm{mg} \cdot \mathrm{mL}^{-1}$. Essa mistura foi incubada a $70^{\circ} \mathrm{C}$, por 1 hora, com agitações em vortex em intervalos de 10 minutos, e extrusada empregando-se o sistema de extrusão Liposofast (Sigma-Aldrich) com uma membrana de policarbonato de $100 \mathrm{~nm}$. A suspensão de vesículas unilamelares homogêneas relativamente pequenas foi estocada a $4^{\circ} \mathrm{C}$ (Bolean et al., 2010, 2011, 2015, 2017a).

Para os lipossomos contendo $\mathrm{Ca}^{2+}$, foi adicionado $2 \mathrm{mM}$ de uma solução de cloreto de cálcio no lipossomo após extrusão.

\subsection{Incorporação da AnxA6 aos lipossomos}

Este ensaio foi realizado utilizando o método de inserção direta descrito por Bolean et al. (2017b). Os lipossomos previamente formados foram incubados overnight a $25^{\circ} \mathrm{C}$ com a proteína $\left(0,2 \mathrm{mg} \cdot \mathrm{mL}^{-1}\right)$ e após incubação, a amostra foi ultracentrifugada a $100.000 \mathrm{~g}$ por 1 hora, a $4^{\circ} \mathrm{C}$. As concentrações de proteína, presente no sobrenadante e no pellet ressuspenso, foram determinadas e utilizadas para calcular a porcentagem de incorporação da AnxA6 aos lipossomos.

\subsection{Medidas de espalhamento de luz dos lipossomos e proteolipossomos}

As medidas de distribuição de tamanho dos lipossomos e proteolipossomos foram realizadas por espalhamento de luz dinâmico empregando-se o equipamento N5 Submicron Particle Size Analyzer (Beckman Coulter), sendo as amostras previamente diluídas e filtradas (Millipore MCE membrane filter - 0,8 $\mu \mathrm{m}$ ), de modo a se obter um índice de polidispersão (IP) adequado. Os valores determinados correspondem a uma média de 5 medidas realizadas à temperatura ambiente (Bolean et al., 2010, 2011, 2015).

Também utilizando o método de espalhamento de luz, verificou-se a estabilidade dessas vesículas por 28 dias, utilizando os mesmos métodos citados acima. 


\subsection{Dosagem de proteína}

As concentrações de proteína foram determinadas pelo método descrito por Hartree (1972) na presença de SDS 2\% (p/v). A albumina de soro bovino foi utilizada como padrão. As determinações foram feitas em triplicatas e a concentração de proteína estimada a partir de uma curva padrão feita para cada dosagem.

\subsection{Medidas de DSC}

Os estudos de calorimetria foram realizados empregando-se o equipamento $\mathrm{N}$ - DSC II: Differential Scanning Calorimeter (Calorimetry Sciences Corporation). As amostras e a referência (tampão Tris- $\mathrm{HCl} 50 \mathrm{mM}$, pH 7,5, contendo $\mathrm{MgCl}_{2} 2 \mathrm{mM}$ e EGTA $200 \mu \mathrm{M}$ ) foram previamente deaeradas antes de serem submetidos à análise (300 $\mu \mathrm{L}$ de cada). Foram realizadas varreduras de temperatura de $0^{\circ} \mathrm{C}$ a $90^{\circ} \mathrm{C}$, com velocidade de aquecimento de $0,5^{\circ} \mathrm{C} / \mathrm{min}$, bem como varreduras de $0^{\circ} \mathrm{C}$ a $90^{\circ} \mathrm{C}$, com velocidade de resfriamento de $0,5^{\circ} \mathrm{C} / \mathrm{min}$.

Durante a transição, a temperatura da amostra permanece constante, enquanto que a da referência continua aumentando. O calorímetro registra uma variação de temperatura que é convertida em diferença de potência $(\Delta P)$. Os dados de potência $(\mu \mathrm{W})$ são transformados em capacidade calorífica molar, possibilitando a determinação dos valores de temperatura crítica de transição $\left(\mathrm{T}_{\mathrm{C}}\right)$, cooperatividade $\left(\Delta \mathrm{T}_{1 / 2}\right)$ e variação de entalpia $(\Delta \mathrm{H})$. As análises de deconvolução, realizadas para se obter uma melhor resolução de picos distintos que podem aparecer em uma mesma corrida, foram realizadas utilizando-se o programa Origin, versão 8.0 (Bolean et al., 2010, 2011, 2015).

\subsection{Microscopia de Força Atômica (AFM)}

As análises de AFM foram obtidas utilizando um equipamento Shimadzu, SPM-9600 Scanning Probe Microscope com modo de fase tapping, à temperatura ambiente, em ar, usando sonda de silicone contendo um cantilever com $124 \mu \mathrm{m}$ de comprimento, rigidez variando de 34 a $51 \mathrm{Nm}^{-1}$ e frequência de ressonância de 324$369 \mathrm{kHz}$. A varredura foi realizada em condições de força constante. 
As amostras de lipossomos e proteolipossomos foram estabilizadas usando glutaraldeído, o qual foi gotejado sobre a superfície de uma mica recém-clivada e seco a temperatura ambiente. A velocidade de varredura foi adequadamente reduzida a 0,2 - 0,3 Hz, e o ganho integral foi obtido da menor maneira possível para evitar a indução de deformação pela ponta nas vesículas ou danos na amostra. As imagens de altura, amplitude, AcosD, AsinD e Fase foram adquiridas simultaneamente sobre uma mesma área selecionada (Sebinelli et al., 2019; Bolean et al., 2017a)

\subsection{Síntese de ACP e PS-CPLX}

A síntese de ACP e PS-CPLX foi realizada de acordo com o método descrito por Genge et al. (2007) e adaptado conforme Simão et al. (2013). Uma emulsão de PS foi preparada secando-se 1,25 mg de PS em clorofórmio, sob atmosfera de nitrogênio, para formar uma película fina num tubo de ensaio. Então, $2 \mathrm{~mL}$ de tampão fosfato intracelular (ICP) rico em Pi foi adicionado. Este tampão, mimetiza a composição de eletrólitos de ultrafiltrados do fluido intracelular de condrócitos de placa de crescimento (Wuthier et al., 1985), contém $\mathrm{K}^{+} 106,7 \mathrm{mM}, \mathrm{Na}^{+} 45,1 \mathrm{mM}$, $\mathrm{Mg}^{2+}$ 1,5 mM, $\mathrm{Cl}^{-} 115,7 \mathrm{mM}$, Pi 23,0 mM, $\mathrm{HCO}^{-} 10 \mathrm{mM}$, SO 2- 1,5 mM e N- 3,1 mM como conservante; sua molaridade total é de 153,3 mM e o pH é 7,2. O tubo foi sonicado por $2 \min$ a $25^{\circ} \mathrm{C}$ para formar uma emulsão translúcida homogênea de vesículas unilamelares pequenas. Para fazer os nucleadores, $17,5 \mu \mathrm{L}$ de $\mathrm{CaCl} 2100$ $\mathrm{mM}$ foi adicionado a $1 \mathrm{~mL}$ da emulsão de PS sob rápida agitação.

Com a adição de $\mathrm{Ca}^{2+}$ ao tampão ICP, o ACP forma-se instantaneamente devido ao alto produto iônico $\mathrm{Ca}^{2+} \times \mathrm{Pi}$, e durante este período de formação, o ACP nascente combina-se com os lipossomos de PS para formar o complexo insolúvel PS-CPLX, que foi então recolhido por centrifugação durante $5 \mathrm{~min}$ a aproximadamente $15.000 \mathrm{~g}$. Os pellets foram ressuspensos em $1 \mathrm{~mL}$ de tampão TrisHCl 16,5 mM, pH 8, por breve sonicação, para se obter suspensões uniformes.

Em alguns experimentos, a PS foi omitida e a solução estoque de $\mathrm{CaCl}_{2} 100$ $\mathrm{mM}$ foi adicionado ao tampão ICP com rápida agitação para formar ACP baseado no ICP. Estes procedimentos modelam os processos que ocorrem em condrócitos de 
placa de crescimento, onde os níveis de $\mathrm{Ca}^{2+}$ intracelular aumentam dramaticamente nos sítios de formação de MVs (Wu et al., 1997).

\subsection{Ensaio de mineralização em microplacas com proteolipossomos}

Os diferentes proteolipossomos produzidos foram incubados em tampão SCL contendo ACP ou PS-CPLX, em pH 7,5. O tampão SCL contém $\mathrm{Ca}^{2+} 2 \mathrm{mM}$ e substrato $1 \mathrm{mM}$ (ATP, ADP, AMP ou PPi) como fonte de Pi, além de $\mathrm{Na}^{+} 104,5 \mathrm{mM}$, $\mathrm{Cl}^{-} 133,5 \mathrm{mM}$, sacarose $63,5 \mathrm{mM}$, Tris $16,5 \mathrm{mM}, \mathrm{K}^{+}$12,7 mM, glicose 5,55 mM, HCO3$^{-}$1,83 mM e MgSO4 0,57 mM (Wuthier, 1977; Simão et al., 2013). Lipossomos vazios sem proteína incorporadas e a AnxA6 foram utilizados como controle. A formação mineral foi medida por turbidez (isto é, absorbância) em $340 \mathrm{~nm}\left(\mathrm{~A}_{340 \mathrm{~nm}}\right)$ empregando-se um sistema de ensaio em microplacas com multi-poços descrito por Genge et al. (2007).

Amostras em quadrutriplicatas $(100 \mu \mathrm{L})$ foram distribuídas sucessivamente nos poços de uma microplaca de 96 poços. As medidas de turbidez foram feitas após breve (10 segundos) agitação da microplaca, durante $30 \mathrm{~h}$ de incubação a $25^{\circ} \mathrm{C}$, utilizando um leitor de microplacas Molecular Devices M3. Todas as medidas foram realizadas em quadruplicada. Alternativamente, esses ensaios foram realizados na presença de colágeno tipo $\mathrm{I}$.

\subsection{Espectroscopia de infravermelho com transformada de Fourier (FTIR)}

Os proteolipossomos foram incubados em tampão SCL, como descrito acima, na presença dos nucleadores ACP e PS-CPLX. Então as amostras foram colocadas no cristal de germânio de um atenuado acessório de refletância total (ATR) para avaliar a substância química grupos nos minerais formados por meio de espectroscopia FTIR (Shimadzu IRPrestige-21). A eficácia da mineralização foi avaliada calculando-se a razão entre as áreas da banda de referência interna do éster fosfolipídio $(\mathrm{C}=\mathrm{O})$ a $1740 \mathrm{~cm}^{-1}$ e a banda correspondente ao alongamento assimétrico do $\mathrm{PO}_{4}{ }^{3-}$ grupo a $1032 \mathrm{~cm}^{-1}$ (Simão et al., 2019). 
0
14
0
0
0
0
0
0
0

II

$\infty$

0

$\square$

4

I
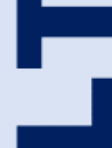

כ

C

II

0 


\section{RESULTADOS E DISCUSSÃO}

\subsection{Características estruturais da AnxA5 e AnxA6}

\subsubsection{Caracterização estrutural das Anexinas A5 e A6 por Dicroísmo Circular}

A estrutura secundária de uma proteína diz respeito à sua organização local mantida em sua maior parte por interações físico-químicas, comumente ligações de hidrogênio, entre os resíduos de aminoácidos que se encontram próximos. As típicas Estruturas secundárias são $\alpha$-hélices e $\beta$-folhas (Rosenberg, 1996). Os diferentes tipos de estruturas secundárias geram espectros de CD característicos na região do ultravioleta distante onde os principais grupos que absorvem radiação são as ligações peptídicas. Ocorre então uma transição fraca e larga do tipo $n \rightarrow \pi^{*}$ em 220 nm e uma transição $\Pi \rightarrow \pi^{*}$ intensa em aproximadamente 190 nm (Pain, 2005; Kelly et al., 2005).

As proteínas são macromoléculas relativamente estáveis, entretanto, altamente susceptíveis à degradação, tanto química quanto física. A degradação química se refere geralmente a modificações envolvendo ligações covalentes, como desaminação e oxidação. Já as degradações físicas envolvem desenovelamento de proteínas e agregação (Mierlo et al., 2000; Chi et al., 2003). Sendo assim, a técnica de dicroísmo circular foi utilizada para acompanhar possíveis alterações estruturais nas proteínas AnxA5 e AnxA6 em decorrência à variação de $\mathrm{pH}$ do meio.

Os espectros de dicroísmo circular das anexinas AnxA5 e AnxA6 foram coletados variando-se o $\mathrm{pH}$ por meio de pequenas adições de $\mathrm{HCl}(1 \mathrm{M})$ e $\mathrm{NaOH}$ (1M) levando aos seguintes valores de pH: 3, 5, 8 e 11 para AnxA5 e 2, 3, 4,5, 7, 8 e 10 para AnxA6.

Observando-se os espectros das Figuras 11 e 12 é possível identificar um sinal negativo em aproximadamente $222 \mathrm{~nm}$ e outro sinal intenso em $209 \mathrm{~nm}$. Esses sinais são característicos de proteínas que apresentam sua estrutura secundária majoritariamente em $\alpha$-hélices (Pain, 2005). No entanto, pode-se verificar também que alterações ácidas e alcalinas ao meio ocasionaram alterações na elipticidade relativa de ambas as proteínas. Chen e colaboradores (1972) apresentaram uma forma de estimar rapidamente o conteúdo helicoidal de proteínas globulares a partir 
das relações apresentadas na eq.4 no item 3.4 de Materiais e Métodos. Para tanto, utilizou-se os valores de elipticidade relativa no comprimento de onda de $222 \mathrm{~nm}$ para as estimativas percentuais de $\alpha$-hélice para cada $\mathrm{pH}$.

Com base nos valores estimados, verifica-se que a AnxA5 apresenta maior porcentagem de $\alpha$-hélice em pH 8 (43\%) seguido pelo $\mathrm{pH} \mathrm{5,0} \mathrm{(35 \% ),} \mathrm{dados} \mathrm{descritos}$ na literatura apresentam cerca de $80 \%$ de a-hélice na estrutura da AnxA5, segundo análises de estrutura secundária por raios-X e CD (Huber et al., 1990). Porém está diferença apresentada na porcentagem de estrutura em a-hélice pode estar relacionada com o método de expressão no qual a proteína é obtida.

Já a AnxA6 exibe em pH ácido 6,5 (86\%) e pH 4,0 (58\%) maiores porcentagens de estruturas $\alpha$-hélice. Golczak e colaboradores (2001a), mostraram que a AnxA6 exibe cerca de $88,2 \%$ de sua estrutura $\alpha$-hélice em pH 7,4 e 50,7\% em pH 3,0 mostrando assim similaridades aos valores obtidos no presente trabalho.

Alguns estudos mostraram que mudanças de $\mathrm{pH}$ são um dos fatores mais potentes que afetam a função e a estrutura das anexinas, a esse respeito, essas mudanças são muito mais eficazes do que as mudanças nas concentrações intracelulares de $\mathrm{Ca}^{2+}$ (Golczak et al., 2001a). Postula-se que a localização intracelular das anexinas está relacionada à sensibilidade ao $\mathrm{pH}$ de algumas delas. Essas proteínas são frequentemente detectadas na superfície de organelas celulares de baixo pH interno (Jackle et al., 1994; Jost et al., 1997; Zeuschner et al., 2001).

Os resultados obtidos para as variações de $\mathrm{pH}$ para cada anexina sugerem alterações estruturais tanto em $\mathrm{pH}$ ácido quanto em $\mathrm{pH}$ básico, no entanto, para uma completa elucidação dos efeitos de alteração de pH seria necessário a realização de outros experimentos, como analisar a variação de hidrofobicidade em diferentes pHs como também estudos de fluorescência para verificar alterações na estrutura terciária das proteínas. Porém, com base nas estimativas obtidas torna-se possível traçar os possíveis valores de $\mathrm{pH}$ mais apropriados para garantir que a proteína esteja com sua estrutura secundária predominante e assim desempenhar sua função corretamente. 


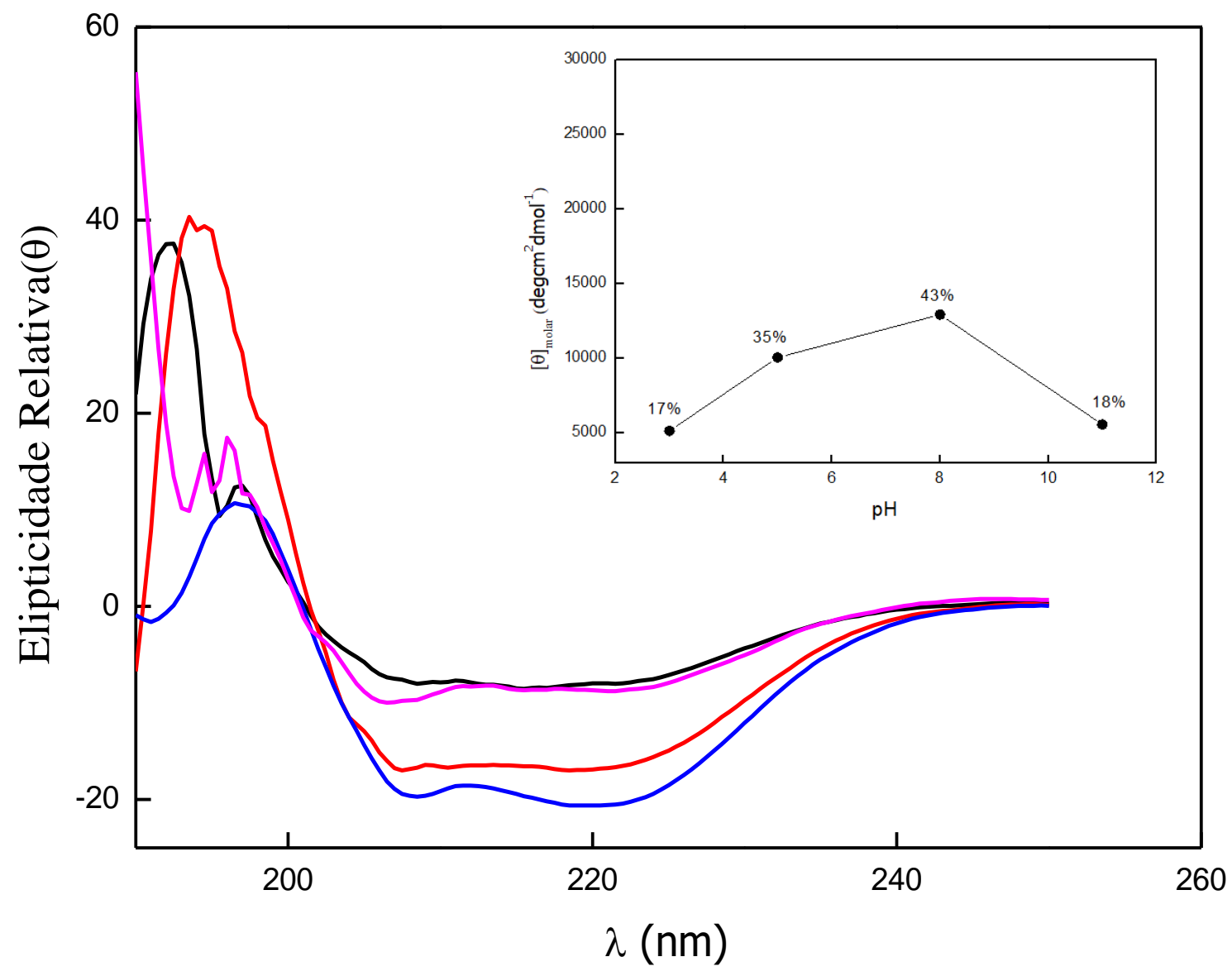

Figura 11. Espectros de Dicroísmo Circular para AnxA5 $\left(2 \mu \mathrm{g} \cdot \mathrm{mL}^{-1}\right)$ para diferentes valores de $\mathrm{pH}$. Inserção: Elipticidade relativa molar em função da variação de $\mathrm{pH}$ com as respectivas estimativas percentuais de estruturas a-hélices. Preto - $\mathrm{pH} \mathrm{3,0;} \mathrm{Vermelho} \mathrm{-} \mathrm{pH} 5,0$; Azul $\mathrm{pH}$ 8,0 e Rosa - pH 11,0. 


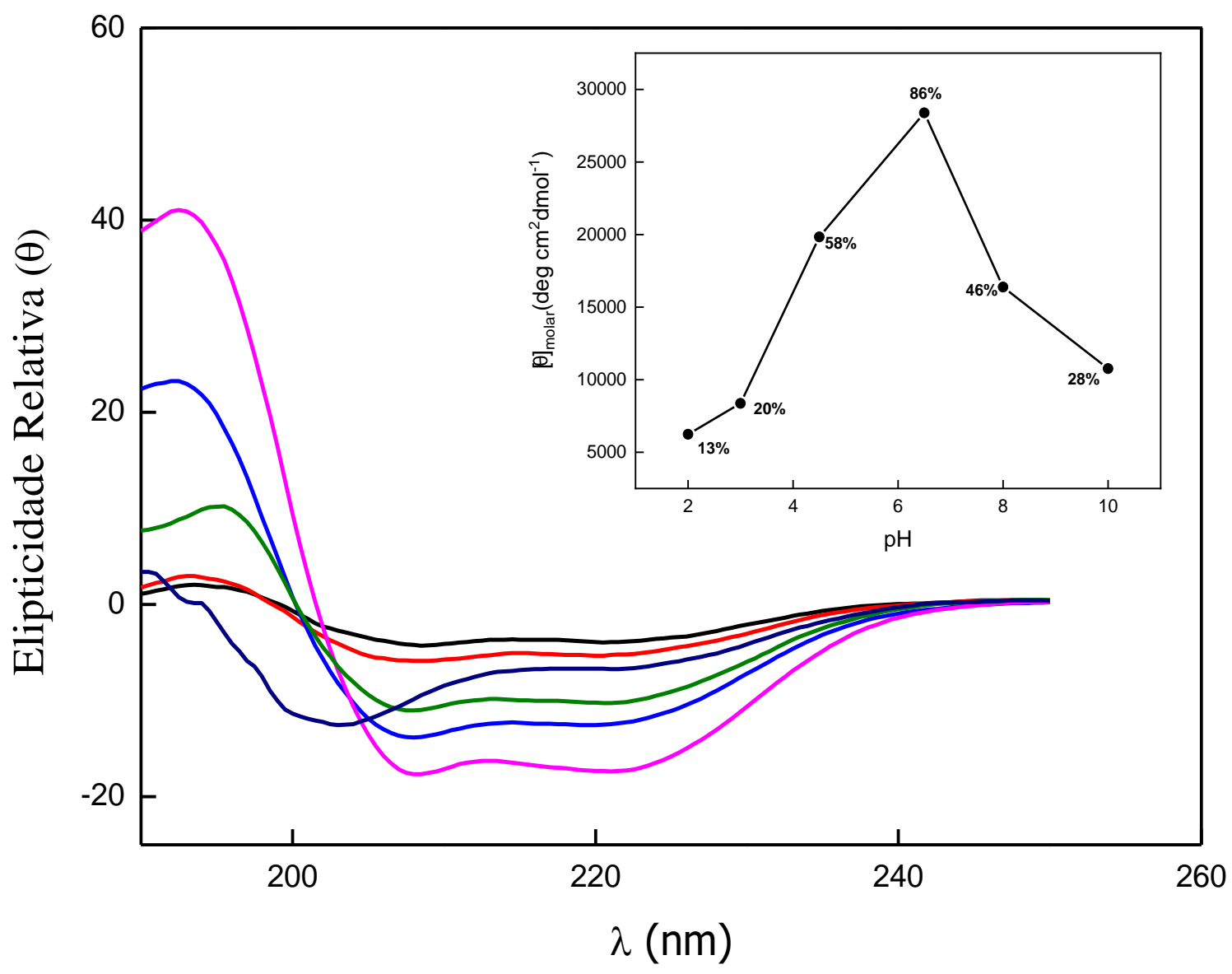

Figura 12. Espectros de Dicroísmo Circular para AnxA6 $\left(2 \mu \mathrm{g} \cdot \mathrm{mL}^{-1}\right)$ para diferentes valores de $\mathrm{pH}$. Inserção: Elipticidade relativa molar em função da variação de $\mathrm{pH} \mathrm{com}$ as respectivas estimativas percentuais de estruturas $\alpha$-hélices. Preto $-\mathrm{pH} 2,0 ;$ Vermelho $-\mathrm{pH} 3,0 ; \mathrm{Azul}-\mathrm{pH}$ 4,0; e Rosa - pH 6,5; Verde - pH 8,0 e Roxo - pH 10,0. 


\subsubsection{Determinação do ponto isoelétrico da AnxA6 por medidas de potencial zeta}

O ponto isoelétrico é definido como o pH no qual a partícula em suspensão tem carga eletrostática superficial igual a zero e esse ponto é único para cada espécie de partículas.

Para a determinação do pl da ANXA6 realizou-se titulações analisadas por potencial zeta, obtendo-se o valor de $\mathrm{pH}$ no ponto onde a carga eletrostática medida foi zero. Como dito, cada proteína possui um pl característico, que reflete a proporção entre aminoácidos ácidos e básicos. Assim, quando no pl, as proteínas apresentam um número de grupo $\mathrm{R}$ ácidos desprotonados (COO-) igual ao número de grupo $\mathrm{R}$ básicos protonados $\left(\mathrm{NH}_{3}{ }^{+}\right)$. Desta forma, as proteínas apresentarão carga líquida positiva em $\mathrm{pH}$ menor que o pl e carga líquida negativa em $\mathrm{pH}$ maior que o pl (Figura 13) (Jiang et al., 2009; Soares, 2009).

No ponto isoelétrico existe um equilíbrio entre o número de cargas positivas e negativas, o que gera uma situação em que as forças de repulsão entre as moléculas de proteína e as forças de interação com o solvente são mínimas. Assim, as proteínas vão formando aglomerados que, cada vez maiores, tendem a precipitar.

A solubilidade das proteínas, depende de vários fatores, dentre eles, destacase a presença das cargas elétricas ao longo da molécula. A existência de uma carga positiva ou negativa determina a interação com o meio aquoso, além de estabelecer um estado de repulsão entre as próprias moléculas de proteína, aumentando a interação com o solvente e, consequentemente, favorecendo a solubilidade. É importante destacar que essa diminuição de solubilidade varia de proteína para proteína.

O valor experimental obtido para o pl da AnxA6 foi de 4,2, sendo que o valor relatado na literatura é de 5,8 (Moss et al., 1990; Golczak et al., 2001b). Para compreender o motivo de tal discrepância seria necessária a realização de um sequênciamento da proteína em uso para verificar possíveis falhas em sua sequência de aminoácidos. 


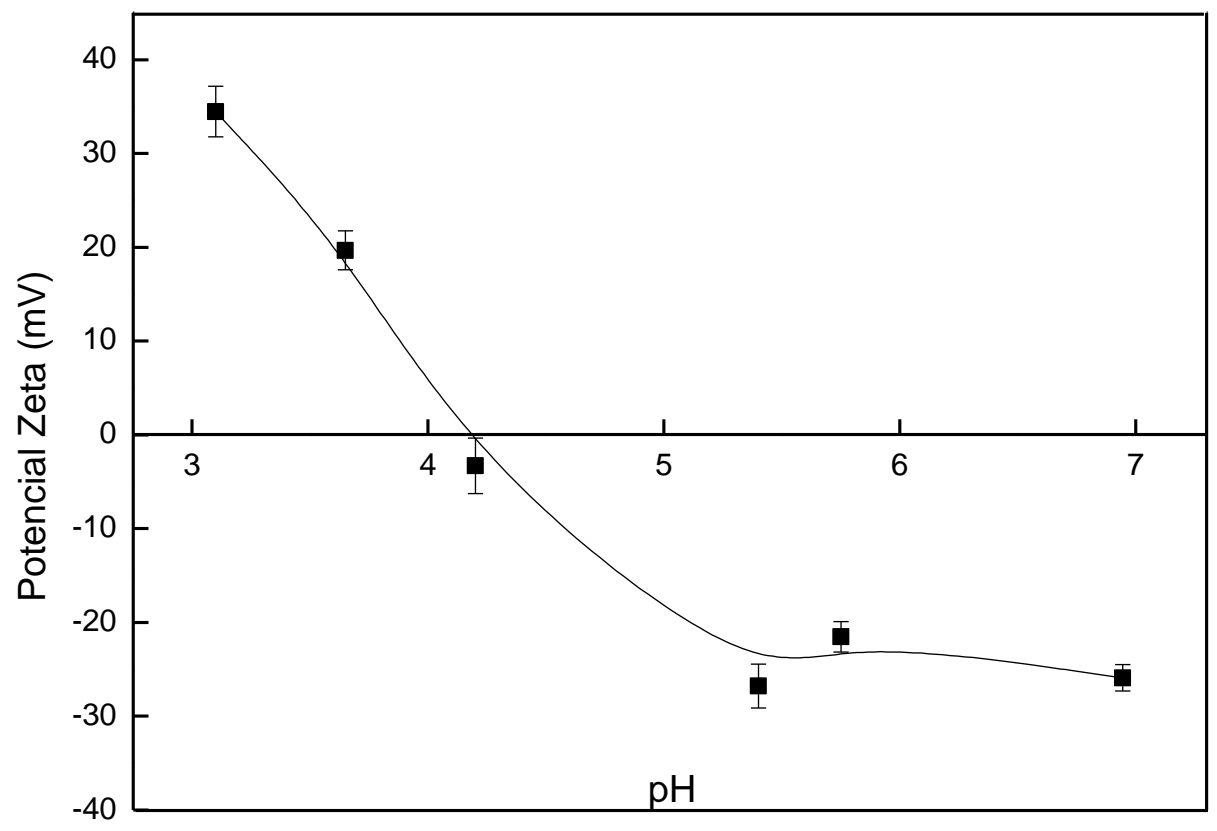

Figura 13. Potencial zeta da AnxA6 em função do pH para obtenção do ponto isoelétrico (pl) 


\subsection{Interação da AnxA6 com monocamadas lipídicas pelo método de gota pendente}

Monocamadas de surfactantes insolúveis, tais como fosfolipídios, constituem um sistema mimético amplamente utilizados para imitar a interação das membranas celulares com proteínas ou outros compostos (Bens et al., 1996).

Dessa forma, a análise do formato da gota foi uma maneira conveniente para estudar interações de diferentes composições lipídicas com a AnxA6, analisou-se as alterações causadas na tensão superficial da gota após adição da proteína ao sistema. Então, foi possível correlacionar a interação da proteína com as composições lipídicas propostas, utilizando uma metodologia com alta sensibilidade e com um emprego de reduzidas quantidades de amostra.

Assim, os dados de tensão superficial e consequentemente pressão de exclusão (חехc) foram obtidos para os sistemas de DPPC, 9:1 DPPC:DPPS e 5:4:1 DPPC:Chol:DPPS, razões molares, na ausência e na presença de cálcio $(2 \mathrm{mM})$.

A dependência linear entre a variação da pressão superficial $(\Delta \pi)$ e a pressão superficial inicial (по) para todas as monocamadas, tanto na presença quanto na ausência de $\mathrm{Ca}^{2+}(2 \mathrm{mM})$, possibilitou a obtenção da interceptação de abscissa correspondente a mexc (Fig. 14 e 15). 


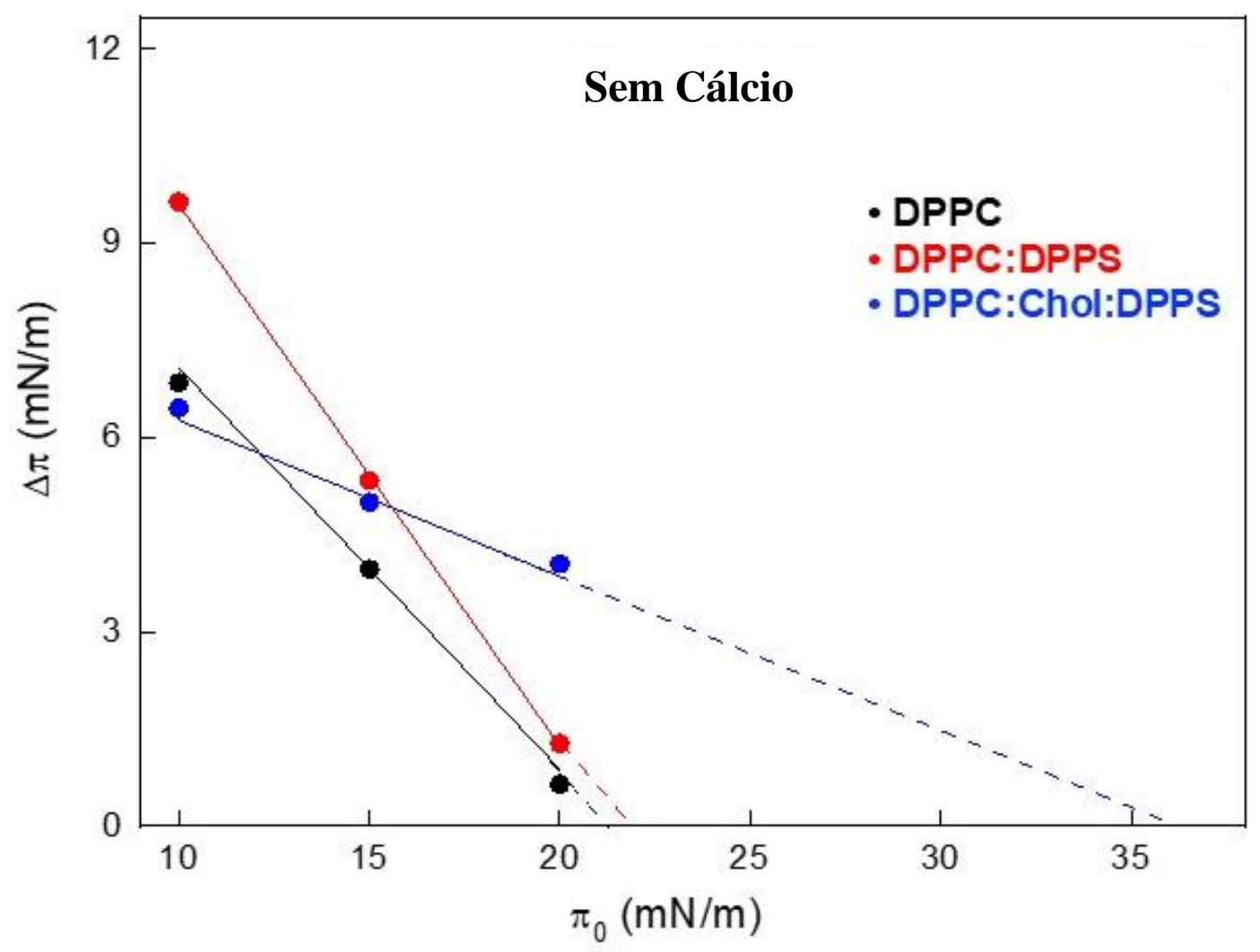

Figura 14. Mudanças na pressão superficial $(\Delta \pi)$ devido à injeção de AnxA6 em função da pressão superficial inicial ( $\left.\pi_{0}\right)$ das monocamadas de Langmuir na ausência de $2 \mathrm{mM}$ de $\mathrm{Ca}^{2+}$. A interceptação com a abscissa é a pressão de exclusão $\left(\pi_{\text {exc }}\right)$. As análises foram ajustadas para $\Pi_{0}$ próximo a 10,15 e $20 \mathrm{mN} / \mathrm{m}$. 


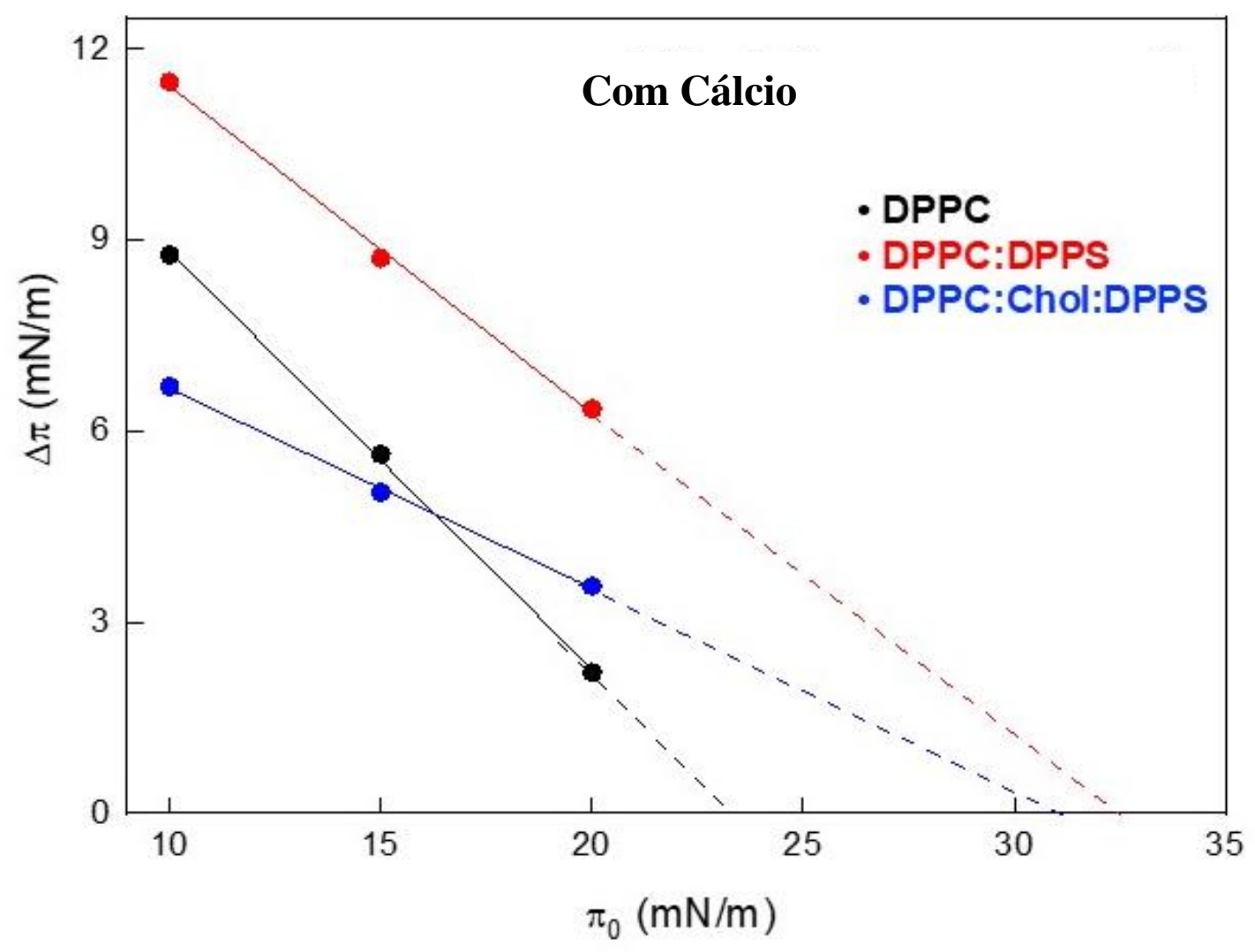

Figura 15. Mudanças na pressão superficial $(\Delta \pi)$ devido à injeção de AnxA6 em função da pressão superficial inicial ( $\left.\pi_{0}\right)$ das monocamadas de Langmuir na presença de $2 \mathrm{mM}$ de $\mathrm{Ca}^{2+}$. A interceptação com a abscissa é a pressão de exclusão $\left(\pi_{\text {exc }}\right)$. As análises foram ajustadas para $\pi_{0}$ próximo a 10,15 e $20 \mathrm{mN} / \mathrm{m}$. 
Os valores de pressão de exclusão quantificam a interação lipídio - proteína, sendo que quanto maior a pressão de exclusão maior é a interação da proteína pela monocamada lipídica formada. Valores de pressão de exclusão elevados mostram uma maior afinidade da proteína com uma dada composição lipídica, uma vez que a quantidade de lipídios presentes na monocamada é maior. Assim, com uma maior barreira lipídica, mais difícil é para a proteína migrar para a interface.

Tabela 1. Valores de $\pi$ exc para cada composição lipídica estudada na monocamada.

\begin{tabular}{lcc}
\hline $\begin{array}{l}\text { Composição Lipídica } \\
\text { (razão molar) }\end{array}$ & $\begin{array}{c}\mathbf{C a}^{2+} \\
(\mathbf{2 m M})\end{array}$ & $\begin{array}{c}\pi \text { exc } \\
(\mathbf{m N} / \mathbf{m})\end{array}$ \\
\hline DPPC & - & $22,2 \pm 2,5$ \\
& + & $25,1 \pm 2,7$ \\
9:1 DPPC:DPPS & - & $23,7 \pm 3,4$ \\
& + & $32,9 \pm 2,0$ \\
6:4 DPPC:Chol & - & $\mathrm{ND}$ \\
& + & $\mathrm{ND}$ \\
5:4:1 DPPC:Chol:DPPS & - & $36,7 \pm 1,0$ \\
\hline *ND, não determinado; & + & $34,3 \pm 1,3$ \\
\hline
\end{tabular}

A adição de Chol induziu aumento da Texc para todas as monocamadas lipídicas testadas, indicando forte interação entre a proteína e as monocamadas mistas na presença desse esterol. Este comportamento foi bem observado em monocamadas lipídicas contendo Chol, tanto na ausência (Fig. 14) quanto na presença (Fig.15) de $\mathrm{Ca}^{2+}$.

A presença de $\mathrm{Ca}^{2+}$ contribuiu significativamente para o aumento da interação da AnxA6 com todas as monocamadas, chamando a atenção para a composição contendo cargas negativas DPPC: DPPS de 9:1 (razão molar), conforme revelado pelo aumento nos valores Texc de $23,7 \mathrm{mN} / \mathrm{m}$ na ausência de $\mathrm{Ca}^{2+}$ a $32,9 \mathrm{mN} / \mathrm{m}$ na presença de $\mathrm{Ca}^{2+}$ (Tabela 1$)$. 


\subsection{Interação e caracterização da AnxA6 em lipossomos}

Foram preparados lipossomos com as composições lipídicas: DPPC; 9:1 DPPC:DPPS; 6:4 DPPC:Chol e 5:4:1 DPPC:Chol:DPPS, razões molares, na ausência e na presença de $\mathrm{Ca}^{+2}$. Incorporou-se a AnxA6 nesses sistemas por $24 \mathrm{~h}$ e os proteolipossomos obtidos foram utilizados na caracterização termodinâmica e estudos de interação da proteína com as bicamadas lipídicas.

\subsubsection{Interação e Caracterização termodinâmica dos lipossomos e proteolipossomos de AnxA6}

Através da quantificação de proteínas pela metodologia descrita por Hartree, foi possível verificar a concentração de AnxA6 incorporada nas diferentes composições de lipossomos, como pode ser observado na Tabela 2.

Tabela 2. Efeito da composição lipídica e da presença dos íons $\mathrm{Ca}^{2+}$ na incorporação de AnxA6 em proteolipossomos.

\begin{tabular}{lcc}
\hline $\begin{array}{l}\text { Composição Lipídica } \\
\text { (razão molar) }\end{array}$ & $\begin{array}{c}\mathbf{C a}^{2+} \\
(\mathbf{2 m M})\end{array}$ & $\begin{array}{c}\text { [Proteína] incorporada em } \\
\text { lipossomos }\left(\boldsymbol{\mu g} \cdot \mathbf{m L}^{-1}\right)\end{array}$ \\
\hline DPPC & - & $18,0 \pm 0,4$ \\
& + & $59,0 \pm 1,1$ \\
9:1 DPPC:DPPS & - & $17,0 \pm 0,3$ \\
& + & $43,0 \pm 0,9$ \\
6:4 DPPC:Chol & - & $0,60 \pm 0,01$ \\
& + & $13,0 \pm 0,3$ \\
5:4:1 DPPC:Chol:DPPS & - & $19,0 \pm 0,4$ \\
& + & $54,0 \pm 1,0$ \\
\hline
\end{tabular}

Verifica-se que houve incorporação da proteína em todos as composições de lipossomos utilizados. $\mathrm{Na}$ ausência de $\mathrm{Ca}^{2+}$, observa-se que os valores de incorporação ficaram relativamente próximos entre si, sendo apenas a composição 6:4 DPPC:Chol apresentou um valor abaixo do obtido nas outras composições, no entanto, a adição de $2 \mathrm{mM}$ de $\mathrm{Ca}^{2+}$ resultou em um aumento significativo na 
associação da proteína aos lipídios para todas as bicamadas lipídicas. Tais dados de dosagem mostram que a AnxA6 possui grande interação com a composição de DPPC apresentando o melhor resultado de incorporação, como também possui uma alta afinidade por fosfolipídios carregados negativamente como o DPPS e a presença do colesterol estimula a afinidade de ligação da AnxA6 à membrana.

Para o estudo e caracterização das interações lipídio - lipídio e lipídio proteína, utilizou-se a calorimetria diferencial de varredura (DSC) que é uma técnica de grande importância na caracterização termodinâmica de modelos de membranas e biomembranas. pois apresenta alta sensibilidade, sendo capaz de medir as propriedades termodinâmicas de transições induzidas termicamente.

As diferentes composições de lipossomos e proteolipossomos foram analisadas por DSC e os termogramas estão apresentados nas Figuras 16 - 19. Os dados obtidos de temperatura de transição principal de fase (Tm), entalpia de transição $(\Delta \mathrm{H})$ e cooperatividade de transição de fase $\left(\Delta \mathrm{T}_{1 / 2}\right)$ estão resumidos na Tabela 3. 

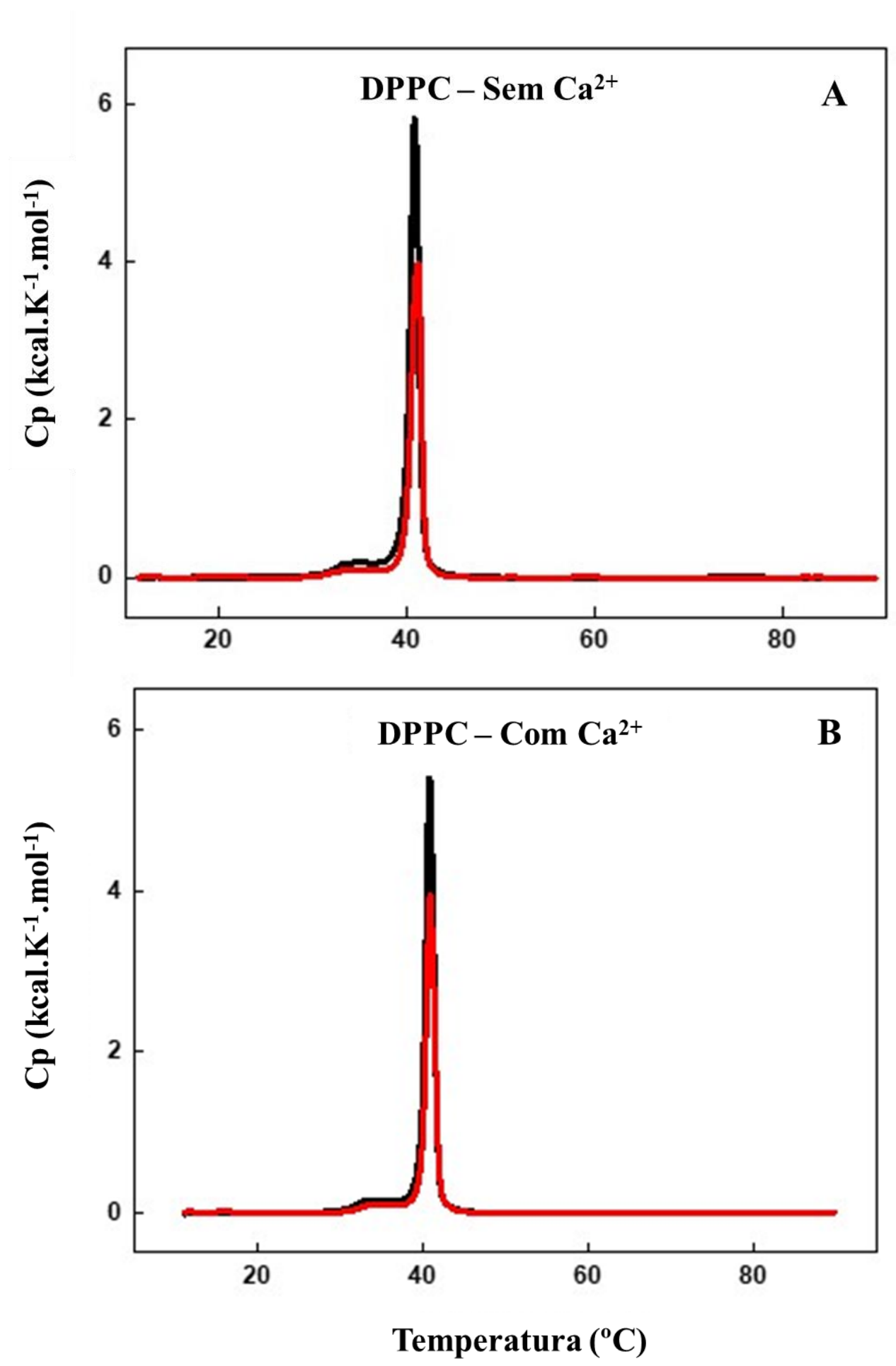

Figura 16. Termogramas de calorimetria de varredura diferencial (DSC) dos lipossomos de DPPC na ausência (A) e na presença de $2 \mathrm{mM}$ de $\mathrm{Ca}^{2+}(B)\left(10 \mathrm{mg} \cdot \mathrm{mL}^{-1}\right.$, concentração total de lipídios). Os termogramas de DSC foram processados em excesso de capacidade de calor (Cp) (kcal. $\left.\mathrm{K}^{-1} \cdot \mathrm{mol}^{-1}\right)$ em função da temperatura $\left({ }^{\circ} \mathrm{C}\right)$ dos lipossomos (linha preta) e proteolipossomos (linha vermelha). 

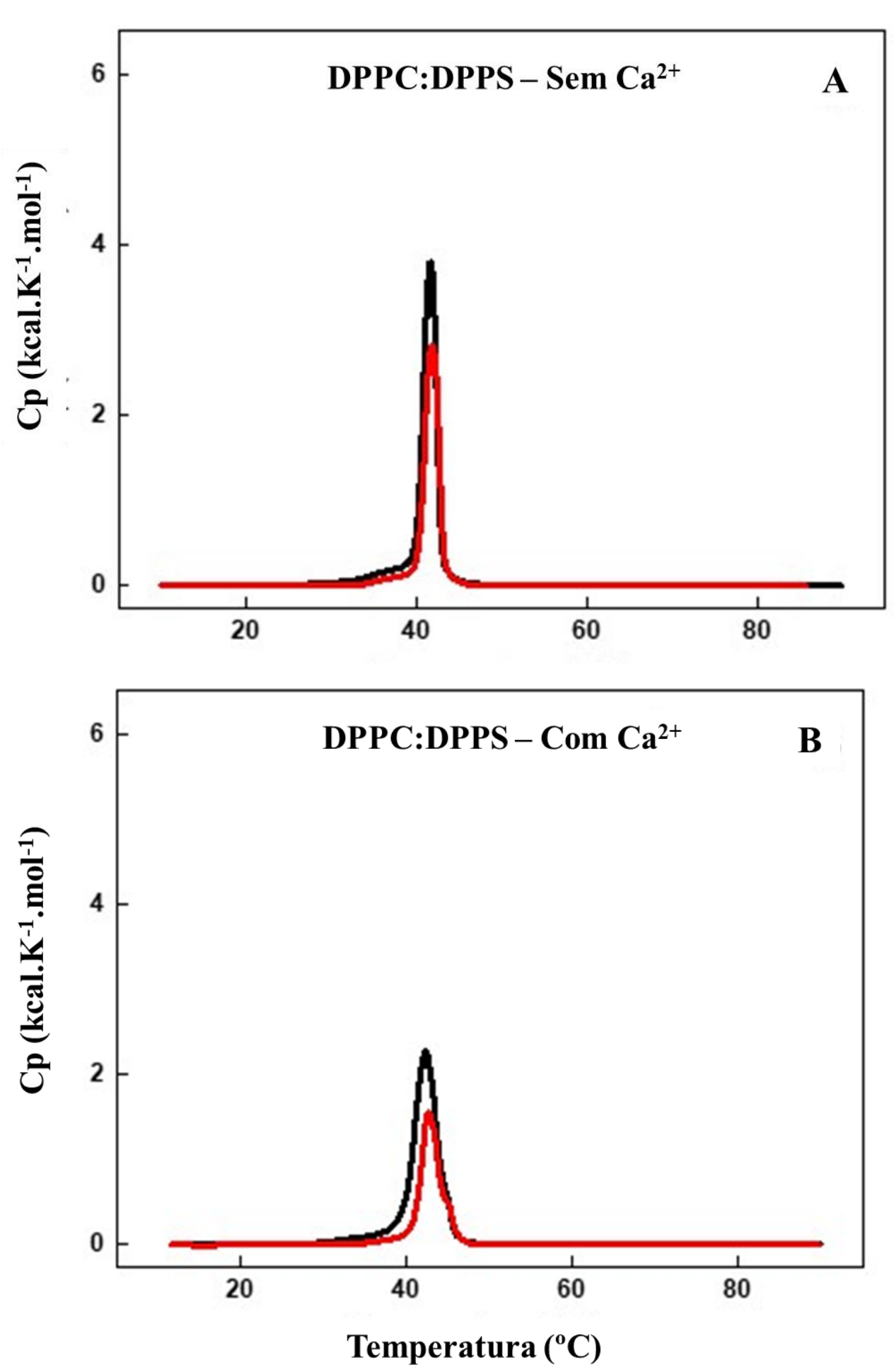

Figura 17. Termogramas de calorimetria de varredura diferencial (DSC) dos lipossomos de DPPC:DPPS (9:1 - razão molar) na ausência $(A)$ e na presença de $2 \mathrm{mM} \mathrm{de} \mathrm{Ca}^{2+}(\mathrm{B})$ (10 $\mathrm{mg} \cdot \mathrm{mL}^{-1}$ concentração total de lipídios). Os termogramas de DSC foram processados em excesso de capacidade de calor $(\mathrm{Cp})\left(\mathrm{kcal}^{\mathrm{K}} \mathrm{K}^{-1} \cdot \mathrm{mol}^{-1}\right)$ em função da temperatura $\left({ }^{\circ} \mathrm{C}\right)$ dos lipossomos (linha preta) e proteolipossomos (linha vermelha). 

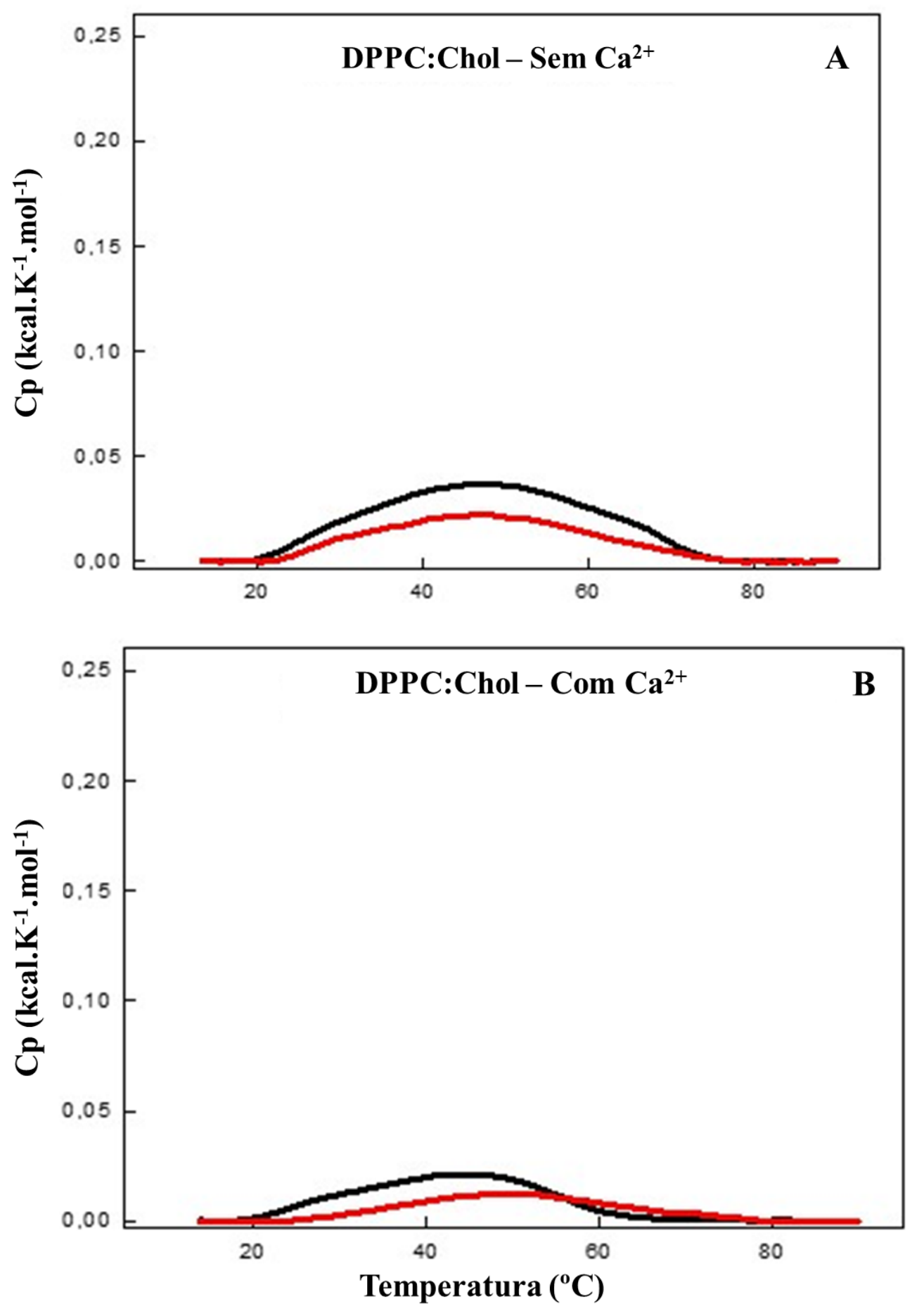

Figura 18. Termogramas de calorimetria de varredura diferencial (DSC) dos lipossomos de DPPC:Chol (6:4 - razão molar) na ausência $(A)$ e na presença de $2 \mathrm{mM}$ de $\mathrm{Ca}^{2+}(B)$ (10 $\mathrm{mg} \cdot \mathrm{mL}^{-1}$, concentração total de lipídios). Os termogramas de DSC foram processados em excesso de capacidade de calor $(\mathrm{Cp})\left(\mathrm{kcal} . \mathrm{K}^{-1} \cdot \mathrm{mol}^{-1}\right)$ em função da temperatura $\left({ }^{\circ} \mathrm{C}\right)$ dos lipossomos (linha preta) e proteolipossomos (linha vermelha). 

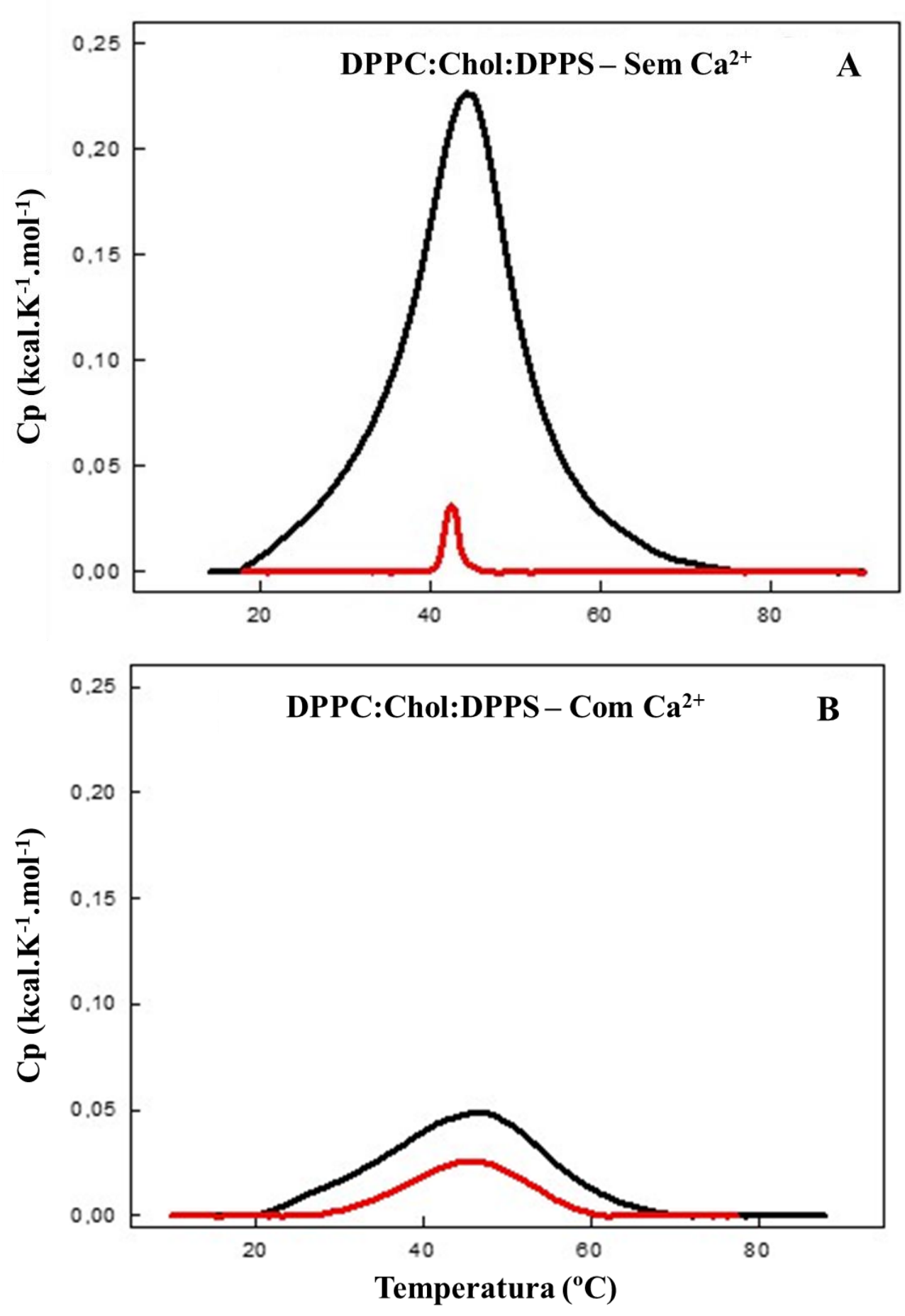

Figura 19. Termogramas de calorimetria de varredura diferencial (DSC) dos lipossomos de DPPC:Chol:DPPS (6:4:1 - razão molar) na ausência (A) e na presença de $2 \mathrm{mM}$ de $\mathrm{Ca}^{2+}$ (B) (10 $\mathrm{mg} \cdot \mathrm{mL}^{-1}$, concentração total de lipídios). Os termogramas de DSC foram processados em excesso de capacidade de calor (Cp) $\left(\mathrm{kcal} . \mathrm{K}^{-1} \cdot \mathrm{mol}^{-1}\right)$ em função da temperatura $\left({ }^{\circ} \mathrm{C}\right)$ dos lipossomos (linha preta) e proteolipossomos (linha vermelha). 
Tabela 3. Parâmetros termodinâmicos de diferentes composições de lipossomos (10 mg. $\mathrm{mL}^{-1}$ ) e proteolipossomas contendo AnxA6 por meio de DSC, na presença e ausência de $\mathrm{Ca}^{2+}(2 \mathrm{mM})$.

\begin{tabular}{|c|c|c|c|c|c|c|c|}
\hline \multirow[b]{2}{*}{$\begin{array}{l}\text { Composição lipídica } \\
\text { (Razão Molar) }\end{array}$} & \multirow[b]{2}{*}{ AnxA6 } & \multicolumn{3}{|c|}{ Sem Ca ${ }^{2+}$} & \multicolumn{3}{|c|}{$\mathrm{Com} \mathrm{Ca}^{2+}$} \\
\hline & & $\begin{array}{c}\Delta \mathrm{H} \\
(\mathrm{kcal} / \mathrm{mol})\end{array}$ & $\begin{array}{l}\mathrm{T}_{\mathrm{m}} \\
\left({ }^{\circ} \mathrm{C}\right)\end{array}$ & $\Delta \mathrm{T}_{1 / 2}$ & $\begin{array}{c}\Delta \mathrm{H} \\
(\mathrm{Kcal} / \mathrm{mol})\end{array}$ & $\begin{array}{l}\mathrm{T}_{\mathrm{m}} \\
\left({ }^{\circ} \mathrm{C}\right)\end{array}$ & $\Delta \mathbf{T}_{1 / 2}$ \\
\hline \multirow[t]{2}{*}{ DPPC } & - & 9,25 & 40,8 & 1,00 & 8,08 & 40,8 & 1,02 \\
\hline & + & 6,75 & 41,2 & 1,07 & 6,08 & 41,0 & 1,09 \\
\hline \multirow[t]{2}{*}{ 9:1 DPPC:DPPS } & - & 6,56 & 41,6 & 1,42 & 8,72 & 42,3 & 2,80 \\
\hline & + & 5,29 & 41,7 & 1,50 & 4,96 & 42,7 & 2,29 \\
\hline \multirow[t]{2}{*}{ 6:4 DPPC:Chol } & - & 1,24 & 46,7 & 29,59 & 0,57 & 44,3 & 22,86 \\
\hline & + & 0,70 & 46,2 & 26,97 & 0,36 & 49,5 & 24,66 \\
\hline $5: 4: 1$ & - & 5,36 & 43,6 & 14,54 & 1,14 & 46,3 & 19,37 \\
\hline DPPC:Chol:DPPS & + & 0,06 & 42,4 & 1,63 & 0,43 & 46,2 & 13,89 \\
\hline
\end{tabular}

As análises de DSC mostram o efeito da interação da AnxA6 no comportamento termodinâmico dos lipossomos (Tabela 3). A adição da AnxA6 diminuiu o $\Delta \mathrm{H}$ para todas as membranas lipídicas, independente da presença de $\mathrm{Ca}^{2+}$.

Para as vesículas de DPPC, tanto na ausência quanto na presença de $\mathrm{Ca}^{2+}$ não houve alterações significativas nos valores de $\Delta T_{1 / 2}$ e Tm (Figura $16 \mathrm{~A}$ e B). No entanto, a presença da AnxA6 provocou uma diminuição nos valores de $\Delta \mathrm{T}_{1 / 2}$ após a adição de $\mathrm{Ca}^{2+}$ de 2,80 a 2,29 para proteolipossomos contendo cargas negativas (9:1 DPPC:DPPS) e de 19,37 a 13,89 para proteolipossomos de 5:4:1 DPPC:Chol:DPPS. Porém, observa-se que a presença de Chol diminuiu fortemente os valores de $\Delta T_{1 / 2}$ independentemente da presença de $\mathrm{Ca}^{2+}$, resultando em transições de fase muito mais cooperativas e exibindo o efeito sinérgico da proteína.

As alterações termodinâmicas causadas pelo colesterol nas bicamadas lipídicas dependem de sua concentração. A adição da razão molar de $40 \%$ do colesterol eliminou a pré-transição de fase lipídica de DPPC $\left( \pm 33^{\circ} \mathrm{C}\right)$ e proporcionou um alargamento do pico principal de transição, evidenciado pela diminuição da $\Delta \mathrm{H}$. Tais alterações termodinâmicas devem ser levadas em consideração e 
correlacionadas às interações da proteína com o fosfolipídio e, consequentemente, com a estabilidade física da formulação vesicular. De forma geral, pôde-se verificar que a incorporação de AnxA6 aos lipossomos proporcionou uma diminuição nos valores de $\Delta \mathrm{H}$ para todas as membranas lipídicas na presença e ausência de $\mathrm{Ca}^{2+}$. Essa diminuição é consistente com as interações proteicas na superfície das bicamadas ou incorporações nas bicamadas, impedindo a participação de algumas moléculas lipídicas na transição de fase (Kyrikou et al., 2005)

A composição binária (6:4 DPPC:Chol), bem como a composição ternária (5:4:1 DPPC:Chol:DPPS), mostraram uma diminuição significativa em $\Delta \mathrm{H}$ na presença e ausência de $\mathrm{Ca}^{2+}$ (Figuras 18 e 19) como em comparação aos lipossomos sem Chol (Figuras 16 e 17). A adição de AnxA6 diminuiu $\circ \Delta \mathrm{H}$ da transição de fase lipídica em sistemas ternários (5:4:1 DPPC:Chol:DPPS) e binários (6:4 DPPC:Chol). Este efeito foi dependente de $\mathrm{Ca}^{2+}$ para ambos os sistemas.

A maior diminuição de $\Delta \mathrm{H}$ foi observada para os proteolipossoos de 9:1 DPPC: DPPS na presença de $\mathrm{Ca}^{2+}$ e para composição ternária na ausência de $\mathrm{Ca}^{2+}$. Essa diminuição é consistente com a interação da AnxA6 com as superfícies da bicamada ou incorporado nas bicamadas, evitando que algumas moléculas de lipídios participem da transição de fase. Tais mudanças nos parâmetros termodinâmicos devem ser levadas em consideração e correlacionadas às interações da proteína com os fosfolipídios e, consequentemente, com a estabilidade física da formulação lipossômica.

As alterações termodinâmicas podem ainda serem evidenciadas de forma qualitativa pelos respectivos termogramas obtidos (Figuras 16 - 19), corroborando com o fato de que a presença de $\mathrm{Ca}^{2+}$, cargas negativas e Chol, foram fatores que contribuíram significativamente para a interação da proteína com as bicamadas formadas.

Como pode-se observar ainda, a interação da AnxA6 com lipossomos foi avaliada usando as mesmas composições lipídicas das monocamadas de Langmuir. Em geral, a adição de $\mathrm{Ca}^{2+}$ levou a um aumento significativo na associação da proteína com todas as bicamadas lipídicas. É importante notar que o aumento mais significativo na quantidade de AnxA6 interagindo foi com a membrana dos lipossomos de 5:4:1 DPPC:Chol:DPPS na presença de $\mathrm{Ca}^{2+}$, fato que quando comparado a monocamadas não levou a uma mudança significativa na Texc. Esse resultado aparentemente controverso pode ser atribuído à possibilidade de a proteína penetrar na bicamada, no entanto, não se mantém completamente inserida 
na ausência de $\mathrm{Ca}^{2+}$. A adição de $\mathrm{Ca}^{2+}$ aumentou a interação da AnxA6 com as monocamadas, traduzindo-se em uma maior incorporação nos lipossomos (Veschi et al., 2020).

\subsubsection{Microscopia de Força Atômica (AFM)}

A técnica de AFM têm se mostrado uma valiosa ferramenta para estudos de lipossomos e proteolipossomos, pois proporciona análises em nanoescala de morfologia e propriedades mecânicas de vesículas simultaneamente. Ela fornece imagens de topografia superficial com resolução espacial próxima de $1 \AA$ e curvas de força x distância com limite de detecção próximo de a $10^{-12} \mathrm{~N}$, além de utilizar de uma ponteira que pode mover-se no topo de vesículas individuais de modo que as propriedades mecânicas de vesículas menores possam ser mensuradas em nanoescala.

Visto que os lipossomos e proteolipossomos são amostras moles, optou-se por realizar as medidas utilizando o modo "tapping", onde a ponteira faz contato intermitente com a amostra, pois evita a influência das forças laterais que são aplicadas sobre a amostra no modo contato e a ausência do contato contínuo diminui a deformação da amostra. Dessa forma, buscando evitar deformações, foi ajustado um valor de ganho integral pequeno, ainda que isso tenha ocasionado uma diminuição da resolução da imagem topográfica, e uma baixa velocidade de varredura (Mao et al., 2004).

Quando uma imagem de AFM é obtida no modo contato intermitente, diferentes tipos de informações sobre a amostra podem ser obtidos a partir do atraso de fase ocasionado por interações de adesão (viscosidade e elasticidade) entre a ponteira e a composição das diferentes regiões da amostra desde que a fase da frequência de oscilação da ponteira esteja sendo monitorada (Tamayo e Garcia, 1996; James et al., 2001).

Além dos sinais de altura, que fornecem informações topográficas, a componente do sinal de fase relacionada ao cosseno fornece informações que refletem especialmente diferenças de elasticidade na amostra. Podem ser obtidos também sinais que são sensíveis a diferentes domínios visco-elásticos, ou seja, imagens de diferenças de fases (chamados simplesmente de imagens de Fase). 
As imagens de Fase fornecem informações sobre os domínios visco-elásticos da amostra. Regiões que ocasionam um grande atraso de fase (alta elasticidade e alta viscosidade) aparecem mais claras nas imagens obtidas. Considerando-se que proteínas e lipídios apresentam diferenças em suas propriedades físicas, a presença desses compostos pode ser detectada como domínios visco-elásticos distintos em imagens de Fase e de elasticidade, por AFM.

As amostras de lipossomos constituídos de DPPC foram analisadas e os resultados obtidos por AFM mostraram que foi possível obter imagens de lipossomos intactos (Figura 20).

Lipossomos de 5:4:1 DPPC:Chol:DPPS também foram analisados por AFM a fim de avaliar se a presença de um esterol (Chol) e cargas negativas provindas do DPPS proporcionariam alterações morfológicas e mudanças nas propriedades mecânicas dos lipossomos quando comparado com lipossomos constituídos apenas por DPPC (Figura 21). 

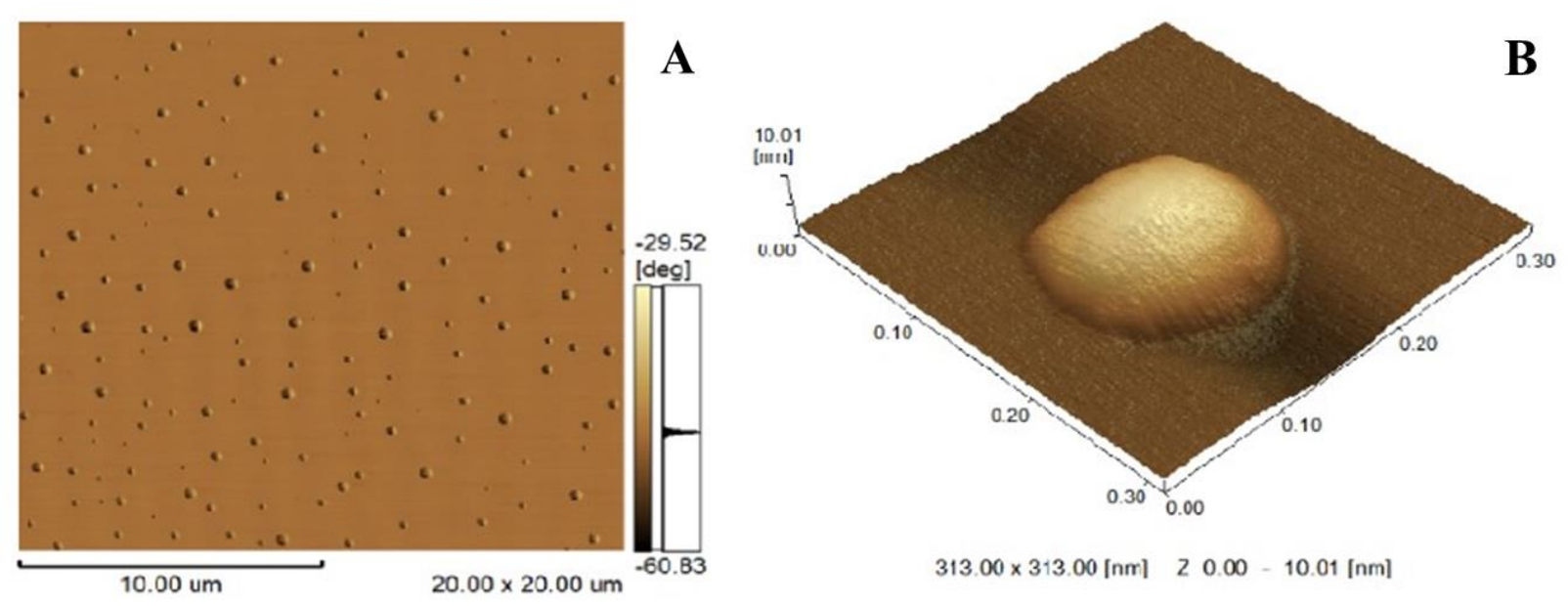

$313.00 \times 313.00[\mathrm{~nm}] \quad 20.00-10.01[\mathrm{~nm}]$

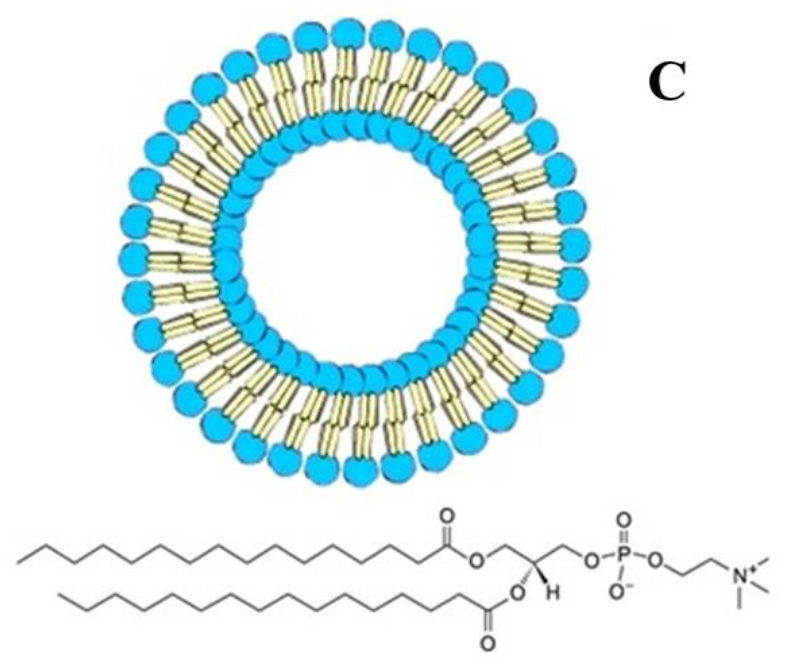

Figura 20. Análise de AFM dos lipossomos de DPPC (1,5 mg.mL $\left.{ }^{-1}\right)$ : imagem de fase $(A)$, perfis topográficos 3D (B) e estrutura química do DPPC e representação esquemática dos lipossomos (C). 


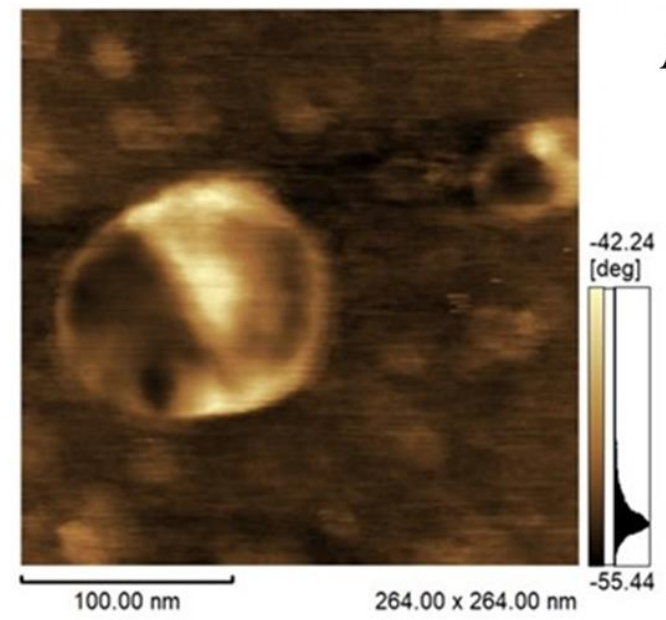

A

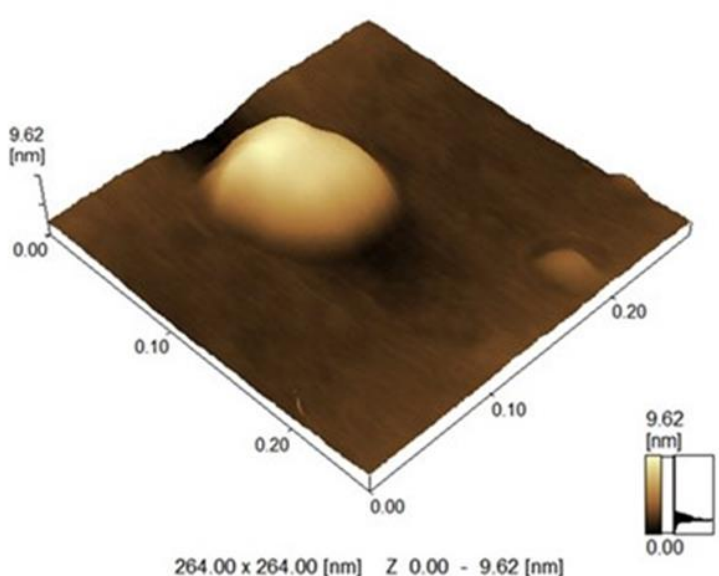

B

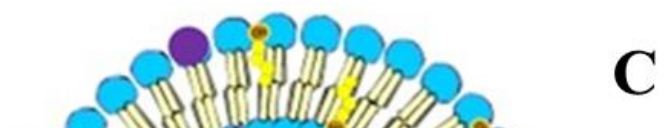

C
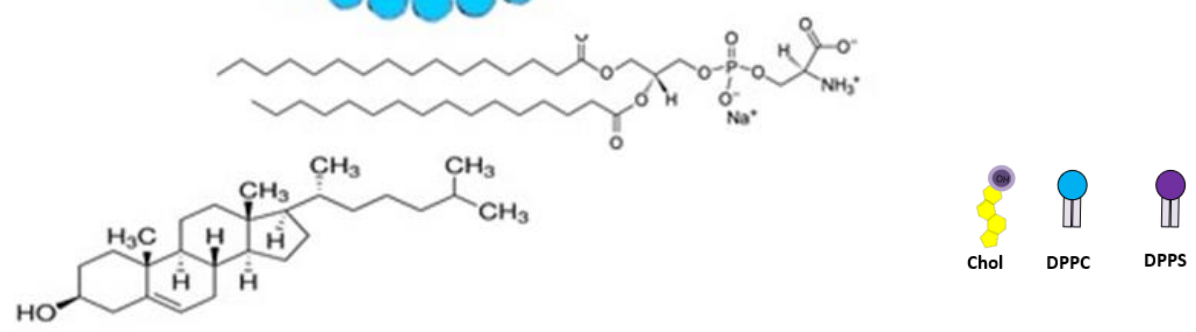

Figura 21. Análise de AFM dos lipossomos de 5:4:1 DPPC:Chol:DPPS (1,5 mg. $\left.\mathrm{mL}^{-1}\right)$ : imagem de fase $(A)$, perfis topográficos 3D $(B)$ e estrutura química do DPPS e colesterol com representação esquemática dos lipossomos (C). 
Os lipossomos constituídos de DPPC mostraram partículas esféricas com uma distribuição uniforme de tamanho e uma superfície lisa e homogênea sem quaisquer mudanças de fase significativas (Figura 20).

As imagens obtidas para 5:4:1 DPPC:Chol:DPPS apresentaram vesículas esféricas, porém com o aparecimento de alterações de fase proveniente da composição ternária utilizada (Figura 21)

Assim, como observado para lipossomos constituídos de DPPC, lipossomos constituídos de 5:4:1 DPPC:Chol:DPPS também permaneceram intactos durante a realização da varredura, não apresentando deformações significativas causadas pela ponteira sobre a amostra, como pode ser notado nas imagens provenientes das análises de Fase e topográficas.

A largura lateral ou diâmetro das esferas de lipossomos também foram mensurados por AFM. Utilizando o perfil de altura para lipossomos DPPC e 5:4:1 DPPC:Chol:DPPS, obtiveram-se os diâmetros médios de 101,2 nm e 113,1 nm, respectivamente. 
A
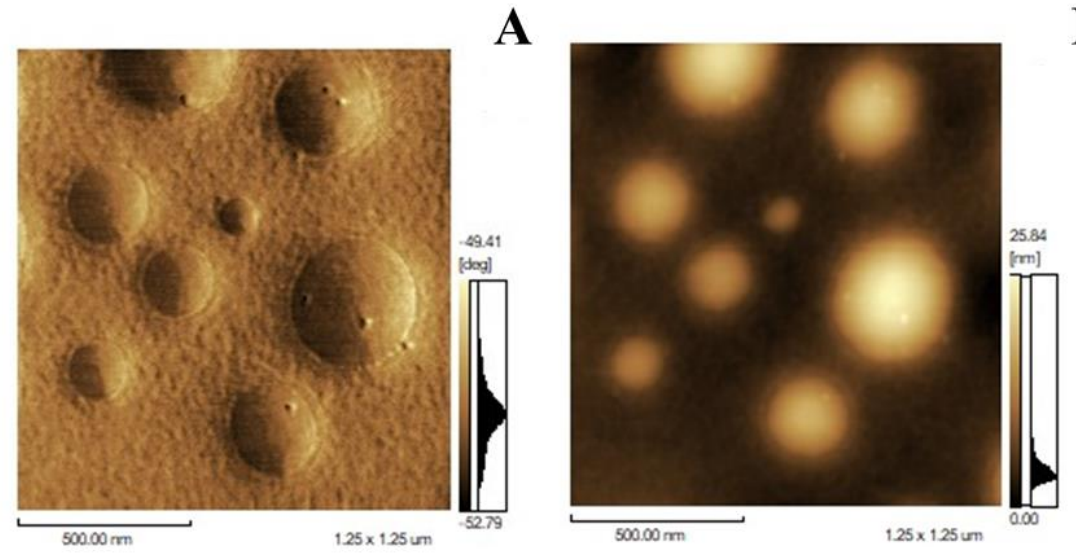
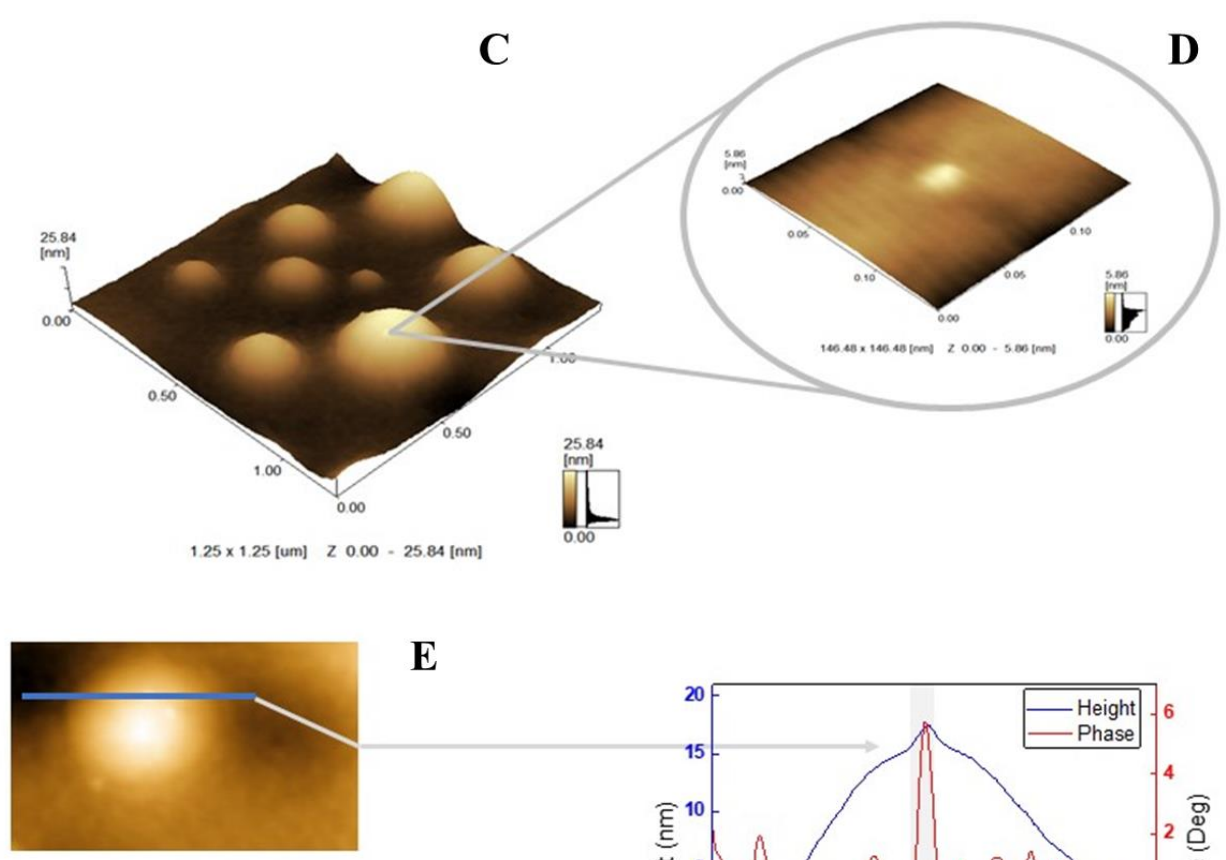

$\mathbf{E}$
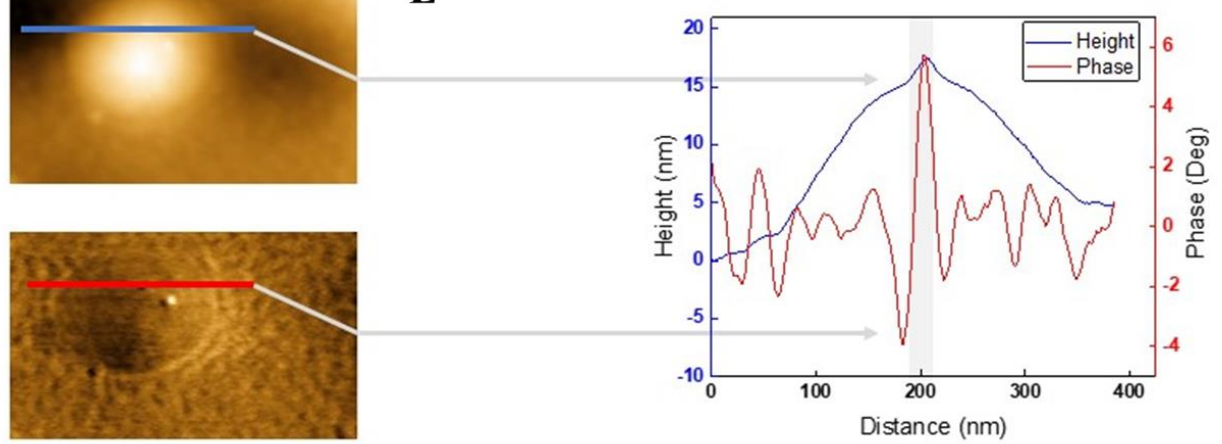

Figura 22. Análise de AFM dos proteolipossomos de DPPC contendo AnxA6: (A) imagem de fase, (B) imagem de altura, (C) perfil topográfico 3D (D) Zoom (146,48 nm x 146,48 nm) da superfície do proteolipossomo mostrando domínios de proteína; (E) Análise de linha simultânea de fase e altura (linhas azuis e vermelhas) dos domínios AnxA6 inseridos em proteolipossomos, e (F) Perfis de altura e análise derivada de fase de linhas azuis e vermelhas no proteolipossomo DPPC-AnxA6, a sombra cinza destaca as saliências. A Figura E foi preparada usando o software WSxM 4.0 Beta 9.1 desenvolvido por Horcas et al. (2007). 
A

B
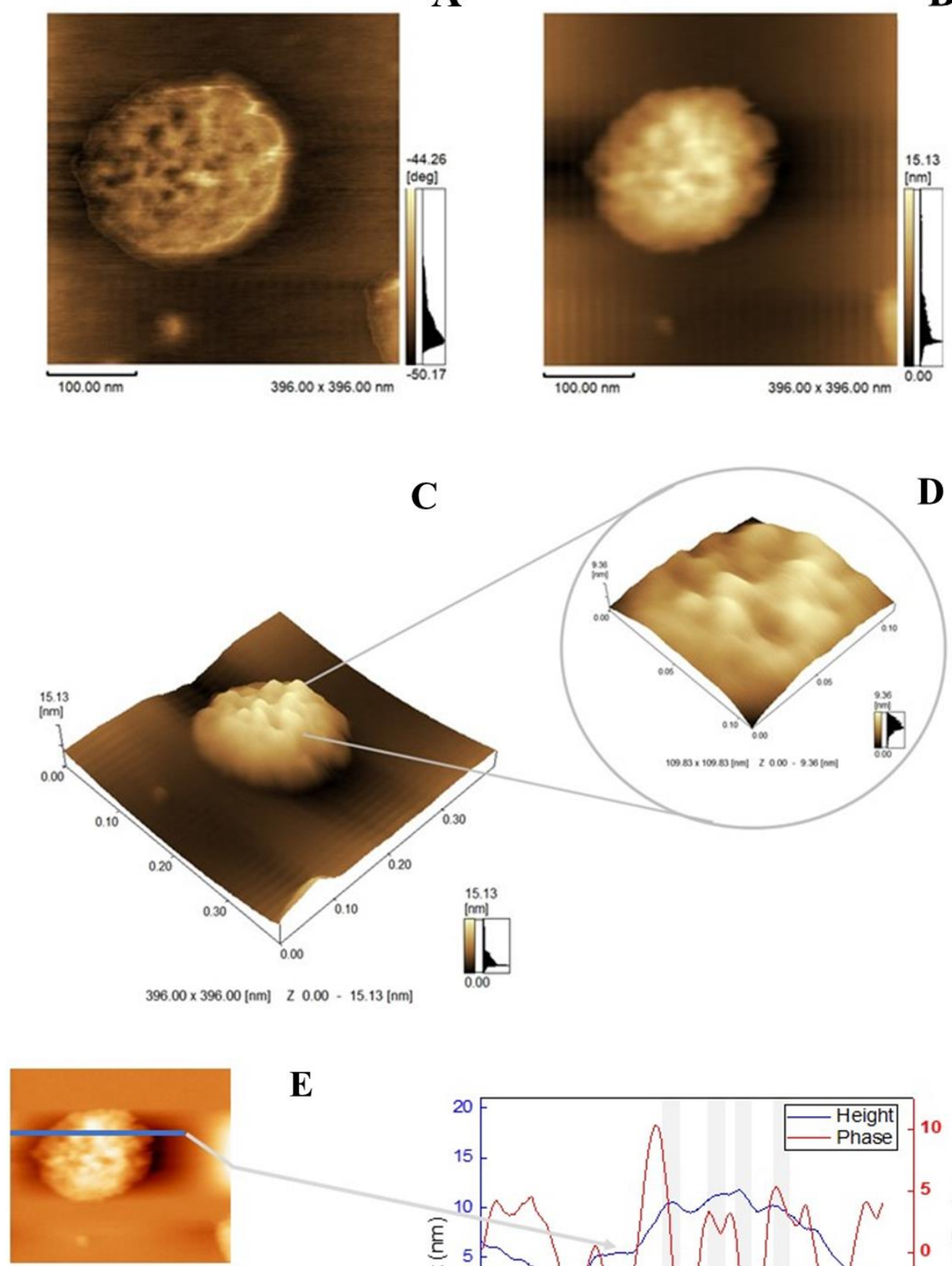

$\mathbf{E}$

D
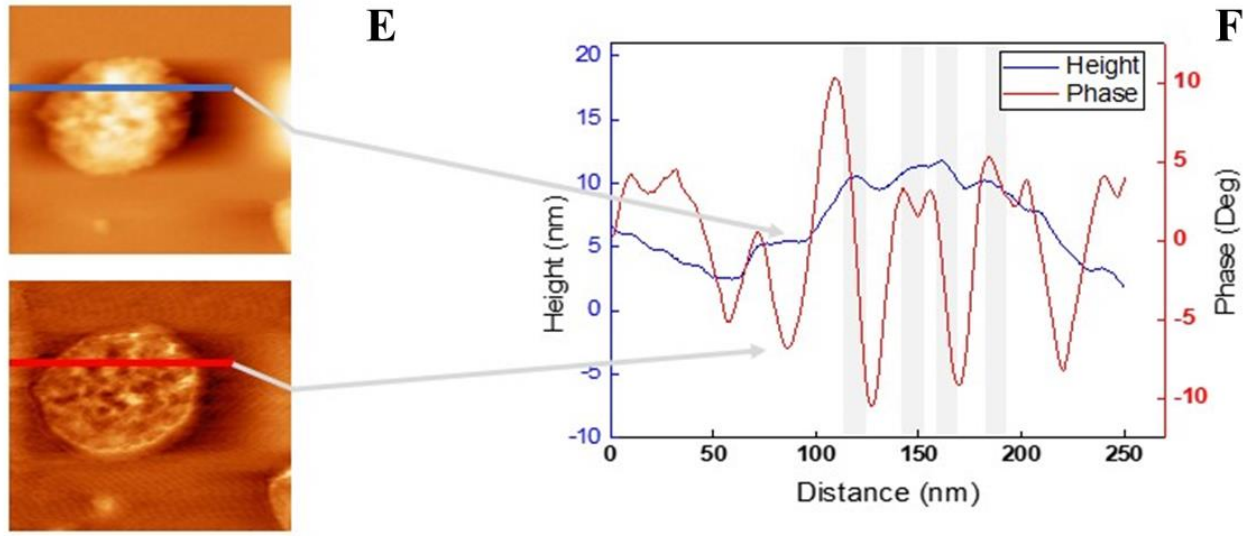

Figura 23. Análise de AFM dos proteolipossomos de 5:4:1 DPPC:Chol:DPPS contendo AnxA6: (A) imagem de fase, (B) imagem de altura, (C) perfil topográfico 3D (D) Zoom $(109,83 \mathrm{~nm} \times 109,83 \mathrm{~nm})$ da superfície do proteolipossomo mostrando domínios de proteína; (E) Análise de linha simultânea de fase e altura (linhas azuis e vermelhas) dos domínios AnxA6 inseridos nos proteolipossomos, e (F) Perfis de altura e análise derivada de fase de linhas azuis e vermelhas no proteolipossomo DPPC:Chol:DPPS-AnxA6, a sombra cinza destaca as saliências. A Figura E foi preparada usando o software WSxM 4.0 Beta 9.1 desenvolvido por Horcas et al. (2007). 
Os proteolipossomos que abrigam AnxA6 mostraram irregularidades de superfície formadas por saliências que parecem se aglutinar em vários locais (Figuras 22 e 23). Ao registrar as seções transversais topográficas, foi possível determinar que as protusões verificadas tinham 21,37 \pm 4,83 nm de largura e 1,15 \pm $0,41 \mathrm{~nm}$ de altura ( $\mathrm{N}=20$ ) para os proteolipossomos de DPPC (Figura 22), enquanto que os proteolipossomos de 5:4:1 DPPC:Chol:DPPS apresentaram protrusões com 26,97 $\pm 7,62 \mathrm{~nm}$ de largura e 2,01 $\pm 0,89 \mathrm{~nm}$ de altura ( $\mathrm{N}=22$ ) (Figura 23).

Este achado é consistente com o tamanho dos dímeros ou trímeros da AnxA6 devido a sua forma de $\mathrm{V}$ com dois loops flexíveis de $6 \mathrm{~nm}$ de comprimento (Bandorowicz-Pikula et al., 2003). As protusões na superfície das vesículas observadas nas imagens AFM sugerem que AnxA6 dimérica ou trimérica estava na superfície dos proteolipossomos. Por possuir dois lóbulos flexíveis (Benz et al., 1996), a AnxA6 pode adotar várias conformações com seus lóbulos ligando a monocamada em uma orientação paralela ou antiparalela ou com um dos lóbulos saindo da monocamada. (Avila-Sakar et al., 2000).

\subsubsection{Estabilidade das vesículas utilizando o espalhamento de luz dinâmico}

A estabilidade dos lipossomos pode ser afetada por processos químicos, físicos e biológicos. A meia-vida dos lipossomos depende intimamente da sua composição e formulação final. A estabilidade física dos lipossomos pode ser entendida como um tipo de estabilidade coloidal. Um dos aspectos mais importantes dessa estabilidade é a mudança do tamanho das partículas e de sua distribuição. No caso de lipossomos, agregação e fusão são as principais fontes de instabilidade (Batista et al., 2007; Chang e Yeh, 2012; New, 1990).

Sendo assim, utilizou-se da técnica de DLS para acompanhar a variação do tamanho médio e o índice de polidispersão das vesículas preparadas em um período de 28 dias, com intervalo de 7 dias entre as leituras. A mesma avaliação foi realizada para os proteolipossomos contendo AnxA6 e formulações lipossômicas na presença de $\mathrm{Ca}^{2+}$ (Figuras $24-27$ ). 


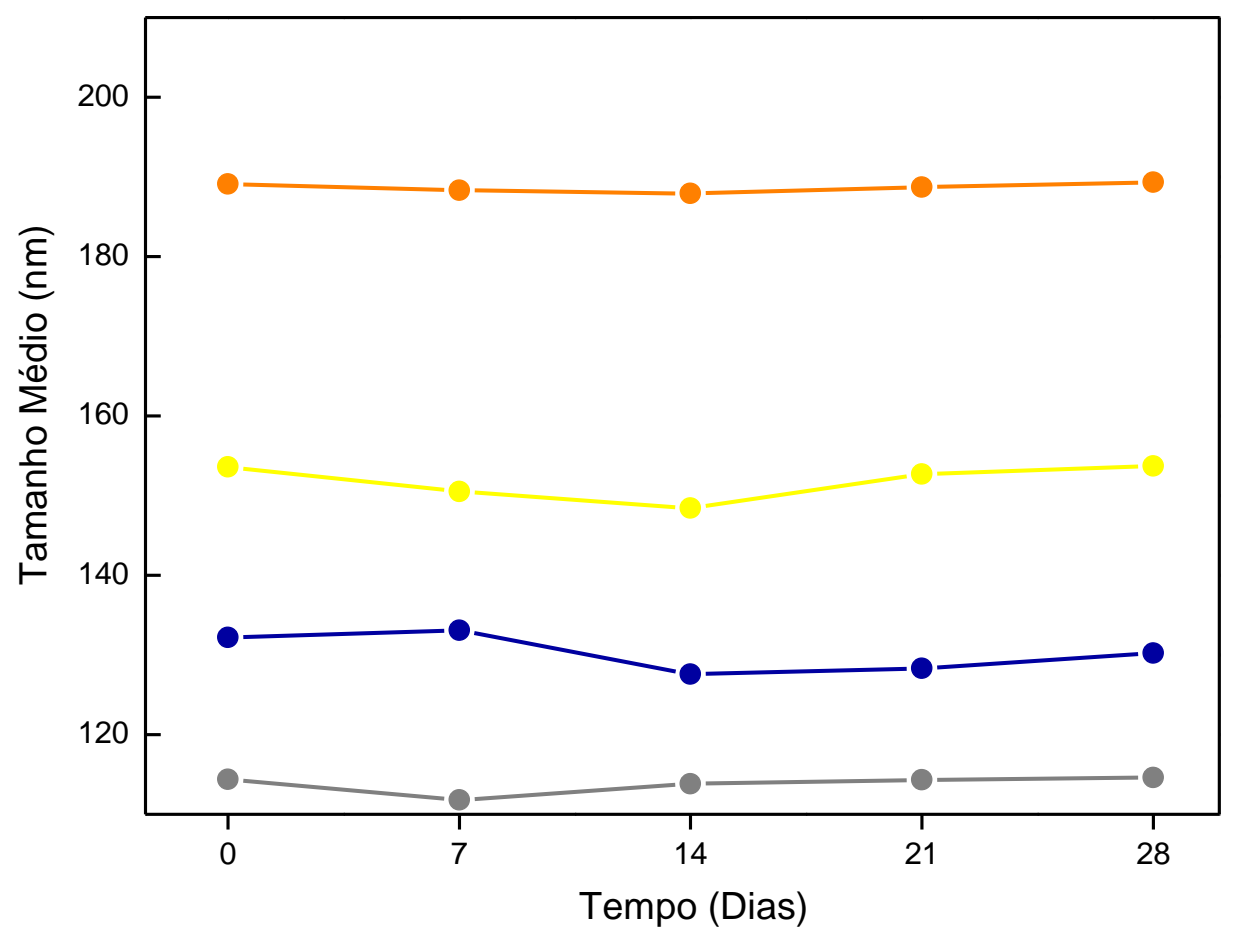

A

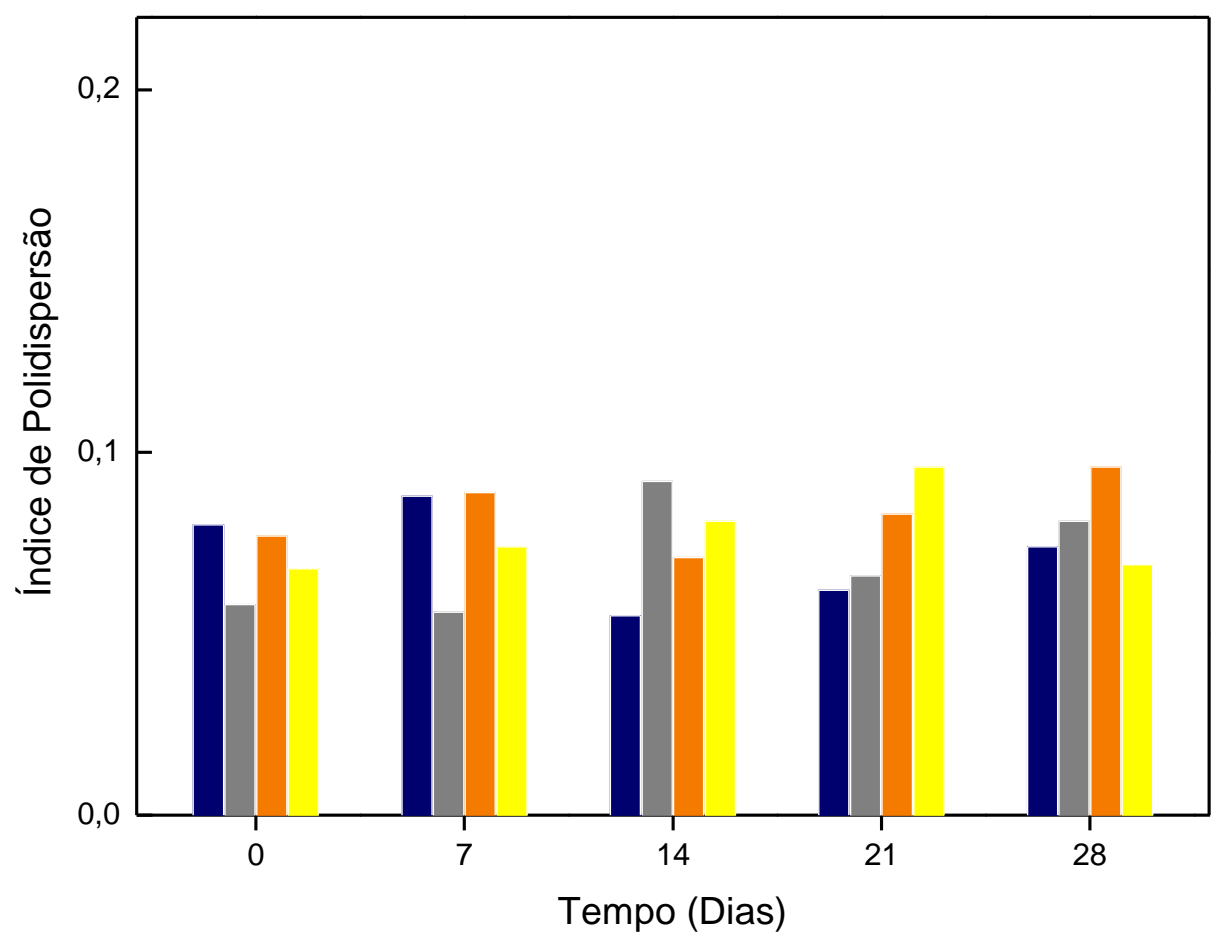

B

Figura 24. DLS de lipossomos $\left(10 \mathrm{mg} \cdot \mathrm{mL}^{-1}\right)$ na ausência de $\mathrm{Ca}^{2+}$. (A) Diâmetro médio das vesículas; (B) Índice de polidispersão. Azul - DPPC; Cinza - 9:1 DPPC:DPPS; Laranja - 6:4 DPPC:Chol e amarelo - DPPC:Chol:DPPS (6:4:1), razões molares. Os gráficos de dispersão de luz diferencial foram registrados usando o N5 Submicron Particle Size Analyzer. O valor médio $(n=5)$ dos diâmetros dos lipossomas foi obtido a $25^{\circ} \mathrm{C}$ por distribuição unimodal, previamente filtrado $(0,8 \mu \mathrm{m})$. 


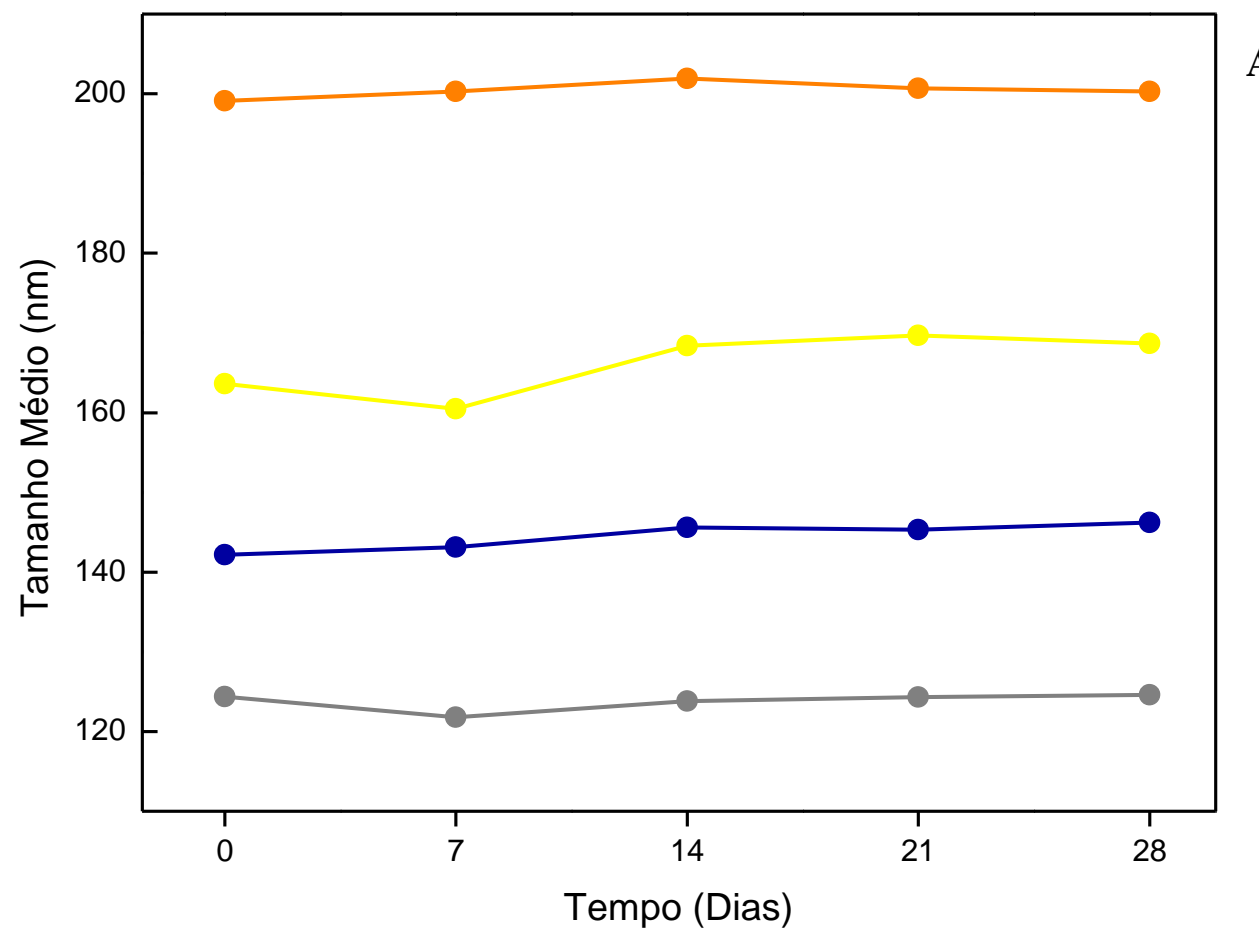

A

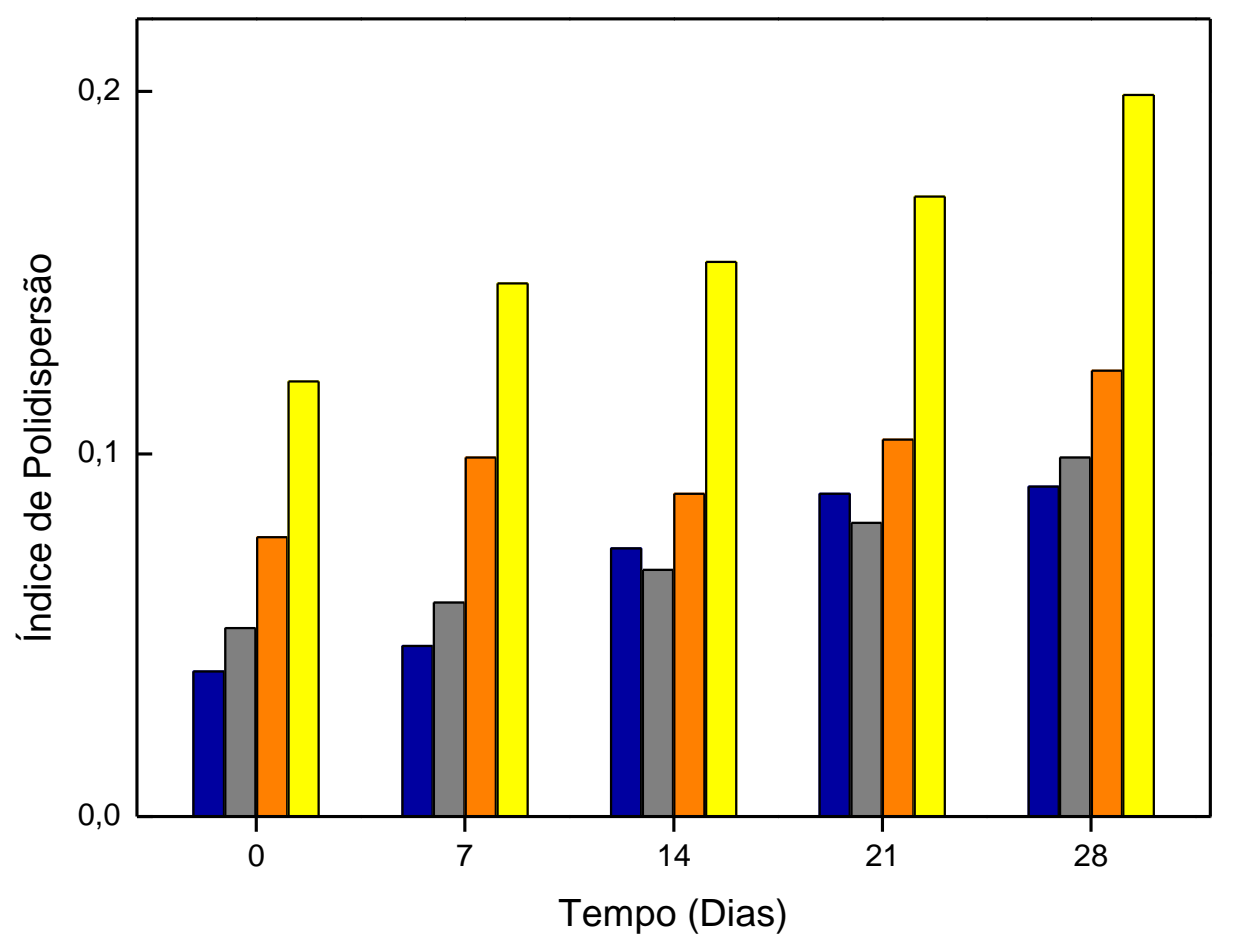

Figura 25. DLS de proteolipossomos $\left(4,6 \mathrm{mg} \mathrm{mL}^{-1}\right)$ na ausência de $\mathrm{Ca}^{2+}$. (A) Diâmetro médio das vesículas; (B) Î́ndice de polidispersão. Azul - DPPC; Cinza - 9:1 DPPC:DPPS; Laranja 6:4 DPPC:Chol e Amarelo - DPPC:Chol:DPPS (6:4:1), razões molares. Os gráficos de dispersão de luz diferencial foram registrados usando o N5 Submicron Particle Size Analyzer. O valor médio $(n=5)$ dos diâmetros dos lipossomas foi obtido a $25^{\circ} \mathrm{C}$ por distribuição unimodal, previamente filtrado $(0,8 \mu \mathrm{m})$. 


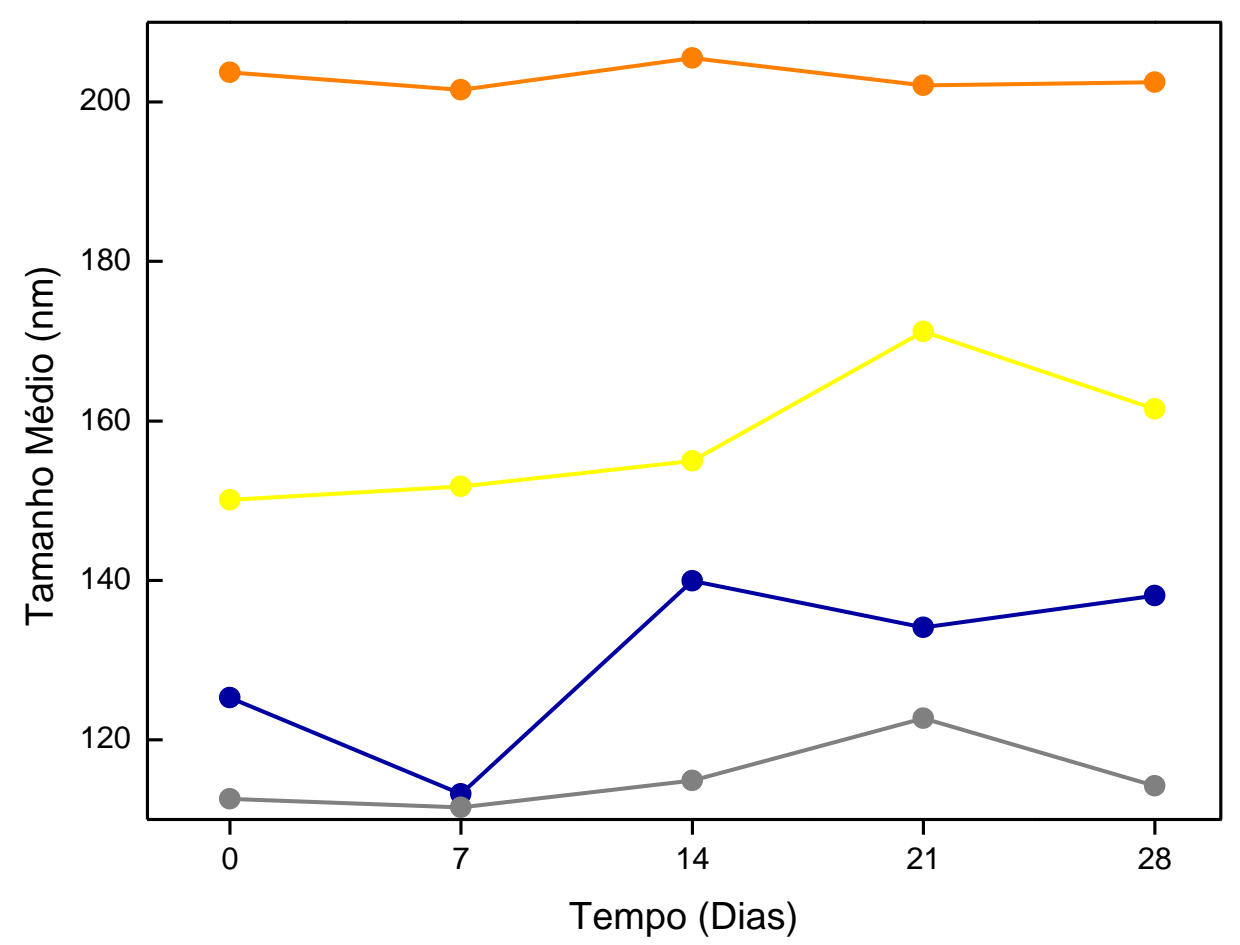

A

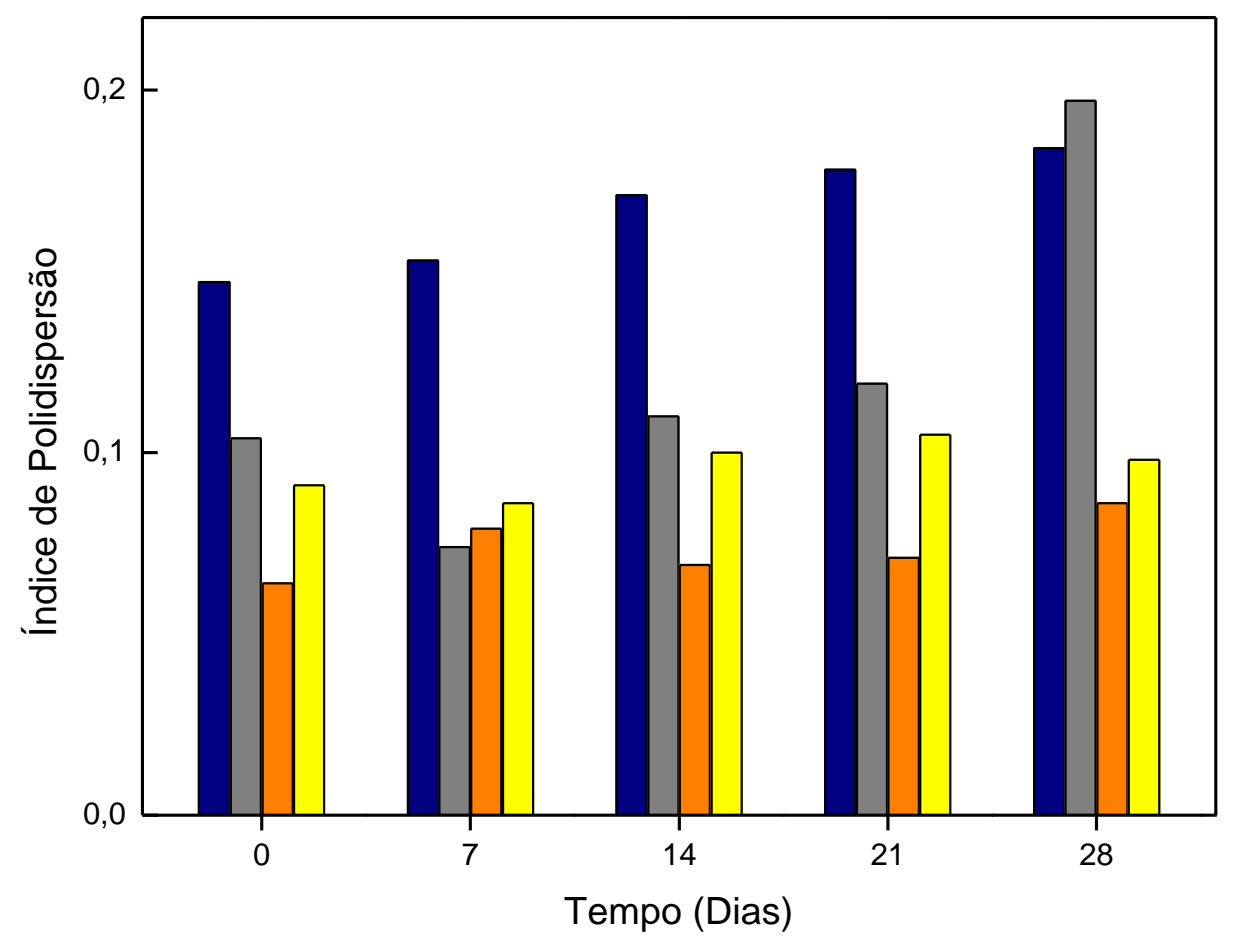

Figura 26. DLS de lipossomos $\left(10 \mathrm{mg} \cdot \mathrm{mL}^{-1}\right)$ na presença de $\mathrm{Ca}^{2+}$. (A) Diâmetro médio das vesículas; (B) Índice de polidispersão. Azul - DPPC; Cinza - 9:1 DPPC:DPPS; Laranja - 6:4 DPPC:Chol e Amarelo - DPPC:Chol:DPPS (6:4:1), razões molares. Os gráficos de dispersão de luz diferencial foram registrados usando o N5 Submicron Particle Size Analyzer. O valor médio $(n=5)$ dos diâmetros dos lipossomas foi obtido a $25^{\circ} \mathrm{C}$ por distribuição unimodal, previamente filtrado $(0,8 \mu \mathrm{m})$. 


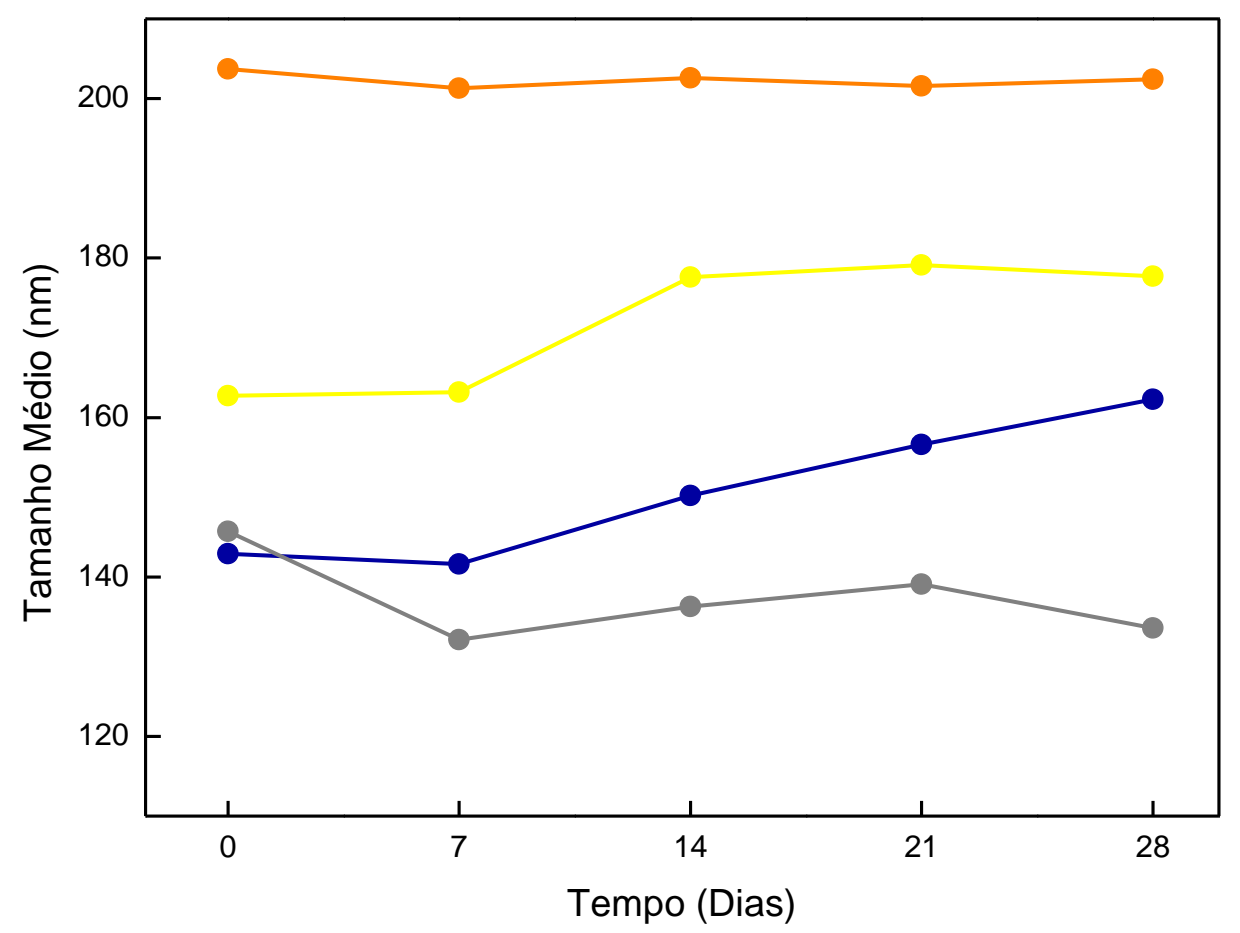

A

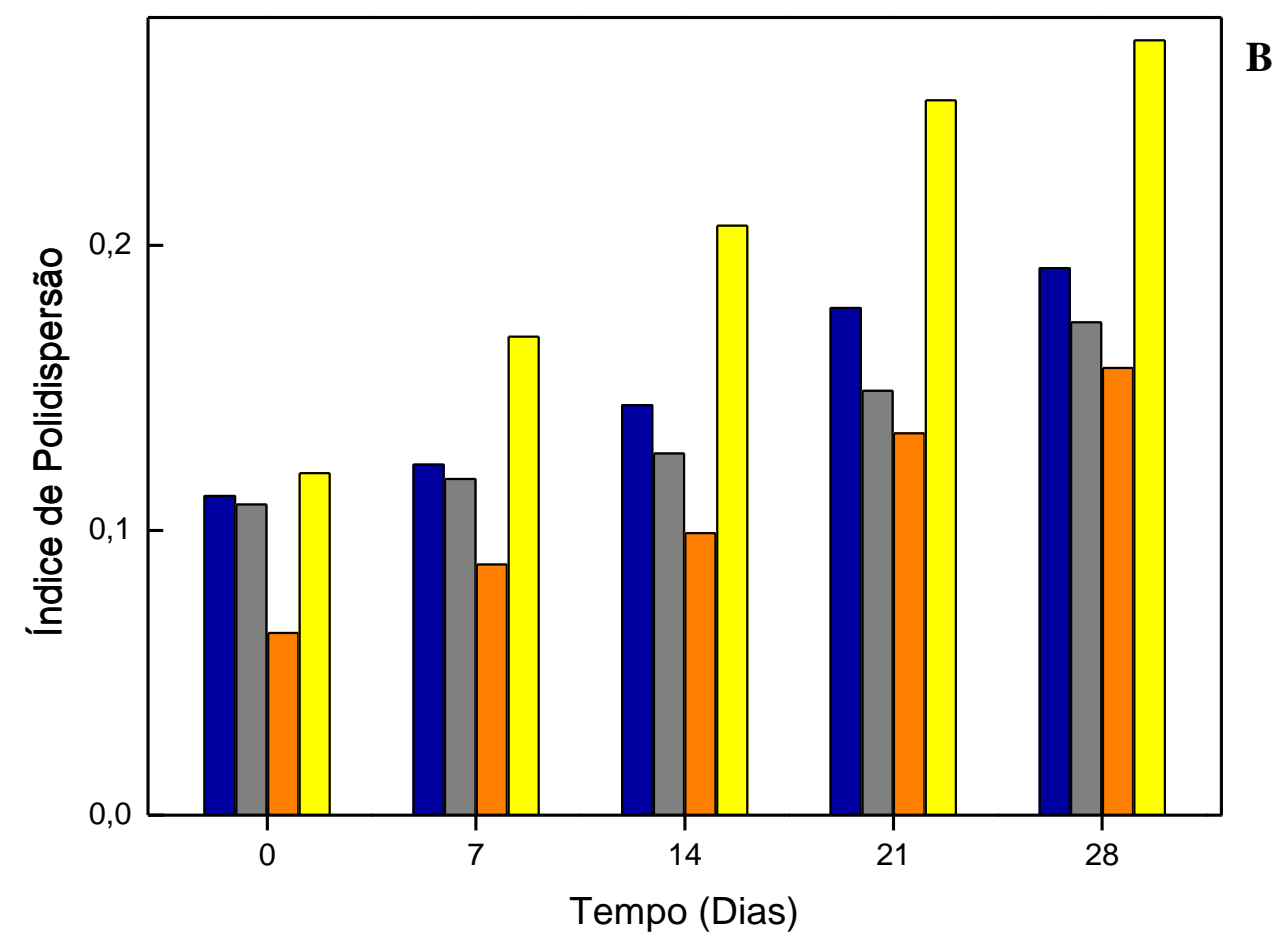

Figura 27. DLS de proteolipossomos $\left(4,6 \mathrm{mg} \cdot \mathrm{mL}^{-1}\right)$ na presença de $\mathrm{Ca}^{2+}$. (A) Diâmetro médio das vesículas; (B) Índice de polidispersão. Azul - DPPC; Cinza - 9:1 DPPC:DPPS; Laranja 6:4 DPPC:Chol e Amarelo - DPPC:Chol:DPPS (6:4:1), razões molares. Os gráficos de dispersão de luz diferencial foram registrados usando o N5 Submicron Particle Size Analyzer. O valor médio $(n=5)$ dos diâmetros dos lipossomas foi obtido a $25^{\circ} \mathrm{C}$ por distribuição unimodal, previamente filtrado $(0,8 \mu \mathrm{m})$. 
A produção de lipossomos pelo método de extrusão leva preferencialmente à obtenção de lipossomos unilamelares grandes (LUV). Sendo assim, as vesículas obtidas devem apresentar um diâmetro médio ao redor $100 \mathrm{~nm}$, dependendo da complexidade lipídica utilizada, e um índice de polidispersão aceitável para o uso dessas vesículas abaixo de 0,2.

A obtenção de lipossomos com diâmetro reduzido e distribuição homogênea das vesículas é um importante fator para garantir sua estabilidade ao longo do tempo.

Assim, análises de DLS confirmaram a obtenção de vesículas menores que 200 nm na ausência de $\mathrm{Ca}^{2+}$ (Figura 24A) e não se observou variações significativas quando adicionado íons cálcio aos lipossomos (Figura 26A). O mesmo pôde ser observado para os valores de índice de polidispersão (IP) obtidos, sendo todos inferiores a 0,2 (Figuras 24B e 26B).

Os proteolipossomos tanto na ausência quanto na presença de $\mathrm{Ca}^{2+}$ não apresentaram alterações significativas no tamanho médio e os valores de IP ficaram dentro da faixa aceitável (Figuras 24 e 27). Apenas observa-se que a composição 5:4:1 DPPC:Chol:DPPS apresentou maior propensão de instabilidade com possível agregação da proteína ao final dos 28 dias por exibir um aumento de IP tanto na ausência quanto na presença de $\mathrm{Ca}^{2+}$.

\subsection{Ensaio de mineralização em microplacas com proteolipossomos}

O ensaio de mineralização realizado consiste em um modelo in vitro que busca mimetizar a mineralização in vivo de forma a ser monitorado continuamente sem perturbações externas (Genge et al., 2007b).

Estudos mostraram que a formação mineral em MVs nativas é impulsionada por um núcleo de nucleação, constituído principalmente por fosfato de cálcio amorfo (ACP), que complexado com fosfatidilserina (PS) leva a formação do complexo cálcio-fosfato-lipídio (PS-CPLX) (Termine et al., 1970; Eanes, 1970) e também a presença das anexinas A5, A2 e A6. Sendo a AnxA5 a mais abundante e a principal proteína de ligação $\mathrm{Ca}^{2}+$ lipídio-dependente (Genge et al., 2007a).

O método utilizado para análise se baseia na dispersão da luz pela nascente de cristalitos a $340 \mathrm{~nm}$ monitorando a formação mineral (por aumento de turbidez) em intervalos regulares sem perturbar o sistema usando um leitor de placas 
automatizado (Genge et al., 2007b). Sendo assim, a propagação do mineral foi medida por turbidez a $340 \mathrm{~nm}$ (representada aqui como a absorbância registrada pelo equipamento, conforme detalhado em materiais e métodos) durante $30 \mathrm{~h}$ de incubação a $25^{\circ} \mathrm{C}$ ). $\mathrm{O}$ mesmo ensaio foi realizado adicionando colágeno do tipo I, como descrito por Wu e colaboradores (1993).

Foi utilizado um tampão fosfato intracelular (ICP) com conteúdo de eletrólitos semelhante ao observado em ultrafiltrados de lisados de condrócitos isolados de placa de crescimento, afim de se obter o ACP e PS-CPLX, que foram utilizados para iniciar a formação de minerais a partir de SCL in vitro (Genge at al., 2007a). 

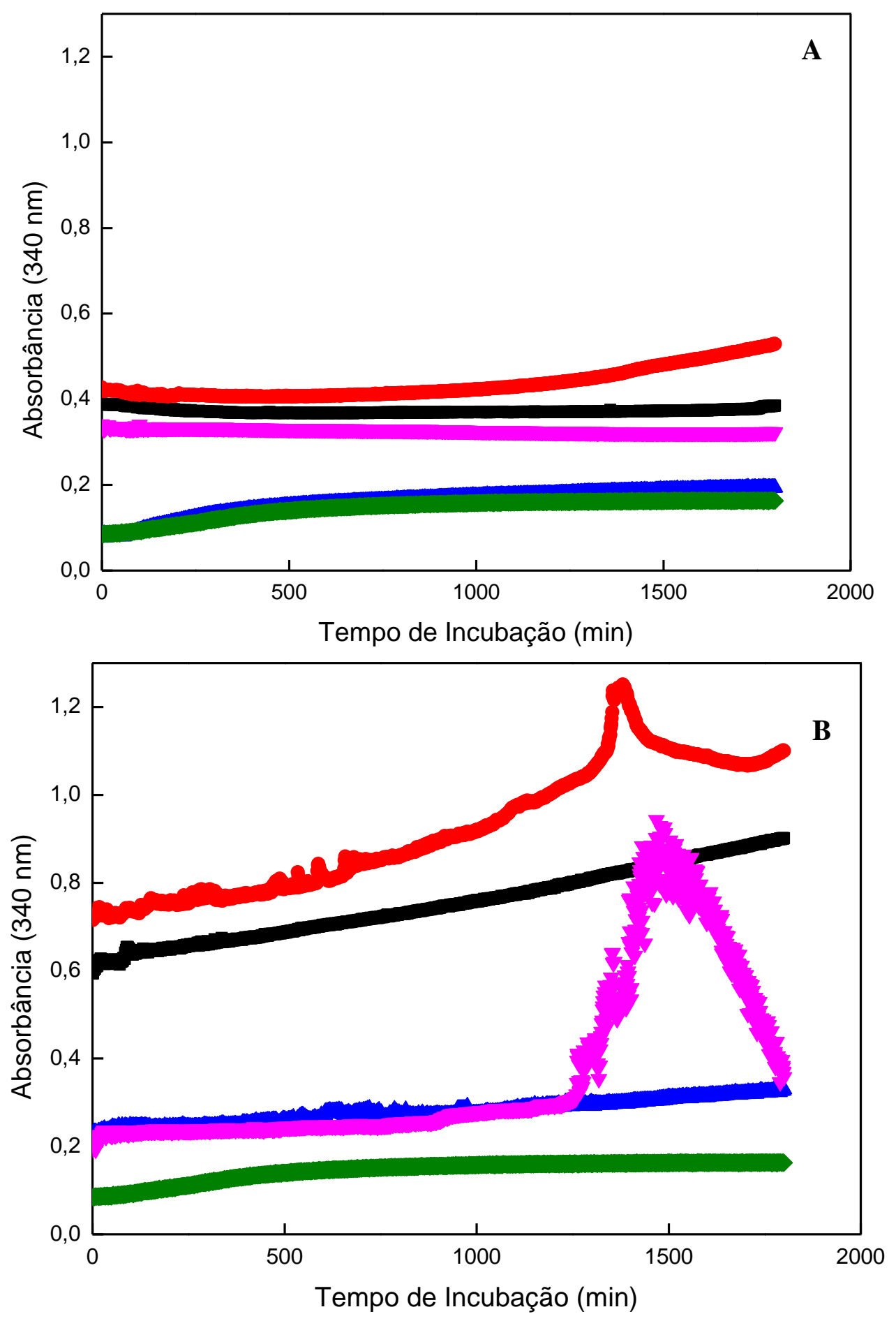

Figura 28. Teste de mineralização in vitro empregando formulações de DPPC. (A) Nucleador ACP; (B) Nucleador PS-CPLX. Vermelho - Proteolipossomo; Preto - somente Lipossomo; Rosa - AnxA6 (em solução) + nucleador; Azul - somente o Nucleador e Verde - AnxA6 sozinha (em solução). 

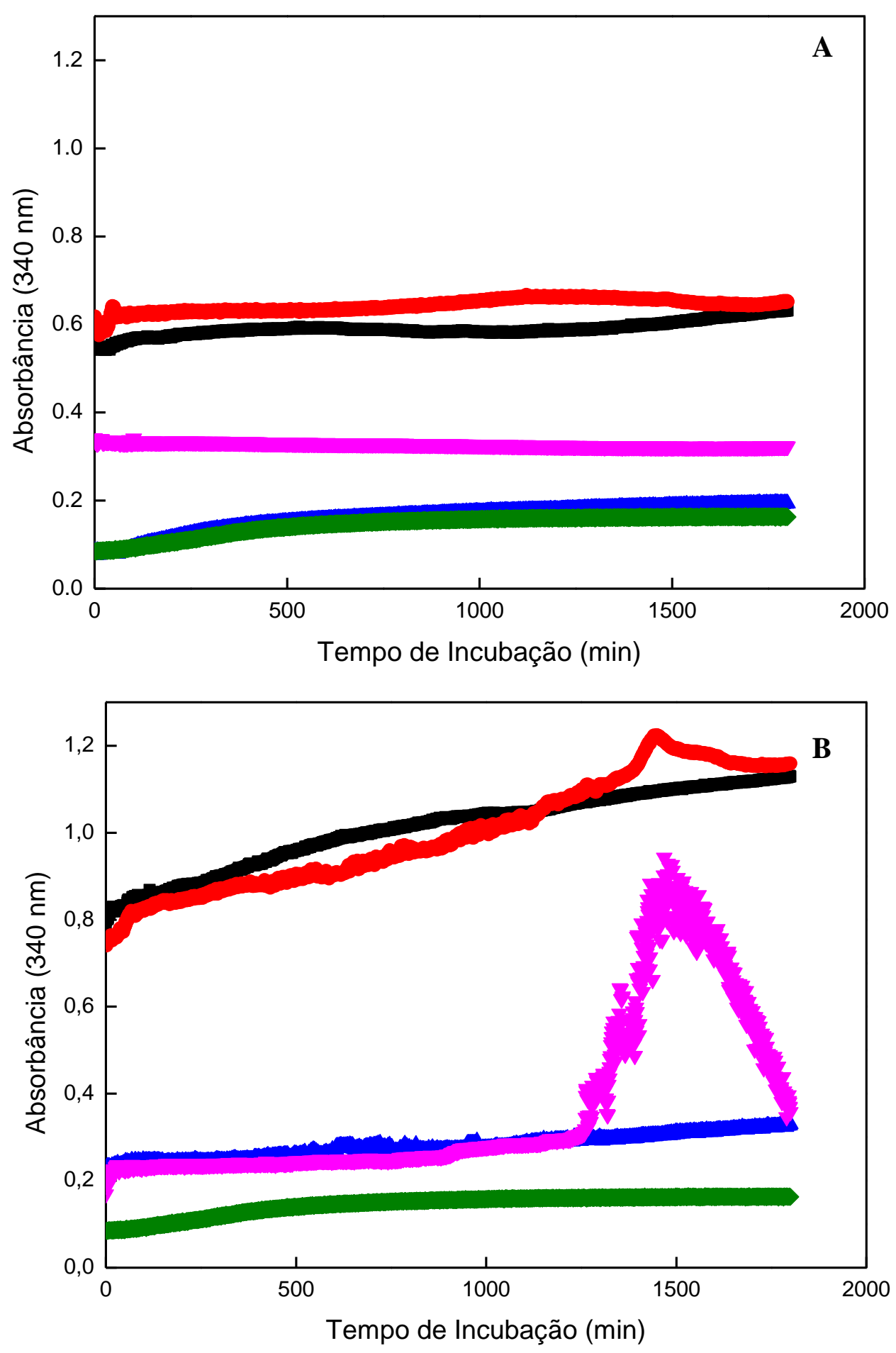

Figura 29. Teste de mineralização in vitro empregando formulações de 9:1 DPPC:DPPS. (A) Nucleador ACP; (B) Nucleador PS-CPLX. Vermelho - Proteolipossomo; Preto somente Lipossomo; Rosa - AnxA6 (em solução) + nucleador; Azul - somente o Nucleador e Verde - AnxA6 sozinha (em solução). 

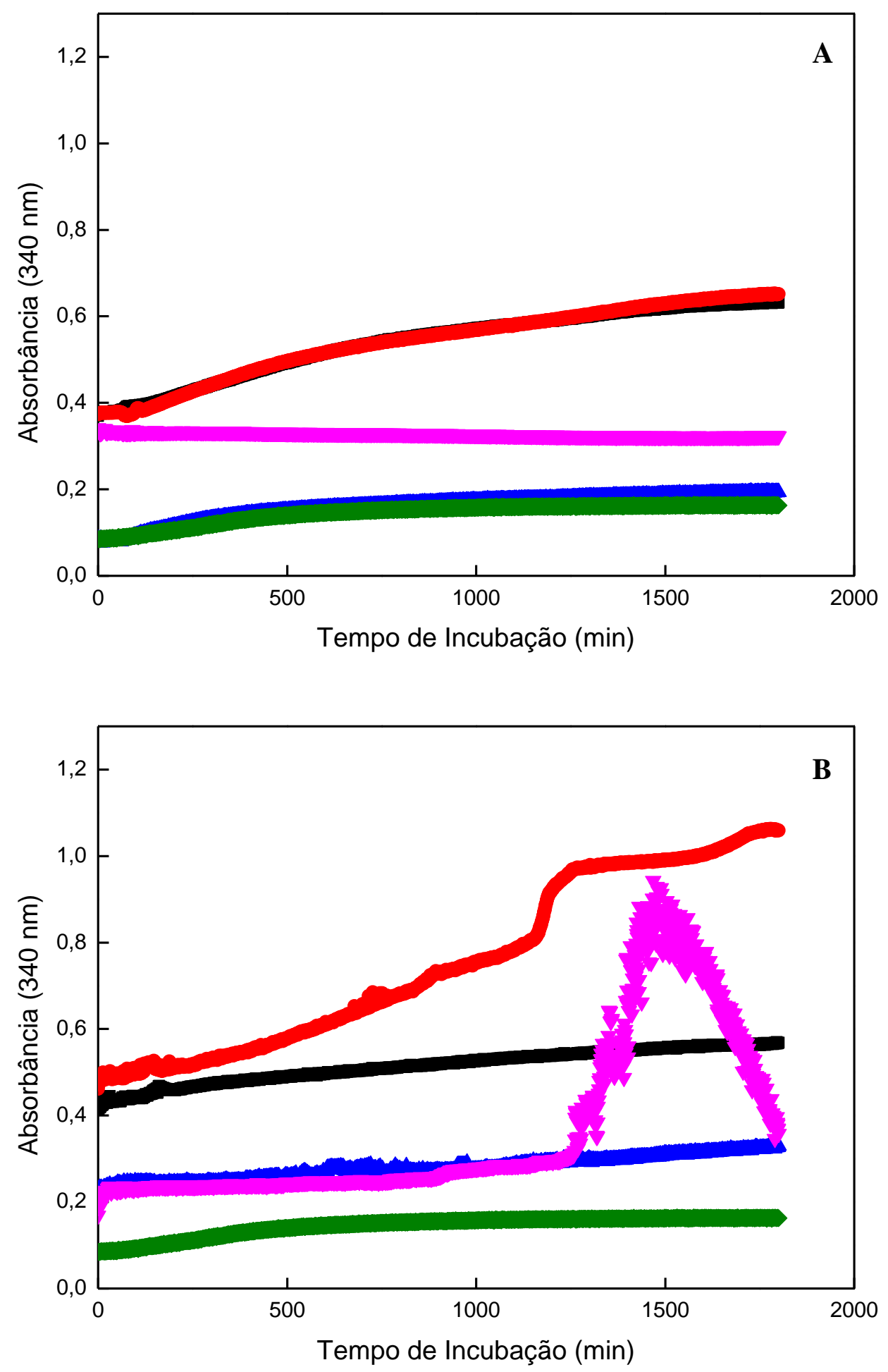

Figura 30. Teste de mineralização in vitro empregando formulações de 5:4:1 DPPC:Chol:DPPS. (A) Nucleador ACP; (B) Nucleador PS-CPLX. Vermelho Proteolipossomo; Preto - somente Lipossomo; Rosa - AnxA6 (em solução) + nucleador; Azul - somente o Nucleador e Verde - AnxA6 sozinha (em solução). 
Analisando qualitativamente 0 ensaio, verifica-se que os nucleadores sozinhos tanto ACP quanto PS-CPLX (Figuras 28, 29 e 30 - linha azul) não foram eficazes para aumentar a turbidez, logo não foi registrado alterações nos valores obtidos de absorbância. O mesmo foi observado para a AnxA6, quando em solução, sozinha (Figuras 28, 29 e 30 - linha verde) ou na presença do ACP como nucleador (Figuras 28A, 29A, 30A - linha rosa). Sendo assim, não houve nenhuma formação mineral evidente.

No entanto, AnxA6, em solução, com o nucleador PS-CPLX apresentou um período melhor definido de rápido aumento da absorbância após aproximadamente 20 horas de ensaio, exibindo pico máximo em 25 horas com absorbância registrada em aproximadamente 0,90. Após atingir esse máximo, verifica-se uma diminuição constante de absorbância até o final do tempo de ensaio. (Figuras 28B, 29B e 30B linha rosa). Algumas hipóteses para a diminuição subsequente do pico formado se corroboram em uma possível sedimentação do mineral formado, visto que todas as composições utilizadas permanecem estáticas ao longo do ensaio. Ou então, pelo deslocamento de equilíbrio químico, que pode ser ora favorecido pela formação do mineral ora deslocado para a dissolução da espécie formada, assim outros estudos serão necessários para confirmar qual destas hipóteses é verdadeira ou ambas as combinações.

As três composições de lipossomos e proteolipossomos (DPPC, 9:1 DPPC:DPPS e 5:4:1 DPPC:Chol:DPPS) utilizados na presença do nucleador ACP não apresentaram alterações significativas na absorbância ao longo das 30 horas de experimento, como também não exibiram formação de picos como observado para outras amostras com diferente nucleador (Figuras 28A, 29A e 30A - linhas pretas e vermelhas).

Lipossomos incubados com o nucleador PS-CPLX das três composições lipídicas, exibiram características similares entre si, apresentando discretos aumentos de absorbância ao longo do tempo, porém nenhuma formação pico (Figuras 28B, 29B e 30B - linha preta).

Evidentemente, proteolipossomos com o nucleador PS-CPLX apresentaram características mais evidentes de alterações de turbidez. Proteolipossomos de DPPC (Figura 28B - linha vermelha) mostrou gradativo aumento de absorbância ao longo de aproximadamente 22 horas de experimento, iniciando assim um aumento de absorbância levando a formação de um ponto máximo em 23 horas com absorbância de 1,2. De forma similar, proteolipossomos de 9:1 DPPC:DPPS (Figura 
29B - linha vermelha) apresentaram progressivo aumento de absorbância até 22 horas de ensaio, e então formação de um pico máximo 2 horas após o início da subida com absorbância de 1,2.

Protelipossomos contendo Chol (Figura 30B, linha vermelha) apresentaram também crescentes aumentos de absorbância até 19 horas e abrupta subida formando pico máximo em 21 horas com absorbância de 0,98 . No entanto, não foi verificado declínio do pico, sendo que após leve queda ele permaneceu subindo gradativamente até o final do ensaio.

Afim de verificar o comportamento da AnxA6 e possíveis interações que pudessem alterar a sua capacidade de propagação mineral, foi realizado estudo similar na presença de colágeno tipo I. 

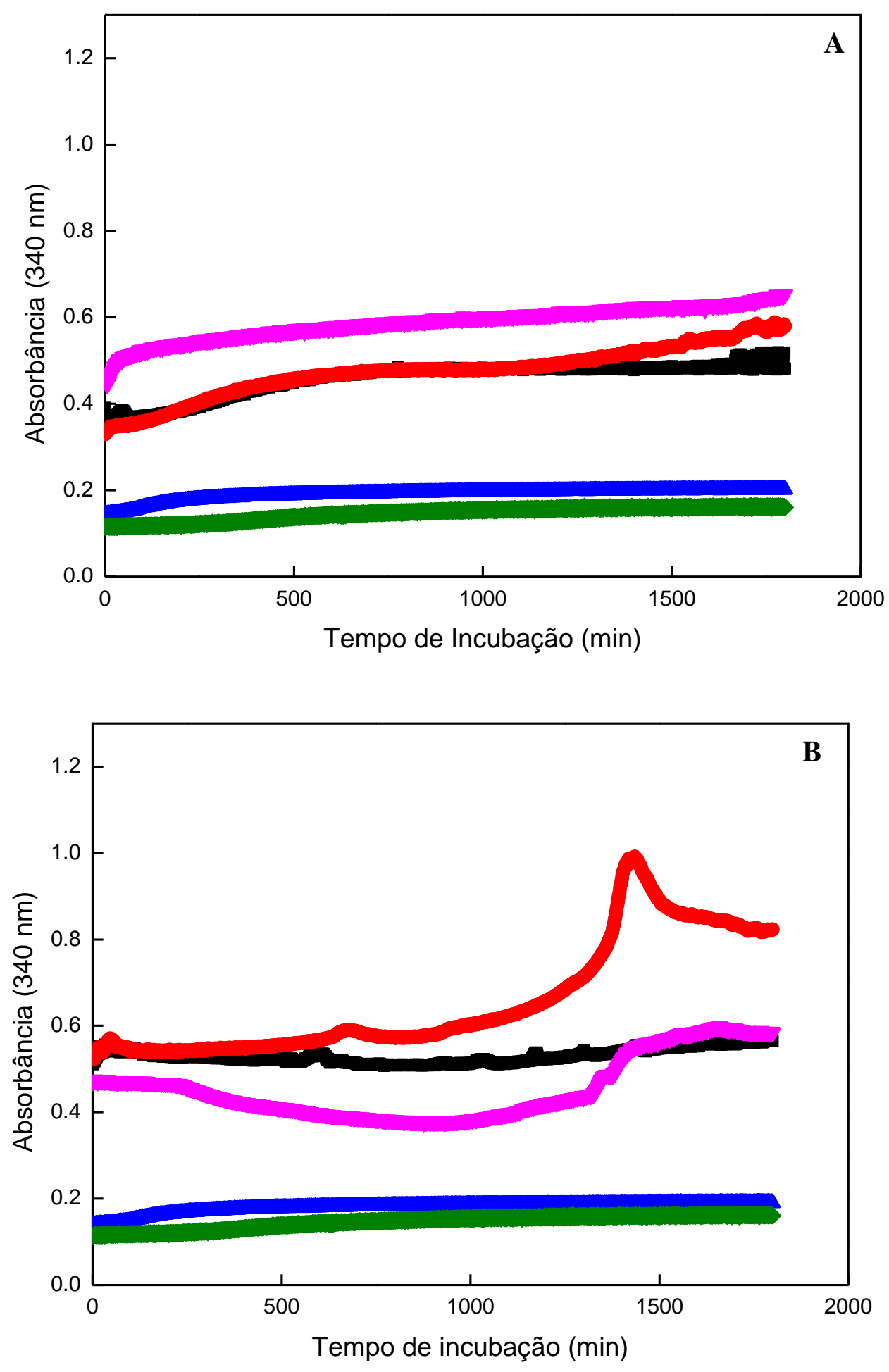

Figura 31. Teste de mineralização in vitro empregando formulações de DPPC na presença de colágeno tipo I. (A) Nucleador ACP; (B) Nucleador PS-CPLX. Vermelho Proteolipossomo; Preto - somente Lipossomo; Rosa - AnxA6 (em solução) + nucleador; Azul - somente o Nucleador e Verde - AnxA6 sozinha (em solução). 

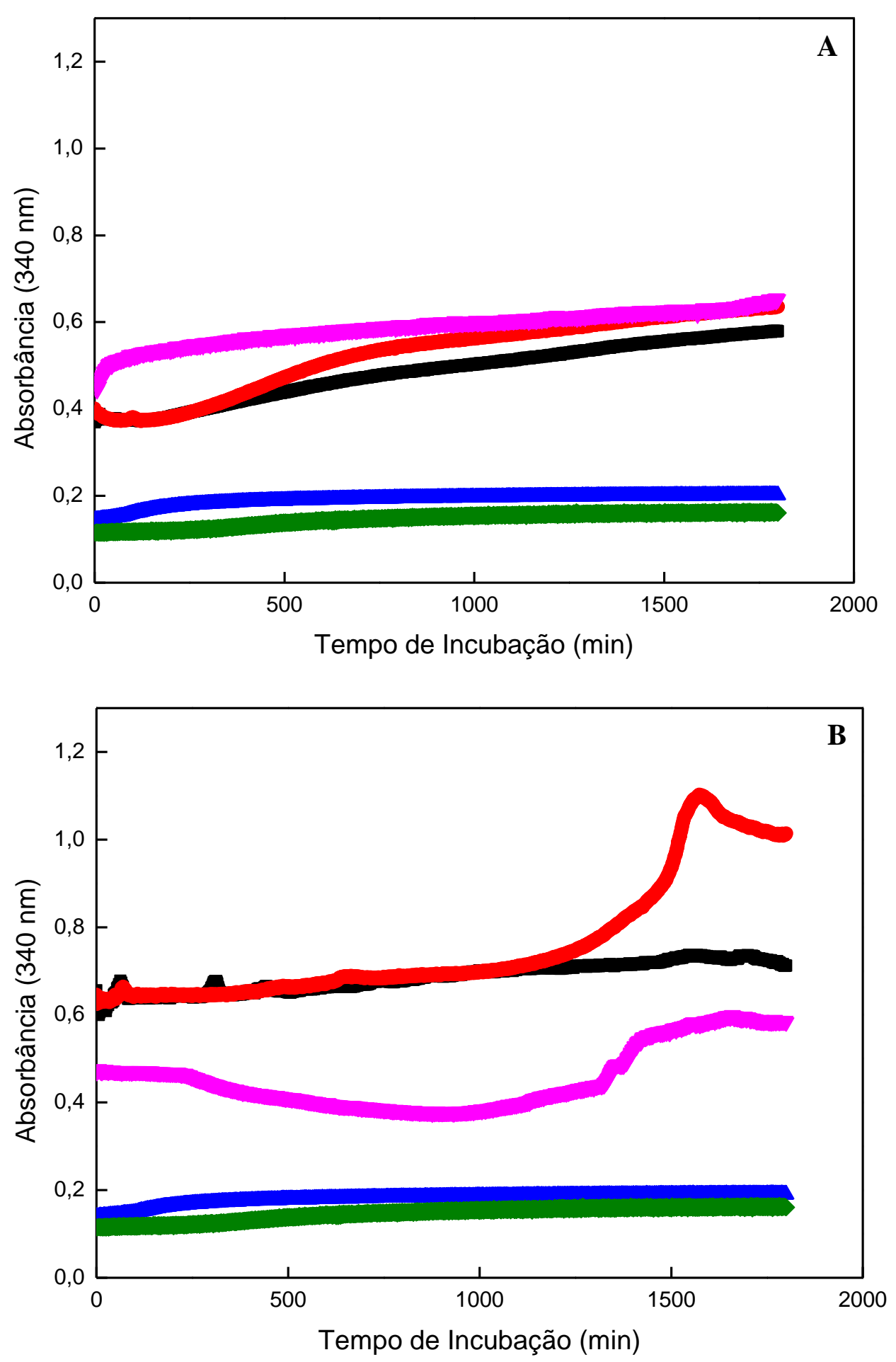

Figura 32. Teste de mineralização in vitro empregando formulações de 9:1 DPPC:DPPS na presença de colágeno tipo I. (A) Nucleador ACP; (B) Nucleador PS-CPLX. Vermelho Proteolipossomo; Preto - somente Lipossomo; Rosa - AnxA6 (em solução) + nucleador; Azul - somente o Nucleador e Verde - AnxA6 sozinha (em solução). 

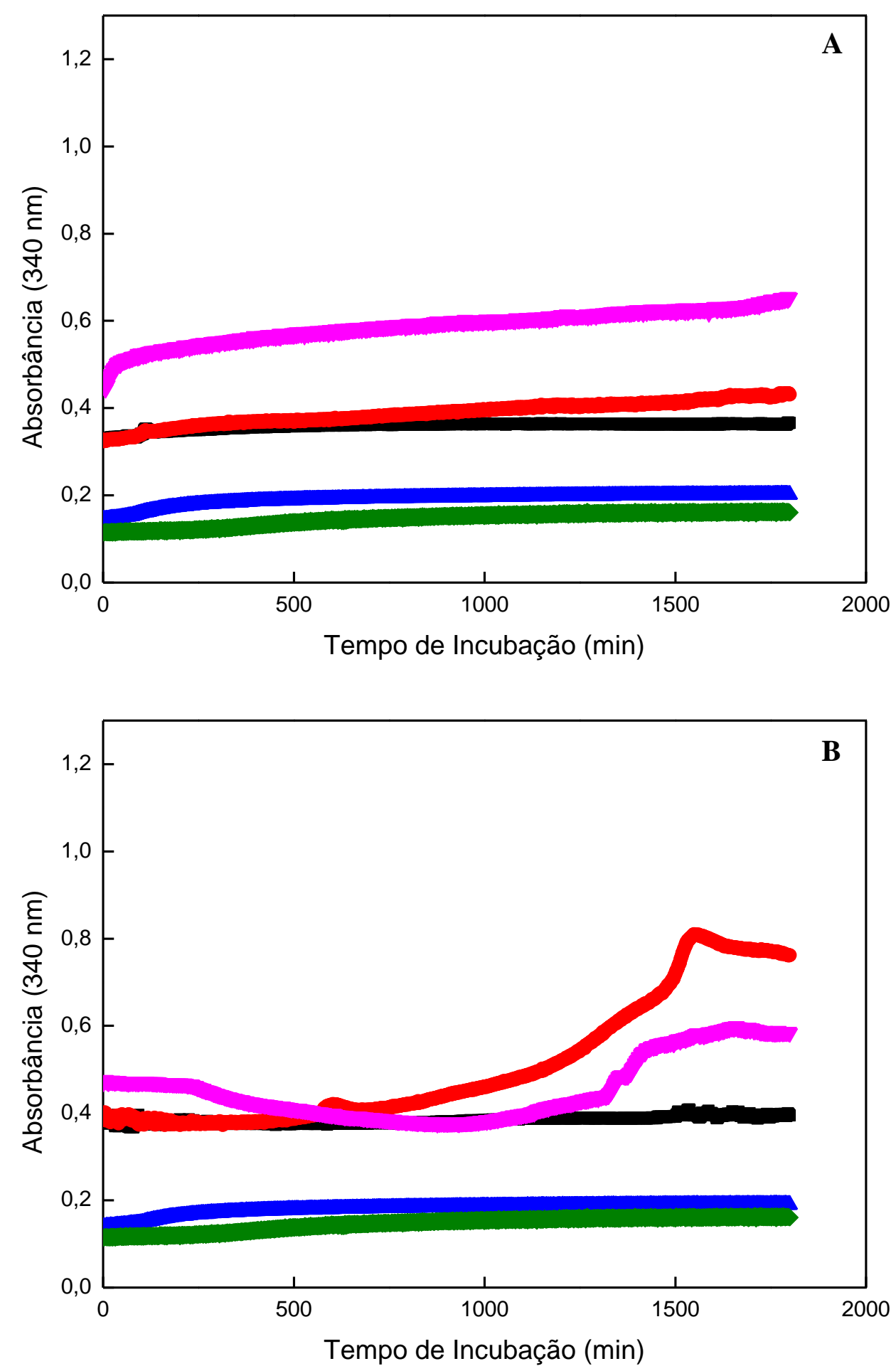

Figura 33. Teste de mineralização in vitro empregando formulações de 5:4:1 DPPC:Chol:DPPS na presença de colágeno tipo I. (A) Nucleador ACP; (B) Nucleador PSCPLX. Vermelho - Proteolipossomo; Preto - somente Lipossomo; Rosa - AnxA6 (em solução) + nucleador; Azul - somente o Nucleador e Verde - AnxA6 sozinha (em solução). 
A propagação do mineral na presença do colágeno tipo I também foi medida por turbidez a $340 \mathrm{~nm}$ utilizando um ensaio de microplaca de múltiplos poços, em quadruplicatas a cada 1 minuto durante $30 \mathrm{~h}$ de incubação a $25^{\circ} \mathrm{C}$. O colágeno em solução foi depositado no fundo dos poços 24 horas antes do início do ensaio.

Como verificado para o ensaio na ausência de colágeno do tipo I, nucleadores sozinhos (tanto ACP quanto PS-CPLX) não apresentaram variações de absorbância exibida ao longo do experimento (Figuras 31, 32 e 33 - linha azul). O mesmo foi observado para a AnxA6 em solução sem a presença de nenhum dos nucleadores (Figuras 31, 32 e 33 - linha verde), bem como na amostra de AnxA6, em solução, com o nucleador ACP (Figuras 31A, 32A e 33A - linha rosa). No entanto, a AnxA6, em solução, com o nucleador PS-CPLX apresentou aumento de absorbância após 22 horas de experimento, se mantendo constante até o final do ensaio (Figuras 31B, 32B e 33B - linha rosa).

Lipossomos e proteolipossomos de todas as composições lipídicas utilizadas (DPPC, 9:1 DPPC:DPPS e 5:4:1 DPPC:Chol:DPPS) na presença do nucleador ACP não apresentaram alterações significativas na absorbância ao longo do experimento, como também não exibiram formação de picos como observado para outras amostras com diferente nucleador (Figuras 31A, 32A e 33A - linhas pretas e vermelhas).

Os lipossomos incubados com o nucleador PS-CPLX das três composições lipídicas, exibiram características similares entre si também, apresentando discretos aumentos de absorbância ao longo do tempo, porém nenhuma formação um pico de turbidez como nos ensaios da ausência de colágeno (Figuras 31B, 32B e 33B - linha preta).

Os proteolipossomos com o nucleador PS-CPLX na presença de colágeno tipo I apresentaram similaridades entre si, todos exibiram a formação um discreto pico por volta de 9 - 10 horas de ensaio e então aumentos gradativos de absorbância até um pico máximo após aproximadamente 25 horas, com absorbância de 1,0 - 1,1 para proteolipossomos de DPPC e 9:1 DPPC:DPPS respectivamente (Figura 31 B e 32 B, linha vermelha) e 0,89 para 5:4:1 DPPC:Chol:DPPS (Figura 33 $B$, linha vermelha).

Com base nas variações de absorbâncias verificadas, foi possível estimar uma porcentagem equivalente de precipitação de $\mathrm{Ca}^{2+}$ no SCL. Segundo estudos realizados por Genge e colaboradores (2007) a comparação deste método com sistemas de ensaio baseados em radioisótopos (Warner e colaboradores, 1983) 
indica que um aumento de 0,1 na absorbância é equivalente a precipitação de aproximadamente $10 \%$ do total de $\mathrm{Ca}^{2+}$ no SCL.

Para tanto, calculou-se a diferença da absorbância inicial no tempo zero em relação aos valores máximos de absorbâncias obtidas para cada amostra, e então estimou-se a precipitação aproximada de $\mathrm{Ca}^{2+}$ (Tabela 4).

Tabela 4. Porcentagem de formação mineral estimada em (\%), conforme descrito por Warner e colaboradores (1983). Cada amostra utilizada no ensaio (lipossomos e proteolipossomos) com os nucleadores ACP e PS-CPLX na ausência ou na presença de colágeno tipo I.

\begin{tabular}{lccccc}
\hline \multirow{2}{*}{ Composição do ensaio } & \multirow{2}{*}{ AnxA6 } & \multicolumn{2}{c}{ Sem Colágeno } & \multicolumn{2}{c}{ Com Colágeno } \\
\cline { 3 - 6 } & & ACP & PS-CPLX & ACP & PS-CPLX \\
\hline \multirow{2}{*}{ DPPC } & - & 1 & 31 & 13 & 5 \\
& + & 14 & 55 & 26 & 44 \\
9:1 DPPC:DPPS & - & 7 & 21 & 27 & 15 \\
& + & 11 & 49 & 26 & 45 \\
5:4:1 DPPC:Chol:DPPS & - & 26 & 16 & 6 & 4 \\
& + & 30 & 52 & 14 & 45 \\
Nucleador & - & 7 & 11 & 8 & 6 \\
Sem Lipídio & $\left.{ }^{*}\right)_{+}$ & 2 & 75 & 19 & 15 \\
\hline AnxA6 em solução usada como controle & & & 6 & 8 \\
\hline
\end{tabular}

A formação mineral (propagação) induzida por nucleadores incubados em SCL foi melhor observada para a composição contendo AnxA6, em solução, utilizando o PS-CPLX como nucleador na ausência de colágeno tipo I ( 75\%). Para fins comparativos, a AnxA6, assim como a AnxA5, ambas em solução, se mostraram estimuladores significativamente eficazes da formação mineral usando o nucleador PS-CPLX (Genge et al., 2007a). Proteolipossomos de DPPC ( 55\%), 5:4:1 DPPC:Chol:DPPS (52\%) e 9:1 DPPC:DPPS (49\%), na ausência de colágeno, também apresentaram considerável efeito estimulante para a formação mineral, como pode ser visto na Tabela 4. 
Para o ensaio com o colágeno tipo I, é possível observar que formação mineral para todas as três composições lipídicas estudadas com a AnxA6 e o nucleador PS-CPLX apresentaram 45\% de formação mineral estimada. Tal porcentagem retrata uma menor interação e influência do colágeno com a AnxA6 para estimulo da formação mineral se comparado com estudos utilizando a AnxA5, onde essa influência foi mais expressiva (Genge et al., 2007b).

Lipossomos, tanto na presença quanto na ausência de colágeno com ambos os nucleadores (ACP e PS-CPLX) apresentaram porcentagens semelhantes entre si, sendo igual ou inferior a 30\%, validando assim, que a presença de AnxA6 conferiu uma condição favorável para a propagação mineral.

$\mathrm{Na}$ literatura atual não é relatado estudos de mineralização in vitro com a AnxA6 em proteolipossomos como foi empregado em nossos experimentos. Dessa forma, apenas a AnxA5 possui um perfil melhor elucidado de sua contribuição como potente ativadora da mineralização e não temos como comparar nossos dados com outros trabalhos da literatura.

\subsubsection{Espectroscopia de infravermelho com transformada de Fourier (FTIR)}

A espectroscopia com transformada de Fourier (FTIR) é uma técnica de grande sensibilidade que fornece evidências da presença de vários grupos funcionais na estrutura orgânica. O espectro formado aparece na forma de bandas, que são originadas quando a amostra absorve a energia incidente e converte-se em vibração molecular.

Sendo assim, ao finalizar as 30 horas de ensaio nas microplacas, realizou a análise espectral de cada uma das amostras, o que revelou a presença de uma banda larga variando de 3470 a $3410 \mathrm{~cm}^{-1}$ atribuída ao alongamento $\mathrm{O}-\mathrm{H}$ (ocultada na Figura 34), como também uma banda em aproximadamente $1740 \mathrm{~cm}^{-1}$ atribuída ao grupamento éster presente em fosfolipídios $(\mathrm{C}=\mathrm{O})$ e uma a banda característica da apatita, relacionada ao alongamento assimétrico do sinal de fosfato proveniente do mineral dentro das vesículas $-\mathrm{PO}_{4}{ }^{3-}\left(\sim 1032 \mathrm{~cm}^{-1}\right)$ (Favarin et al., 2020; Simão et al., 2019). 

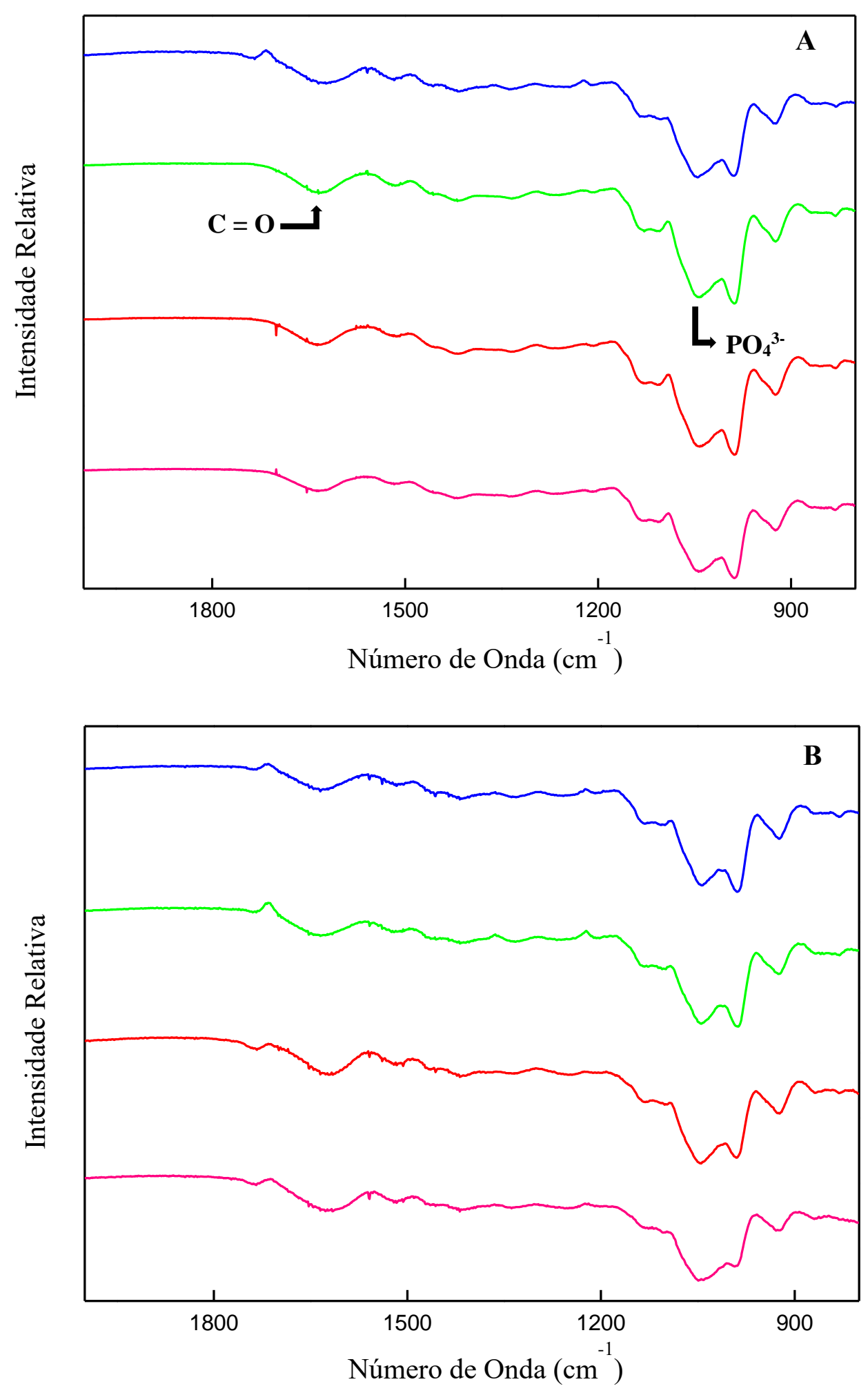

Figura 34. Espectros de FTIR de proteolipossomos com o nucleador PS CPLX. (A) ausência de colágeno; (B) presença de colágeno. Azul - DPPC; Verde - 9:1 DPPC:DPPS; Vermelho 5:4:1 DPPC:Chol:DPPS e Rosa - AnxA6, em solução, + nucleador 
Visto que a turbidez não fornece informações sobre a natureza do mineral formado, optou-se por utilizar o FTIR para verificar a eficácia da mineralização por meio do cálculo da razão entre as áreas da banda de referência interna do éster do fosfolipídio $(\mathrm{C}=\mathrm{O})$ em $1740 \mathrm{~cm}^{-1}$ e a banda correspondente ao alongamento assimétrico do grupo $\mathrm{PO}_{4}{ }^{3-}$ em $1032 \mathrm{~cm}^{-1}$.

Tabela 5. Razões entre as áreas das bandas em $1032\left(\mathrm{PO}_{4^{3-}}\right)$ e $1740(\mathrm{C}=\mathrm{O}) \mathrm{cm}^{-1}$ obtidas por FTIR para as diferentes amostras de proteolipossomos.

\begin{tabular}{|c|c|c|c|}
\hline \multirow{2}{*}{ Nucleador } & \multirow{2}{*}{$\begin{array}{l}\text { Proteolipossomos } \\
\text { (Razão Molar) }\end{array}$} & \multirow{2}{*}{$\begin{array}{c}\text { Sem Colágeno } \\
\mathrm{PO}_{4}{ }^{3-} / \mathrm{C}=0\end{array}$} & \multirow{2}{*}{$\begin{array}{l}\text { Com Colágeno } \\
\mathrm{PO}_{4}{ }^{3-/ \mathrm{C}=0}\end{array}$} \\
\hline & & & \\
\hline \multirow{4}{*}{ ACP } & DPPC & 1,4 & 1,4 \\
\hline & 9:1 DPPC:DPPS & 1,5 & 1,3 \\
\hline & 5:4:1 DPPC:Chol:DPPS & 1,6 & 1,5 \\
\hline & ${ }^{(*)} A n \times A 6$ & 1,3 & 1,4 \\
\hline \multirow{4}{*}{ PS-CPLX } & DPPC & 2,2 & 1,7 \\
\hline & 9:1 DPPC:DPPS & 1,6 & 1,8 \\
\hline & 5:4:1 DPPC:Chol:DPPS & 2,1 & 1,9 \\
\hline & ${ }^{(*)} \mathrm{An} \times \mathrm{A} 6$ & 2,8 & 1,5 \\
\hline
\end{tabular}

$\left.{ }^{*}\right) A n \times A 6$ em solução como controle

Utilizando as proporções estequiométricas de cálcio e fosfato para averiguar a eficiência da propagação mineral, temos que a razão molar $\mathrm{Ca} / \mathrm{P}$ é aproximadamente 1,7 (Dorozhkin, 2016; Cruz et al., 2021).

Considerando as razões calculadas, verifica-se que nenhuma composição lipídica na presença do nucleador ACP com ou sem colágeno, chegou a atingir o valor base de 1,7. Tal fato, corrobora com os dados da Tabela 3 , quanto à estimativa de formação mineral obtida com base nos deltas do ensaio de mineralização, onde os valores estimados ficaram quantitativamente abaixo de $30 \%$, e qualitativamente analisando as figuras correspondentes (Figuras 28A, 29A, 30A, 31A, 32A e 33A) não se verificou alterações significativas ao longo do ensaio.

Com exceção à composição lipídica de 9:1 DPPC:DPPS (sem colágeno) e o nucleador PS-CPLX com AnxA6 (na presença de colágeno), todas as demais 
composições analisadas apresentaram razões entre as áreas das bandas, acima de 1,7 na presença do nucleador PS-CPLX.

Estudos paralelos realizados por nosso grupo de pesquisa utilizando outra proteína importante para o processo de mineralização, tem mostrado valores acima de 2,0 para tal análise (Favarin et al., 2020; Simão et al., 2019). Sendo assim, estimando a capacidade da AnxA6 em propagar mineral de apatita verifica-se que proteolipossomos com nucleador PS-CPLX na ausência de colágeno apresentaram os melhores resultados. Elencando tais dados obtidos para formação mineral, temos: - Ausência de colágeno: DPPC > DPPC:Chol:DPPS > DPPC:DPPS seguido por DPPC:Chol:DPPS > DPPC:DPPS > DPPC na presença de colágeno. Assim como foi verificado nos valores de porcentagem de formação mineral estimada (Tabela 3).

A AnxA6, em solução, com o nucleador PS-CPLX apresentou a melhor evidência de propagação mineral, resultado condizente com a porcentagem estimada para a precipitação de cálcio $\sim 75 \%$ (Tabela 3 ). Tal fato pode estar intrinsicamente relacionado com a capacidade da AnxA6 em formar matrizes cristalinas bidimensionais ordenadas mediante ligação dependente de $\mathrm{Ca}^{2+} \mathrm{a}$ monocamadas ricas em PS, que está presente no nucleador empregado (AvilaSakar et al., 2000).

Dada a complementariedade das técnicas utilizadas para analisar o quão efetivo foi ensaio in vitro de mineralização proposto, podemos buscar compreender qual a possível relevância e a importância da AnxA6 nesse processo. Apesar de muito faltar para uma completa elucidação do seu papel, podemos esboçar características apresentadas por ela que sugerem uma atribuição distinta da AnxA5 na mineralização.

Estudos com a AnxA5 mostraram que ela reduz o tempo de início como também aumenta significativamente a taxa e a quantidade final de mineral formada pelo nucleador PS-CPLX, indicando que ela não apenas aumenta a nucleação da formação mineral, mas também pode proteger os cristais em crescimento da adsorção de inibidores, permitindo um crescimento mais amplo e perfeito dos cristais (Wu et al., 1997).

Já a AnxA6 pode participar na organização de domínios de membrana que contribuem para a atividade nucleacional de PS-CPLX nas MVs. Apresentando capacidade única de se associar à esfingomielina e ao colesterol, que reduzem a atividade nucleacional dos PS-CPLXs, indicando que a AnxA6 pode ter um papel especial no aumento da mineralização nas MVs (Babiychuk et al., 1999; Genge et 
al., 2007a; Veschi et al., 2020; Wang et al., 2021). Além disso, ela se mostrou possível inibidora na formação mineral na presença de ACP evidenciando assim, sua maior afinidade por fosfatidilserina (PS). Na mineralização, a estabilidade do ACP e sua capacidade de se transformar em apatita são reguladas por muitos fatores, sendo a presença de PS um dos mais importantes, visto que ele rapidamente se complexa com o ACP (Genge et al., 1990), estabilizando e ordenando seus componentes $\mathrm{Ca}^{2+}$ e Pi (Ali et al., 1970), podendo propiciar a transformação eficiente em mineral cristalino (Kirsch et al., 1997).

Além do que já foi relatado, a AnxA5 também possui a capacidade de transportar cálcio para dentro das MVs (Genge et al., 1992; Bolean et al., 2015; 2017), enquanto que, ainda não foi possível verificar tal habilidade para a AnxA6, é conhecido apenas sua aptidão à ligação com cálcio.

É apresentado ainda na literatura, a alta afinidade de ligação da AnxA5 a fibrilas de colágeno tipo II, o que indica um possível papel dela na ligação de MVs à matriz orgânica durante a mineralização (Wu et al., 1991; Kirsch et al., 2000; Bolean et al., 2020). Nos estudos realizados com a AnxA6 (tanto em solução quanto em proteolipossomos) na presença de colágeno tipo I, não foram observados resultados que demonstrassem expressiva afinidade entre eles para propagação mineral. Estudos futuros devem ser feitos utilizando colágeno tipo II para verificar se ambos juntos (AnxA6 e colágeno tipo II) podem induzir a nucleação ou propagação mineral. Ou ainda, observar se mudanças nos parâmetros experimentais podem levar a um aumento da propagação. 


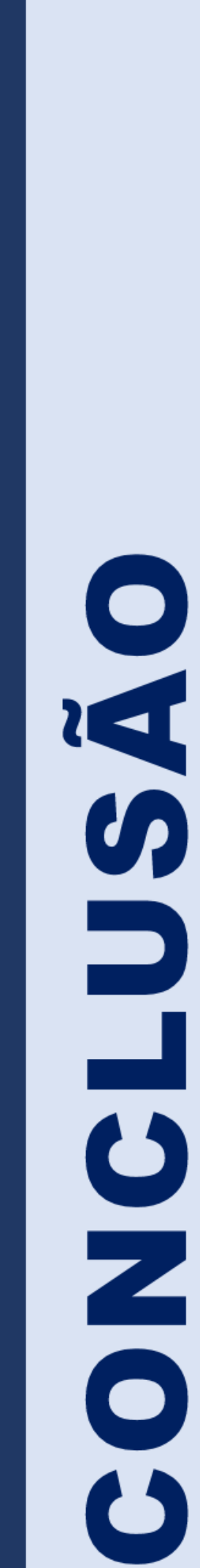




\section{CONCLUSÃO}

Apesar de pertencerem à mesma família e possuírem várias características semelhantes, a AnxA5 e a AnxA6 apresentam singularidades intrínsecas a cada uma, tal como especificidades únicas em diferentes processos biológicos.

Além das particularidades estruturais já relatadas na literatura, verificamos que a AnxA6 possui melhor estabilidade estrutural em $\mathrm{pH}$ ácido diferindo do comportamento da AnxA5 que melhor se estrutura em pH alcalino.

Quanto a sua associação com diferentes composições lipídicas, verificou-se que a AnxA6 interagiu de forma eficaz com todas as composições lipídicas estudadas, porém os melhores resultados obtidos foram para a composição 5:4:1 DPPC:Chol:DPPS, sendo que a presença de cálcio favoreceu a interação lipídioproteína como pode ser observado nos experimentos em monocamadas bem como em lipossomos.

Com base nos estudos realizados em lipossomos a respeito da interação da AnxA6 com as diferentes composições lipídicas, é possível concluir que AnxA6 exibe diferentes tipos de interação com a membrana dependendo do pH e da composição lipídica, uma vez que diferentes alterações nos parâmetros termodinâmicos foram obtidas dependendo da composição lipídica dos proteolipossomos. Os resultados de DSC corroboram que AnxA6 pode ser encontrada em regiões distintas da membrana MVs. As imagens de AFM mostraram protusões que sugerem domínios diméricos ou triméricos de AnxA6 na superfície dos proteolipossomos estudados, indicando que ela pode adotar diferentes conformações quando interage com a membrana lipídica. Estudos com a AnxA5 em lipossomos (previamente realizados por Bolean et al., 2015), tem revelado sua maior afinidade por composição lipossômica de 9:1 DPPC:DPPS, tal fato não foi averiguado para a AnxA6, que se mostrou mais propensa a interagir com a composição lipídica de 5:4:1 DPPC:Chol:DPPS. A maior afinidade da AnxA6 pela composição ternária contendo carga negativa da serina juntamente com colesterol pode ser motivada por suas distintas localizações nas MVs.

Estudos de mineralização in vitro foram realizados com a finalidade de verificar se a presença da proteína e dos lipídios estudados levariam a propagação mineral. Nossos achados sugerem que a AnxA6 se mostra capaz de propagar mineral de forma mais eficiente com o nucleador PS-CPLX na ausência de colágeno tipo I. Estudos realizados por turbidimetria e espectros de FTIR apontaram melhores 
resultados de propagação mineral para a AnxA6 em solução com o nucleador PSCPLX na ausência de colágeno tipo I, seguidos pela presença dela nos proteolipossomos. A propagação mineral analisada para o mesmo nucleador (PSCPLX) e formulações com AnxA6 na presença do colágeno tipo I se mostraram menos eficientes quando comparado aos dados obtidos para sua ausência.

A presença do nucleador ACP tanto na ausência quanto na presença de colágeno tipo I, não se mostrou capaz de induzir propagação mineral.

Assim, com base nos resultados obtidos para o estudo de mineralização in vitro, concluímos que a AnxA6 pode desempenhar papel na propagação mineral, porém talvez essa não seja sua função principal na mineralização, uma vez que, os dados obtidos não resultaram de valores tão evidentes quanto verificado para a AnxA5 em estudos similares. Tal fato sugere, que a AnxA6 pode atuar de forma mais eficiente diretamente na nucleação do mineral dentro das MVs. Para tanto seria necessário estudos que analisassem diretamente a nucleação e não apenas a propagação mineral.

Associando os resultados obtidos nesse trabalho com outros estudos realizados em parceria com o grupo de pesquisa da França, propomos um possível mecanismo de translocação da AnxA6 através da membrana das MVs durante a mineralização com base em suas características (Figura 35). 


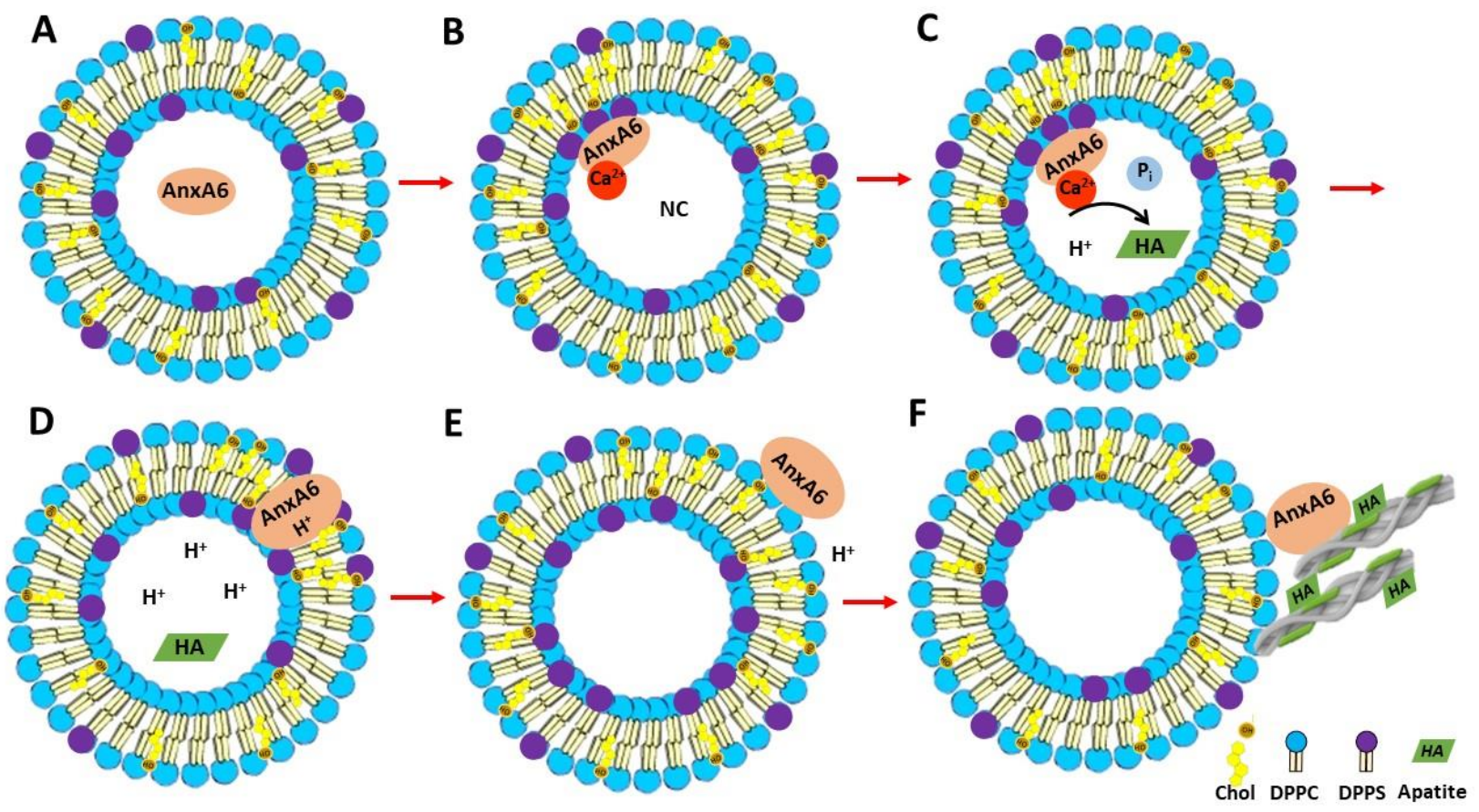

Figura 35. Mecanismo de translocação da AnxA6 em vesículas de matriz durante a mineralização e suas funções. (A) Em baixa concentração de cálcio, a AnxA6 está localizada no lúmen das MVs. (B) O acúmulo de cálcio dentro das MVs favorece a ligação da AnxA6, onde sua afinidade de ligação para $\mathrm{Ca}^{2+}$ está na faixa de $\mathrm{mM}$, então a AnxA6 liga-se a lamela interna das MVs, contendo fosfatidilserina (PS), de uma maneira dependente de cálcio, formando um núcleo nucleacional, iniciando a formação de apatita. (C) Durante a formação da apatita, ocorre a liberação de prótons $\left(\mathrm{H}^{+}\right)$, induzindo a protonação da AnxA6, tornando-a mais hidrofóbica devido ao seu potencial de ionização em torno de 5,5. Uma parte da AnxA6 pode ser inserida na bicamada das MVs, onde pode formar um poro de íon. (D) $\mathrm{O}$ pH externo corresponde ao da matriz extracelular e é neutro, (E) AnxA6 pode ser desprotonada e liberada para a superfície externa das MVs ricas em fosfatidilcolina (PC). (F) Sua ligação a fosfolipídios neutros não depende do cálcio. O AnxA6 ou AnxA5 podem se ligar às fibras de colágeno, contribuindo para fixar as MVs às fibras de colágeno (Veschi et al., 2020).

A AnxA6 no lúmen das MVs se liga à fosfatidilserina (PS) presente na lamela interna da bicamada da $\mathrm{MV}$ na presença de $\mathrm{Ca}^{2+}$, desencadeando a formação de um núcleo nucleacional com possível auxílio da AnxA5 e outras proteínas (Figuras 35A e B). Sua contribuição também poder ser para o acúmulo de $\mathrm{Ca}^{2+}$ e estabilização da ligação de $\mathrm{Ca}^{2+}$ à $\mathrm{PS}$, promovendo um ambiente favorável para a formação de apatita (Figura 35C). Seguida por uma queda local do pH durante a formação da apatita, pode-se promover a inserção da AnxA6 dentro da bicamada da MV (Figura 35D). Lembrando que, ainda não foi estabelecido se a AnxA6 transmembranosa tem a capacidade de transportar $\mathrm{Ca}^{2+}$. 
A inserção da AnxA6 induzida por $\mathrm{pH}$ ácido é reversível com o aumento do $\mathrm{pH}$, o que pode expelir a AnxA6 em direção ao meio extracelular onde o pH é neutro, e então a AnxA6 se liga também a fosfatidilcolina ( $P C)$, mimetizando a associação de AnxA6 com a lamela externa da bicamada das MVs (Figura 35E). Isso pode ocorrer durante a translocação da AnxA6 do lúmen das MVs em direção à lamela extracelular das MVs, ou então, por sua presença no início da liberação das MVs para selar os orifícios da membrana. A AnxA6 associada ou não com a AnxA5 extracelular pode contribuir para reforçar as interações das MVs com as fibras de colágeno (Figura 35F).

Concluímos então, que a AnxA6 em sua complexidade estrutural e comportamental pode desempenhar diferentes funções no processo de biomineralização. Tais funções podem ser motivadas por sua capacidade de interagir em diferentes ambientes lipídicos e em diferentes faixas de $\mathrm{pH}$ como podemos verificar em nosso estudo. Muito ainda deve ser analisado e estudado sobre a AnxA6 e seu papel na mineralização para uma elucidação completa de suas funções, os resultados obtidos até o momento e as metodologias utilizadas poderão servir de auxílio para estudos futuros, uma vez que os modelos miméticos de membrana utilizados (monocamadas de Langmuir, lipossomos e proteolipossomos) para as análises biofísicas e estudos in vitro se mostraram uma eficiente ferramenta, tornando possível reduzir a complexidade dos meios estudados, como também controlar os parâmetros experimentais empregados facilitando o estudo e análise dos dados obtidos. 


\section{REFERÊNCIAS BIBLIOGRÁFICAS}

ADLER, A.J.; GREENFIELD, N.J.; FASMAN, G.D. In methods in Enzimology. Hirs, C.H.W. (ed.) Academic Press, London and New York, v. 27, p. 675, 1973.

ALI, S. Y., SAJDERA, S. W., AND ANDERSON, H. C. Isolation and characterization of calcifying matrix vesicles from epiphyseal cartilage. Proc. Natl. Acad. Sci. U S A., v. 67, p. $1513-1520,1970$.

ANDERSON, H. C. Matrix vesicles and calcification. Current Rheumatology Reports., v. 5, n.3, p. 222 - 226, 2003.

ANDERSON, H. C. Molecular biology of matrix vesicles. Clin. Orthop. Rel. Research, v. 314, p. 266-280, 1995.

ANDERSON, H. C. Vesicles associated with calcification in the matrix of epiphyseal cartilage. Journal of Cell Biology, v. 4, n. 1, p. 59 - 72, 1969.

ANDERSON, H. C.; GARIMELLA, R.; TAGUE, S. E. The role of matrix vesicles in growth plate development and biomineralization. Frontiers in Bioscience, v.10, p. 822- 837, 2005.

ANDERSON, H. C.; SIPE, J. B.; HESSLE, L.; DHANYAMRAJU, R.; ATTI, E.; CAMACHO, N. P.; MILLAN, J. L.; DHAMYAMRAJU, R. Impaired calcification around matrix vesicles of growth plate and bone in alkaline phosphatase-deficient mice. Am J Pathol, v. 164, n. 3, p. 841-7, 2004.

ANDRADE, M.A.R.; FAVARIN, B.; DERRADI, R.; BOLEAN, M.; SIMÃO, A.M.S.; MILLÁN, J.L.; CIANCAGLINI, P.; RAMOS, A.P. Pendant-drop method coupled to ultraviolet-visible spectroscopy: A useful tool to investigate interfacial phenomena. Colloids Surf A Physicochem Eng Asp., v. 504, p. 305-311, 2017.

ANDREE, H.A.; STUART, M.C.; HERMENS, W.T.; REUTELINGSPERGER, C.P.; HEMKER, H.C.; FREDERIK, P.M.; WILLEMS, G.M. Clustering of lipid-bound annexin $\mathrm{V}$ may explain its anticoagulant effect. Journal of Biological Chemistry, v. 267, n. 25, p. 17907-17912, 1992.

ARISPE, N.; ROJAS, E.; GENGE, B. R.; WU, L. N.; WUTHIER, R.E. Similarity in calcium channel activity of annexin $\mathrm{V}$ and matrix vesicles in planar lipid bilayers, Biophysical Journal, v. 71, n. 4, p. 1764-1775, 1996. 
AVILA-SAKAR, A. J.; KRETSINGER, R. H.; CREUTZ, C. E. Membrane-bound 3D structures reveal the intrinsic flexibility of annexin VI. J. Struct. Biol., v. 130, p. 54$62,2000$.

BABIYCHUK, E. B., DRAEGER, A. Annexins in Cell Membrane Dynamics: Ca2+Regulated Association of Lipid Microdomains. J. Cell Biol., v. 150, p. 1113-1124, 2000.

BABIYCHUK, E. B., PALSTRA, R. J., SCHALLER, J., KAMPFER, U.; DRAEGER, A. Annexin $\mathrm{VI}$ participates in the formation of a reversible, membrane-cytoskeleton complex in smooth muscle cells. J. Biol. Chem., v. 274, p. 35191-35195, 1999.

BALCERZAK, M.; HAMADE, E.; ZHANG, L.; PIKULA, S.; AZZAR, G.; RADISSON, J.; BANDOROWICZ-PIKULA, J.; BUCHET, R. The roles of annexins and alkaline phosphatase in mineralization process. Acta Bioquimica Polonica, v. 50 n.4, p. 1019 - 1038, 2003.

BANDOROWICZ-PIKULA, J.; KIRILENKO, A; VAN DEURSEN, R.; GOLCZAK, M.; KÜHNEL, M.; LANCELIN, JM.; PIKULA, S.; BUCHET, R. A Putative Consensus Sequence for the Nucleotide-Binding Site of Annexin A6. Biochemistry, v. 42, n. 30, p. 9137-9146, 2003.

BANDOROWICZ-PIKUŁA, J.; SELIGA, A.K.; Annexin A6 as a cholesterol and nucleotide binding protein involved in membrane repair and in controlling membrane transport during endo- and exocytosis. Postepy Biochem., v. 64, n. 3, p. 190-195, 2018.

BATISTA, C.M.; CARVALHO, C.M.B.; MAGALHÃES, N.S.S. Lipossomas e suas aplicações terapêuticas: estado da arte. Revista Brasileira de Ciências Farmacêuticas, v. 43, n. 2, 2007.

BENZ, J.; BERGNER, A.; HOFMANN, A.; GOTTIG, P.D.P.; LIEMANN, S.; HUBER, R.; VOGES, D. The Structure of Recombinant Human Annexin VI in Crystals and Membrane-bound. J. Mol. Biol., v. 260, p. 638-643, 1996.

BERRY, J.D.; NEESON, M.J.; DAGASTINE, R.R.; CHAN, D. Y.C.; TABOR, R.F. Measurement of surface and interfacial tension using pendant drop tensiometry. Journal of Colloid and Interface Science, v. 434. p. 226-237, 2015.

BERRY, J.D.; NEESON, M.J.; DAGASTINE, R.R.; CHAN, D. Y.C.; TABOR, R.F. Measurement of surface and interfacial tension using pendant drop tensiometry. Journal of Colloid and Interface Science, v. 434. p. 226-237, 2015. 
BLANDFORD, N.R.; SAUER, G.R.; GENGE, B.R.; WU, L.N.Y.; WUTHIER, R.E. Modeling of matrix vesicle biomineralization using large unilamellar vesicles. Journal Inorganic Biochemistry, v. 94, p. 14 - 27, 2003.

BOLEAN, M.; BORIN, I. A.; SIMÃO, A. M. S.; BOTTINI, M.; BAGATOLLI, L. A.; HOYLAERTS, M. F.; MILLÁN, J. L.; CIANCAGLINI, P. Topographic analysis by atomic force microscopy of proteoliposomes matrix vesicle mimetics harboring TNAP and AnxA5. Biochimica et Biophysica Acta (BBA) - Biomembranes, v. 1859, n. 10, p. 1911-1920, 2017.

BOLEAN, M.; IZZI, B.; VAN KERCKHOVEN, S.; BOTTINI, M.; RAMOS, A. P.; MILLÁN, J. L.; HOYLAERTS, M. F.; CIANCAGLINI, P. Matrix vesicle biomimetics harboring Annexin A5 and alkaline phosphatase bind to the native collagen matrix produced by mineralizing vascular smooth muscle cells, Biochimica et Biophysica Acta (BBA) - General Subjects, v. 1864, n. 8, p. 129629, 2020.

BOLEAN, M.; SIMÃO, A.M.; FAVARIN, B.Z.; MILLÁN, J.L.; CIANCAGLINI, P. Thermodynamic properties and characterization of proteoliposomes rich in microdomains carrying alkaline phosphatase. Biophysical Chemistry, v.158, n. 2 3, p. 111 - 118, 2011.

BOLEAN, M.; SIMÃO, A.M.; KIFFER-MOREIRA, T.; HOYLAERTS, M.F.; MILLÁN, J.L.; ITRI, R. CIANCAGLINI, P. Proteoliposomes with the ability to transport Ca (2+) into the vesicles and hydrolyze phosphosubstrates on their surface. Archives of Biochemistry and Biophysics, v. 584, p. 79 - 89, 2015.

BOLEAN, M.; SIMÃO, A.M.S.; BARIONI, M.B.; FAVARIN, B.Z.; SEBINELLI, H.G.; VESCHI, E.A.; JANKU, T.A.B.; BOTTINI, M.; HOYLAERTS, M.F.; ITRI, R. MILLÀN, J.L. CIANCAGLINI, P. Biophysical aspects of biomineralization. Biophysical Reviews, v. 9, 747-760, 2017a.

BOLEAN, M.; SIMÃO, A.M.S.; FAVARIN, B.Z.; MILLÁN, J.L.; CIANCAGLINI, P. The effect of cholesterol on the reconstitution of alkaline phosphatase into liposomes Biophysical Chemistry, v.152, n. 1 - 3, p. 74 - 79, 2010.

BONUCCI, E. Fine Structure and Histochemistry of "Calcifying Globules" in Epiphyseal Cartilage. Zeitschrift Fur Zellforschung Und Mikroskopische Anatomie, v. 103, n.2, p. 192 - 217, 1970.

BONUCCI, E. Fine Structure of Early Cartilage Calcification. Journal of Ultrastructure Research, v. 20, n.1, p. 33 - 50, 1967. 
BOTTINI, M.; MEBAREK, S.; ANDERSON, K. L.; STRZELECKA-KILISZEK, A.; BOZYCKI, L.; SIMÃO, A. M. S.; BOLEAN; M.; CIANCAGLINI, P.; PIKULA, J. B. PIKULA, S.; MAGNE, D.; VOLKMANN, N.; HANEIN, D.; MILLÁN, J. L.; BUCHET, R. Matrix vesicles from chondrocytes and osteoblasts: Their biogenesis, properties, functions and biomimetic models. Biochimica et Biophysica Acta (BBA) - General Subjects, v. 1862, n. 3, p. 532-546, 2018.

BOYAN, B.D.; SCHWARTZ, Z.; SWAIN, L.D.; KHARE, A. Role of lipids in calcification of cartilage. Anat. Rec., v. 224, p. 211-219, 1989.

BOYE, T. L.; JEPPESEN, J. C.; MAEDA, K. et al., Annexins induce curvature on free-edge membranes displaying distinct morphologies. Sci Rep., v. 8, p. 10309, 2018.

BROWN W. Dynamic Light Scattering: The Method and Some Applications. Clarendon Press, Oxford, ed., 1993.

CAIRNS, R.; FISCHER, A. W.; BLANCO-MUNOZ, P.; ALVAREZ-GUAITA, A.; MENESES-SALAS, E.; EGERT, A.; ... \& GREWAL, T. Altered hepatic glucose homeostasis in AnxA6-KO mice fed a high-fat diet. Plos one, v. 13, n. 8, p. e0201310, 2018.

CAMOLEZI, F. L.; DAGHASTANLI, K. R.; MAGALHÃES, P. P.; PIZAURO, J. M.; CIANCAGLINI, P. Construction of an alkaline phosphatase-liposome system: a tool for biomineralization study. The international journal of biochemistry \& cell biology, v. 34, n. 9, p.1091-1101, 2002.

CAMOLEZI, F. L.; PIZAURO, J. M.; LEONE, F. A.; CIANCAGLINI, P. A simple laboratory experiment to demonstrate the interaction of proteins bearing glycosylphosphatidylinositol anchors with liposomes. Biochemical Education, v. 27, n. 1, p. 41-44, 1999.

CAMOLEZI, F.L.; DAGHASTANLI, K.P.R.; MAGALHÃES, P.P.; PIZAURO, J.M.; CIANCAGLINI, P. Construction of an alkaline phosphatase-liposome system: a tool for biomineralization study, The International Journal of Biochemistry \& Cell Biology, v. 34, n. 9, p. 1091 - 1101, 2002.

CAO, X.; GENGE, B. R.; WU, L.N.Y.; BUZZI, W.R.; SHOWMAN, R.M.; WUTHIER, R.E. Characterization, Cloning and Expression of the 67-kDa Annexin from Chicken Growth Plate Cartilage Matrix Vesicles. Biochemical and Biophysical Research Communications, v. 197, n. 2, p. 556-561, 1993.

CHANDER, A.; XIAO-LIANG CHEN, X. L.; NAIDU, D. G. A role for diacylglycerol in annexin A7-mediated fusion of lung lamellar bodies, Biochimica et Biophysica Acta (BBA) - Molecular and Cell Biology of Lipids, v. 1771, n.10, p. 1308-1318, 2007. 
CHANG, H-I.; YEH, M-K. Clinical developmente of lipossome-based drugs: formulation, characterization, and therapeutic efficacy. International Journal of Nanomedicine, v. 7, p. 49- 60, 2012.

CHEN, Y-H.; YANG, J.T.; MARTINEZ, H.M. Determination of the Secondary of Proteins by Circular Dichroism and Optical Rotatory Dispersion. Biochemistry, v. 11, p. 4120-4131, 1972.

CHEN, Y-H.; YANG, J.T.; MARTINEZ, H.M. Determination of the Secondary of Proteins by Circular Dichroism and Optical Rotatory Dispersion. Biochemistry, v. 11, p. 4120-4131, 1972.

CHI, E.Y.; KRISHNAN, S.; RANDOLPH, T.W.; CARPENTER, J.F. Physical stability of proteins in aqueous solution: mechanism and driving forces in nonnative protein aggregation. Pharmaceutical Research., v. 20, n. 9, p. 1325-1336, 2003.

CIANCAGLINI, P.; SIMÃO, A.M.S.; BOLEAN, M.; MILLÁN, J.L.; RIGOS, C.F.; YONEDA, J.S.; COLHONE, M.C.; STABELI, R.G. Proteoliposomes in nanobiotechnology. Biophysical Reviews, v. 4, n. 1, p. 67 - 81, 2012.

CORNELY, R.; RENTERO, C.; ENRICH, C.; GREWAL, T.; GAUS, K. Annexin A6 is an organizer of membrane microdomains to regulate receptor localization and signalling. IUBMB Life, v. 63, n. 11, p. 1009-1017, 2011

CREUTZ, C. E.; PAZOLES, C. J.; POLLARD, H. B. Identification and purification of an adrenal medullary protein (synexin) that causes calcium-dependent aggregation of isolated chromaffin granules. J Biol Chem, v. 253, n. 8, p. 2858-2866, 1978.

CROISSANT, C.; GOUNOU, C.; BOUVET, F.; TAN, S.; BOUTER, A. Annexin-A6 in membrane repair of human skeletal muscle cell: a role in the cap subdomain. Cells, v. 9, n. 7, p.1742, 2020.

CRUMPTON, M. J. e DEDMAN, J. R. Protein terminology tangle. Nature, v. 345, n. 212, 1990.

CRUZ, M. A. E.; FERREIRA, C. R.; NOGUEIRA, L. F. B.; ANDRILLI, L. H. S.; SANTOS, A. L. N.; MACEDO, J. M. M.; VESCHI, E. A.; FAVARIN, B. Z.; SEBINELLI, H. G.; BOLEAN, M.; RAMOS, A. P.; CIANCAGLINI, P. Aspectos químicos da biomineralização óssea. Química Nova. (Submetido), 2021.

DAGHASTANLI, K. R.; FERREIRA, R. B.; THEDEI JR, G., MAGGIO, B.; CIANCAGLINI, P. Lipid composition-dependent incorporation of multiple membrane proteins into liposomes. Colloids and Surfaces B: Biointerfaces, v. 36, n. 3-4, p.127-137, 2004. 
DAVIDSON, F. F.; LISTER, M. D.; DENNIS, E. A. Binding and inhibition studies on lipocortins using phosphatidylcholine vesicles and phospholipase A2 from snake venom, pancreas, and a macrophage-like cell line. J. Biol. Chem., v. 265, n. 10, p. 5602-5609, 1990.

DE BERNARD, B.; BIANCO, P.; BONUCCI, E.; COSTANTINI, M.; LUNAZZI, G. C.; MARTINUZZI, P.; MODRICKY, C.; MORO, L.; PANFILI, E.; POLLESELLO, P. Biochemical and immunohistochemical evidence that in cartilage an alkaline phosphatase is a $\mathrm{Ca}^{2+}$ - binding glycoprotein. J. Cell. Biol., v. 103, p. 1615-1623, 1986.

DE MORAIS, W. A.; PEREIRA, M. R.; FONSECA, J. L. C. Characterization of gelification of chitosan solutions by dynamic light scattering. Carbohydrate Polymers, v. 87, n. 4, p. 2376-2380, 2012.

DEMETZOS, C. Differential Scanning Calorimetry (DSC): a tool to study the thermal behavior of lipid bilayers and liposomal stability. J. Liposome Res., v. 18, n. 3, p. 159-173, 2008.

DEMONBREUN, A. R.; FALLON, K. S.; OOSTERBAAN, C. C.; BOGDANOVIC, E.; WARNER, J. L.; SELL, J. J.; ... \& MCNALLY, E. M. Recombinant annexin A6 promotes membrane repair and protects against muscle injury. The Journal of clinical investigation, v. 129, n. 11, p. 4657-4670, 2019.

DOS SANTOS, N.; MAYER, L. D.; ABRAHAM, S. A.; GALLAGHER, R. C.; COX, K. A.; TARDI, P. G.; BALLY, M. B. Improved retention of idarubicin after intravenous injection obtained for cholesterol-free liposomes. Biochimica et Biophysica Acta (BBA)-Biomembranes, v. 1561, n. 2, p. 188-201, 2002.

DYNAROWICZ-ŁĄTKA, P.; DHANABALAN, A.; OLIVEIRA JR, O. N. Modern physicochemical research on Langmuir monolayers. Advances in colloid and interface science, v. 91, n. 2, p. 221-293, $2001 a$.

DYNAROWICZ-ŁĄTKA, P.; DHANABALAN, A.; OLIVEIRA JR., O.N. Modern physicochemical research on Langmuir monolayers. Advances in Colloid and Interface Science, v. 91, n. 2, p. 221-293, 2001.

DYNAROWICZ-ŁĄTKA, P.; KITA, K.; MILART, P.; DHANABALAN, A.; CAVALLI, A.; OLIVEIRA JR, O. N. Langmuir Monolayers from Substituted 5'-Phenyl-m-terphenyl Carboxylic Acids. Journal of colloid and interface science, v. 239, n. 1, p. 145157, 2001b.

EANES, E.D.; HAILER, A.W. Liposome-mediated calcium phosphate formation in metastable solutions. Calcif. Tissue Int., v. 37, p. 390-394, 1985. 
EANES, E.D.; Thermochemical studies on amorphous calcium phosphate. Calcif. Tissue Res., v. 5, p. 133-145, 1970.

EGGERS, J. Nonlinear dynamics and breakup of free-surface flow. Reviews of Modern Physics, v. 69, n. 3, p. 865-929, 1997.

EGGERS, J.; VILLERMAUX, E. Physics of liquid jets, Reports on Progress in Physics, v. 71, 2008.

EL KIRAT, K.; MORANDAT, S.; DUFRÊNE, Y. F. Nanoscale analysis of supported lipid bilayers using atomic force microscopy. Biochimica et Biophysica Acta (BBA)Biomembranes, v. 1798, n. 4, p. 750-765, 2010.

EVANS, J. S. The Biomineralization Proteome: Protein Complexity for a Complex Bioceramic Assembly Process. Proteomics: Proteomics and Systems Biology, v. 19, n. 16, p. 1900036, 2019.

FÄNDRICH M.; DOBSON, M. C. The behaviour of polyamino acids reveals an inverse side chain effect in amyloid structure formation. The EMBO Journal, v. 21, n. 21 , p. 5682 - 5690, 2002.

FAVARIN, B. Z.; BOLEAN, M.; RAMOS, A. P.; MAGRINI, A.; ROSATO, N.; MILLÁN, J. L.; ET AL.; CIANCAGLINI, P. Lipid composition modulates ATP hydrolysis and calcium phosphate mineral propagation by TNAP-harboring proteoliposomes. Archives of Biochemistry and Biophysics, v. 691, p. 108482, 2020.

FAVARIN, B.Z., ANDRADE, M.A.R., BOLEAN, M., SIMÃO, A.M.S., RAMOS, A.P., HOYLAERTS, M.F., MILLÁN, J.L., CIANCAGLINI, P. Effect of the Presence of Cholesterol in the Interfacial Microenvironment on the Modulation of the Alkaline Phosphatase Activity during In Vitro Mineralization. Colloids and Surfaces B: Biointerfaces, v. 155, p. 466-476, 2017.

FERREIRA, A. A. P.; COLLI, W.; ALVES, M. J. M.; OLIVEIRA, D. R.; COSTA, P. I.; GÜELL, A. G.; ...et al.; YAMANAKA, H. Investigation of the interaction between Tc85-11 protein and antibody anti-T. cruzi by AFM and amperometric measurements. Electrochimica acta, v. 51, n. 24, p. 5046-5052, 2006.

FERRI, J.K.; KOTSMAR, C.; MILLER, R. From surfactant adsorption kinetics to asymmetric nanomembrane mechanics: pendant drop experiments with subphase exchange. Advances in Colloid and Interface Science, v.161, p. 29-47, 2010. 
FRANZONI, L.; NICASTRO, G.; PERTINHEZ, T.A.; TATÒ, M.; NAKAIE, C.R.; PAIVA, A.C.; SCHREIER, S.; SPISNI, A. Structure of the C-terminal fragment 300320 of the rat angiotensin II AT1A receptor and its relevance with respect to Gprotein coupling. J. Biol. Chem., v. 272, n. 15, p. 9734-9741, 1997.

GARCÍA-MELERO, A.; REVERTER, M.; HOQUE, M.; MENESES-SALAS, E.; KOESE, M.; CONWAY, J.R.; JOHNSEN, C. H.; ALVAREZ-GUAITA, A.; MORALESPAYTUVI, F.; ... \& RENTERO, C. Annexin A6 and Late Endosomal Cholesterol Modulate Integrin Recycling and Cell Migration. J Biol Chem., v. 291, n. 3, p. 132035, 2016.

GENETOS, D.C.; WONG, A.; WEBER, T.J.; KARIN, N.J.; YELLOWLEY, C.E. Impaired osteoblast differentiation in annexin A2- and -A5-deficient cells. PLoS One, v. 9, n. 9, p. 107482, 2014.

GENGE, B. R., WU, L. N.; WUTHIER, R. E. In vitro modeling of matrix vesicle nucleation: synergistic stimulation of mineral formation by annexin A5 and phosphatidylserine. Journal of Biological Chemistry, v. 282, n.36, p. 26035 26045, 2007a.

GENGE, B. R.; CAO, X.; WU, L. N. Y.; BUZZI, W. R.; SHOWMAN, R. W.; ARSENAULT, A. L.; ISHIKAWA, Y.; WUTHIER, R. E. Establishment of the primary structure of the major lipid-dependent $\mathrm{Ca}^{2+}$ binding proteins of chicken growth plate cartilage matrix vesicles: Identity with anchorin cii (annexin V) and annexin II. J Bone Miner Res., v. 7, p. 807-819, 1992.

GENGE, B.R.; WU, L.N.Y.; WUTHIER, R.E. Kinetic analysis of mineral formation during in vitro modeling of matrix vesicle mineralization: effect of annexin $A 5$, phosphatidylserine, and type II collagen. Analyt. Biochem., v. 367, p. 159-166, 2007b.

GIRARD-EGROT, A.P.; GODOY, S.; BLUM, L.J. Enzyme association with lipidic Langmuir-Blodgett films: Interests and applications in nanobioscience. Advances in Colloid and Interface Science, n.116, p. 205 - 25, 2005.

GOLCZAK, M.; KIRILENKO, A.; BANDOROWICZ-PIKULA, J.; PIKULA, S. Conformational states of annexin $\mathrm{VI}$ in solution induced by acidic $\mathrm{pH}$. FEBS Letters, v. 496, n. 1, p. 49-54, 2001.

GOLUB, E. E. Role of matrix vesicles in biomineralization. Biochim Biophys Acta, v. 1790, n. 12, p. 1592-8, 2009.

GREENFIELD, N. J. Methods to estimate the conformation of proteins and polypeptides from circular dichroism data. Analytical Biochemistry, v. 235, n. 1, p. 1-10, 1996. 
GREWAL, T.; HOQUE, M.; CONWAY, J. R. W.; REVERTER, M.; WAHBA, M.; BEEVI, S.S.; TIMPSON, P.; ENRICH, C.; RENTERO, C. Annexin A6 - A multifunctional scaffold in cell motility. Cell Adhesion \& Migration, v. 11, n. 7, p. 288 $-304,2017$.

GRSKOVIC, I.; KUTSCH, A.; FRIE, C.; GROMA, G.; STERMANN, J.; SCHLÖTZERSCHREHARDT, U.; NIEHOFF, A.; MOSS, S.E.; ROSENBAUM, S.; PÖSCHL, E.; CHMIELEWSKI, M.; RAPPL, G.; ABKEN, H.; BATEMAN, J.F.; CHEAH, K.S.; PAULSSON, M.; BRACHVOGEL, B. Depletion of annexin A5, annexin A6, and collagen $X$ causes no gross changes in matrix vesicle-mediated mineralization, but lack of collagen $X$ affects hematopoiesis and the Th1/Th2 response. J. Bone Miner. Res., v. 27, n. 11, p. 2399-2412, 2012.

HARTREE, E.F. Determination of protein: a modification of the Lowry method that gives a linear photometric response. Analytical Biochemistry, v. 48, n. 2, p. 422 427, 1972.

HASKELL, R. J. Characterization of submicron systems via optical methods. Journal of pharmaceutical sciences, v. 87, n. 2, p. 125-129, 1998.

HAUPTMANN, R.; MAURER-FOGY, I.; KRYSTEK, E.; BODO, G.; ANDREE, H.; REUTELINGSPERGER, C. P. M. Vascular anticoagulant $\beta$ : a novel human $\mathrm{Ca}^{2+} /$ phospholipid binding protein that inhibits coagulation and phospholipase A2 activity. European Journal of Biochemistry, v. 185, n. 1, p. $63-71,1989$.

HOFMANN, A.; ESCHERICH, A.; LEWIT-BENTLEYI, A.; BENZ, J.; RAGUENESNICOL, C.; RUSSO-MARIE, F.; GERKE, V.; MORODER, L.; HUBE, R. Interactions of Benzodiazepine Derivatives with Annexins. The Journal of Biological Chemistry, v. 237, n. 5, p. 2885 - 2894, 1998.

HORCAS, I.; FERNÁNDEZ, R.; GOMEZ-RODRIGUEZ, J. M.; COLCHERO, J. W. S. X.; GÓMEZ-HERRERO, J. W. S. X. M.; BARO, A. M. WSXM: a software for scanning probe microscopy and a tool for nanotechnology. Review of scientific instruments, v. 78, n. 1, p. 013705, 2007.

HOUSTON, B.; STEWART, A.J.; FARQUHARSON, C. PHOSPHO1-A novel phosphatase specifically expressed at sites of mineralization in bone and cartilage. Bone, v. 34, p. 629-637, 2004.

HSU, H. H. T.; ANDERSON, H. C. A role for ATPase in the mechanisms of ATPdependent $\mathrm{Ca}$ and phosphate deposition by Isolated rachictic matrix vesicles. Int. J. Biochem., v. 27, p. 1349-1356, 1995.

HUANG, K. S., B. P.; WALLNER, R. J.; MATTALIANO, R.; TIZARD, C.; BURNE, A.; FREY, C.; HESSION, P.; MCGRAY, L. K.; SINCLAIR, E. P.; CHOW, J. L;. 
BROWNING, K. L.; RAMACHANDRAN, J.; TANG, J. E.; SMART, R. B.; PEPINSKY. Two human $35 \mathrm{kd}$ inhibitors of phospholipase $\mathrm{A} 2$ are related to substrates of pp60vsrc and of the epidermal growth factor receptor/kinase. Cell, v. 46, p. 191-199, 1986.

HUBER, R.; ROMISCH, J.; PAQUES, E. P. The crystal and molecular structure of human annexin $\mathrm{V}$, an anticoagulante protein that binds to calcium and membranes. The EMBO Journal, v. 9, n. 12, p. 3867 - 3874, 1990a.

HUBER, R.; SCHNEIDER, M.; MAYR, I.; ROMISCH, J.; PAQUES, E. P. The calcium binding sites in human annexin $\mathrm{V}$ by crystal structure analysis at $2.0 \mathrm{~A}$ resolution. Implications for membrane binding and calcium channel activity. FEBS Letters, v. 275 , p. $15-21,1990 b$.

IERARDI, D. F.; PIZAURO, J. M.; CIANCAGLINI, P. Erythrocyte ghost cell-alkaline phosphatase: construction and characterization of a vesicular system for use in biomineralization studies. Biochimica et Biophysica Acta (BBA)-Biomembranes, v. 1567, p. 183-192, 2002.

IERARDI, D.F.; PIZAURO, J.M.; CIANCAGLINI, P. Erythrocyte ghost cell-alkaline phosphatase: construction and characterization of a vesicular system for use in biomineralization studies. Biochimica et Biophysica Acta, v. 1567, n. 1 - 2, p.183 192, 2002.

IRVING, J. T.; WUTHIER, R. E. Histochemistry and Biochemistry of Calcification With Special Reference to the Role of Lipids. Clinical Orthopaedics and Related Research, v. 56, p. 237-260, 1968.

IZUMI, A.; TAKEUCHI, T.; NAKAO, T.; SHIBAYAMA, M. Dynamic light scattering and small-angle neutron scattering studies on phenolic resin solutions. Polymer, v. 52, n. 19, p. 4355-4361, 2011.

JACKLE, S.; BEISIEGEL, U.; RINNINGER, F.; BUCK, F.; GRIGOLEIT, A.; BLOCK, A.; GROGER, I.; GRETEN, H.; E WINDLER, E. Annexin VI, a marker proteinof hepatocytic endosomes. J. Biol. Chem, v. 269, p. 1026-1032, 1994

JAMES, P.J.; ANTOGNOZZI, M.; TAMAYO, J.; MCMASTER, T.J.; NEWTON, J.M.; MILES, M.J. Interpretation of Contrast in Tapping Mode AFM and Shear Force Microscopy. A Study of Nafion. Langmuir, v. 17, p. 349-360, 2001.

JIANG, J.; OBERDÖRSTER, G.; BISWAS, P. Characterization of size, surface charge, and agglomeration state of nanoparticle dispersions for toxicological studies. Journal of Nanoparticle Research, v. 11, n. 1, p. 77-89, 2009. 
JOST, M.; ZEUSCHNER, D.; SEEMANN, J.; WEBER, K.; AND GERKE.V. Identification and characterization of a novel type of annexin-membraneinteraction: Ca21is not required for the association of annexin II withearly endosomes. J. Cell Sci, v. 110, p. 221-228, 1997.

KANEKO, N.; AGO, H.; MATSUDA, R.; INAGAKI, E.; MIYANO, M. Crystal structure of annexin $V$ with its ligand K-201 as a calcium channel activity inhibitor. Journal of Molecular Biology, v. 274, n. 1, p. 16-20, 1997a.

KANEKO, N.; MATSUDA, R.; TODA, M.; SHIMAMOTO, K. Inhibition of annexin Vdependent $\mathrm{Ca}^{2+}$ movement in large unilamellar vesicles by $\mathrm{K} 201$, a new 1,4benzothiazepine derivative. Biochimica et Biophysica Acta (BBA) Biomembranes, v. 1330, n. 1, p. 1-7, 1997b.

KARABENCHEVA-CHRISTOVA, T. G.; CARLSSON, U.; BALALI-MOOD, K.; BLACK, G. W.; CHRISTOV, C. Z. Conformational Effects on the Circular Dichroism of Human Carbonic Anhydrase II: A Multilevel Computational Study. PLOS ONE, v. 8, n. 2, 2013.

KAWASAKI, H.; AVILA-SAKAR, A.; CREUTZ, C, E.; ROBERT H. KRETSINGER, R.H. The crystal structure of annexin VI indicates relative rotation of the two lobes upon membrane binding. Biochimica et Biophysica Acta (BBA) - Molecular Cell Research, v. 1313, n. 3, p. 277-282, 1996.

KELLY, S. M.; JESS, T. J.; PRICE, N. C. How to study proteins by circular dichroism. Biochimica et Biophysica Acta (BBA), v. 1751, n. 2, p. 119-139, 2005.

KIRSCH, T., NAH, H.D., SHAPIRO, I.M., PACIFICI, M. Regulated production of mineralization-competent matrix vesicles in hypertrophic chondrocytes. The Journal of Cell Biology, v. 137, n. 5, p. 1149 - 1160, 1997.

KIRSCH, T.; HARRISON, G.; GOLUB, E.E.; NAH, H.D. The roles of annexins and types II and $X$ collagen in matrix vesicle-mediated mineralization of growth plate cartilage. J. Biol. Chem, v. 275, p. 35577 - 35583, 2000.

KLEINSCHMIDT, J.H. In: Lipid-Protein Interactions: Methods and Protocols Institut für Biologie, Abteilung Biophysik Universität Kassel, Heinrich-Plett-Strabe 40, Kassel, Germany, 2013.

KYRIKOU, I.; GEORGOPOULOS, A.; HATZIANTONIOU, S.; MAVROMOUSTAKOS, T.; DEMETZOS, C. A comparative study of the effects of cholesterol and sclareol, a bioactive labdane type diterpene, on phospholipid bilayers. Chemistry and physics of lipids, v. 133, n. 2, p. 125-34, 2005. 
LE DU, M. H.; STIGBRAND, T.; TAUSSIG, M. J.; MENEZ, A.; STURA, E.A. Crystal structure of alkaline phosphatase from human placenta at $1.8 \AA$ resolution. Implication for a substrate specificity. J. Biol. Chem., v. 276, p. 9158-9165, 2001.

LE DU, M.H.; MILLÁN, J.L. Structural evidence of functional divergence in human alkaline phosphatases. J. Biol. Chem., v. 277, p. 49808-49814, 2002.

LEHNINGER, T. M.; NELSON, D. L.; COX, M. M. Princípios de Bioquímica. Ed. Artmed, n. 6, 2014.

LIEMANN, S.; HUBER, R. Three-dimensional structure of annexins. Cellular and Molecular Life Sciences, v. 53, p. 516 - 521, 1997.

LIN, YC.; CHIPOT, C.; SCHEURING, S. Annexin-V stabilizes membrane defects by inducing lipid phase transition. Nat Commun, v. 11, p. 230, 2020.

LOGUE, S.E.; ELGENDY, M.; MARTIN, S.J. Expression, purification and use of recombinant annexin $\mathrm{V}$ for the detection of apoptotic cells. Nat. Protoc., v. 4, p. 1383-1395, 2009.

LOWE, M. K.; STRAUSS, A. W.; ALPERS, R.; SEETHARAM, S. Molecular clone and expression of cDNA encoding the membrane-associated rat intestinal alcaline phosphatase. Biochimica et Biophysica Acta (BBA) - Biomembranes, v. 1037, p. 170-177, 1990.

MALDONADO-VALDERRAMA, J.; TORCELLO-GÓMEZ, A.; DEL CASTILLOSANTAELLA, T.; HOLGADO-TERRIZA, J. A.; CABRERIZO-VILCHEZ, M. A. Subphase exchange experiments with the pendant drop technique. Advances in colloid and interface science, v. 222, p. 488-501, 2015.

MANNOCK, D.A.; LEWIS, R.A.H.; MCELHANEY, R.N. Comparative calorimetric and spectroscopic studies of the effects of lanosterol and cholesterol on the thewrmotropic phase behavior and organization of dipalmitoylphosphatidylcholine bilayer membranes. Biophys. J., v. 91, p. 3327-3340, 2006.

MAO, G.; LIANG, X.; NG, KY S. Direct force measurement of liposomes by atomic force microscopy. Dekker Encyclopedia of Nanoscience and Nanotechnology, p. 933-942, 2004.

MCKEE, M.D.; YADAV, M.C.; FOSTER, B.L.; SOMERMAN, M.J.; FARQUHARSON, C.; MILLÁN, J.L. Compounded PHOSPHO1/ALPL deficiencies reduce dentin mineralization. J. Dent. Res., v. 92, n. 8, p. 721-727, 2013. 
MIERLO, C.P.M.; JONGH, H.H.J AND VISSER, J.W.G. Circular dichroism of protein in solution and at interfaces. Applied spectroscopy reviews., v. 35, n. 4, p. 277313, 2000.

MIKOS, A. G.; PEPPAS, N. A. Measurement of the surface tension of mucin solutions. International Journal of Pharmaceutics, v. 53, n. 1, p. 1 - 5, 1989.

MILLÁN, J.L. In: Mammalian Alkaline Phosphatase: From Biology to Applications in Medicine and Biotechnology. Wiley-VCH Verlag GmbH \& Co. KGaA, Weinheim, 2006.

MILLER, R.; SEDEV, R.; SCHANO, K.H.; NG, C.; NEUMANN, A.W. Relaxation of adsorption layers at soiution/air interfaces using axisymmetric drop-shape analysis. Colloids Surface, v. 69, p.209-216, 1993.

MINETTI, C.A.; REMETA, D.P. Energetics of membrane protein folding and stability. Arch. Biochem. Biophys, v. 453, n. 1, p. 32-53, 2006.

MIRONOV, V. L. Fundamentals of Scanning Probe Microscopy, 2004.

MORANDAT, S.; AZOUZI, S.; BEAUVAIS, E.; MASTOURI, A.; EL KIRAT, K. Atomic force microscopy of model lipid membranes. Analytical and bioanalytical chemistry, v. 405, n. 5, p. 1445-1461, 2013.

MORANDAT, S.; AZOUZI, S.; BEAUVAIS, E.; MASTOURI, A.; EL KIRAT, K. Atomic force microscopy of model lipid membranes. Analytical and bioanalytical chemistry, v. 405, n. 5, p. 1445-1461, 2013.

MORTIMER, J. C.; LAOHAVISIT, A.; MACPHERSON, N.; WEBB, A.; BROWNLEE, C.; BATTEY, N.H.; DAVIES, J.M. Annexins: multifunctional components of growth and adaptation, Journal of Experimental Botany, v. 59, n. 3, p. 533-544, 2008.

MOSS, S. E.; CRUMPTON, M. J. Alternative splicing gives rise to two forms of the p68 Ca2(+)-binding protein. FEBS Lett, v. 261, n. 2, p. 299-302, 1990.

MOSS, S. E. E MORGAN, R. O. The anexins. Genome Biol, v. 5, n. 4, p. 219, 2004.

NAKAMURA, T.; NAKAMURA, K.; STINSON, R. A. Release of alcaline phosphatase from human osteosarcoma cell by phosphatidylinositol phospholipase C: effect of tunicamycin. Arch. Biochem. Biophys., 265:190-196, 1988. 
NEW, R. R. Preparation of liposomes. Liposomes: a practical approach, p. 33-104, 1990.

OHNESORGE, F.; BINNIG, G. True atomic resolution by atomic force microscopy through repulsive and attractive forces. Science, v. 260, n. 5113, p. 1451-1456, 1993.

OLIVEIRA, V.J.R.; EDILENE A. SILVA, E.A.; OLIVATI1, C.A. Fabricação e caracterização de filmes finos de OC8OC8-PPV aplicados em dispositivos sensores de umidade. Journal of Experimental Techniques and Instrumentation, v.1, n.1, 2018.

PAIN, R. Determining the CD spectrum of a protein. Current protocols in protein science/editorial board, v.7, n. 7.6, 2005.

PECORA R. Dynamic Light Scattering: Applications of Photon Correlation Spectroscopy. Plenum, New York, ed., 1985.

PECORA, R. Dynamic Light Scattering Measurement of Nanometer Particles in Liquids. Journal of Nanoparticle Research, v. 2, n. 2, p. 123-131, 2000.

PERESS, N. S.; ANDERSON, H. C.; SAJDERA, S. W. The lipids of matrix vesicles from bovine fetal epiphyseal cartilage. Calcified tissue research, v. 14, n. 1, p. 275281, 1974.

PIZAURO, J. M.; CIANCAGLINI, P.; LEONE, F.A. Allosteric modulation by ATP, calcium and magnesium ions of rat osseous plate alkaline phosphatase. Biochem. Biophys. Acta, v. 1202, p. 22-28, 1993.

PIZAURO, J. M.; CURTI, C.; CIANCAGLINI, P.; LEONE, F.A. Triton X-100 solubilized bone matrix-induced alkaline phosphatase. Comp. Biochem. Physiol., v. 87B, p. 921-926, 1987.

RAMOS, P. M.; POTOSME, N. M. R.; COPPEL, I. A. F.; GIL, J. M. Potential of ATRFTIR spectroscopy for the classification of natural resins. BEMS reports., v. 4, n. 1, p. 03-06, 2018.

RIGAUD, J. L.; PITARD, B.; LEVY, D. Reconstitution of membrane proteins into liposomes: application to energy-transducing membrane proteins. Biochimica et Biophysica Acta (BBA)-Bioenergetics, v. 1231, n. 3, p. 223-246, 1995.

RIGOS C. F.; NOBRE, T. M.; ZANIQUELLI, M. E. D.; WARD, R. J.; CIANCAGLINI, $\mathrm{P}$. The association of $\mathrm{Na}, \mathrm{K}-\mathrm{ATP}$ ase subunits studied by circular dichroism, surface tension and dilatational elasticity. J Colloid Interface Sci, v. 325, p. 478-48, 2008. 
ROBERTS, S.J.; STEWART, A.J.; SADLER, P.J.; FARQUHARSON, C. Human PHOSPHO1 exhibits high specific phosphoethanolamine and phosphocholine phosphatase activities. Biochem. J., v. 382, p. 59-65, 2004.

ROSENBERG, I. M. Protein Analysis and Purification. Second ed. Boston, 1996.

ROTENBERG, Y.; BORUVKA, L.; NEWMANN, A.W. Determination of surface tension and contact angle from the shapes of axisymmetric fluid interfaces. Journal Colloid Interface Science, v. 93, p.169-183, 1983.

SAUER, G.R.; ADKISSON, H.D.; GENGE, B.R.; WUTHIER, R. E. Regulatory effect of endogenous zinc and inhibitory action of toxic metal ions on calcium accumulation by matrix vesicles in vitro. Bone Miner., v. 7, p. 233-244, 1989.

SCHLAEPFER, D.D.; JONES, J.; HAIGLER, H. T. Inhibition of Protein Kinase C by Annexin V. Biochemistry, v. 31, p. 1886-1891, 1992.

SEBINELLI, H. G.; BORIN, I. A.; CIANCAGLINI, P.; BOLEAN, M. Topographical and mechanical properties of liposome surfaces harboring $\mathrm{Na}$, K-ATPase by means of atomic force microscopy. Soft matter, v. 15, n. 13, p. 2737-2745, 2019.

SILVIUS, J. R. Solubilization and functional reconstitution of biomembrane components. Annual review of biophysics and biomolecular structure, v. 21, n. 1, p. 323-348, 1992a.

SIMÃO, A. M. S.; BOLEAN, M.; FAVARIN, B. Z.; VESCHI, E. A.; TOVANI, C. B.; RAMOS, A. P.; BOTTINI, M.; BUCHET, R.; MILLÁN J. L.; CIANCAGLINI, P. Lipid microenvironment affects the ability of proteoliposomes harboring TNAP to induce mineralization without nucleators. J. Bone Miner. Metab., v. 37, n. 4, p. 607- 613, 2019.

SIMÃO, A.M.S.; BOLEAN, M.; HOYLAERTS, M.F.; MILLÁN, J.L.; CIANCAGLINI, P. Effects of $\mathrm{pH}$ on the Production of Phosphate and Pyrophosphate by Matrix Vesicles' Biomimetics. Calcified Tissue International, v. 93, n. 3, p. 222 -232, 2013.

SIMÃO, A.M.S.; YADAV, M.C.; CIANCAGLINI, P.; MILLÁN, J.L. Proteoliposomes as matrix vesicles biomimetics to study the initiation of skeletal mineralization. Brazilian Journal of Medical and Biological Research, v. 43, p. 234 - 241, 2010a.

SOARES, V. F. Dispersão e estabilização de partículas submicrométricas de óxido de alumínio em sistemas líquidos destinados à produção de materiais refratários. Belo Horizonte, MG: UFMG, 2009. (Dissertação de mestrado da Universidade Federal de Minas Gerais). 
SREERAMA, N.; WOODY, R. W. Estimation of protein secondary structure from CD spectra: Comparison of CONTIN, SELCON and CDSSTR methods with an expanded reference set. Analytical Biochemistry, v. 287, n. 2, p. 252-60, 2000.

SREERAMA, N.; WOODY, R. W. On the analysis of membrane protein circular dichroism spectra. Protein Science, v. 13, p. 100-12, 2004.

STEC, B.; CHELTSOV, A.; MILLÁN, J.L. Refined structures of placental alcaline phosphatase show a consistent pattern of interactions at the peripheral site. Acta Crystallogr. Sect. F. Struct. Biol. Cryst. Commun., v. 66, p. 866-870, 2010.

STEFANIU, C.; BREZESINSKI, G.; MÖHWALD, H. Langmuir monolayers as models to study processes at membrane surfaces. Advances in Colloid and Interface Science, v. 208, p. 197 - 213, 2014.

STRZELECKA-KILISZEK, A.; ROMISZEWSKA, M.; BOZYCKI, L.; MEBAREK, S.; BANDOROWICZ-PIKULA, J.; BUCHET, R.; PIKULA, S. Src and ROCK Kinases Differentially Regulate Mineralization of Human Osteosarcoma Saos-2 Cells. International Journal of Molecular Sciences, v. 20, n. 12, p. 2872, 2019.

TAMAYO, J.; GARCIA, R. Deformation, Contact Time, and Phase Contrast in Tapping Mode Scanning Force Microscopy. Langmuir, v. 12, p. 4430-4435, 1996.

TERMINE, J.D.; PECKAUSKAS, R.A.; POSNER, A.S. Calcium phosphate formation in vitro: II. Effects of environment on amorphouscrystalline transformation. Arch. Biochem. Biophys., v. 140, p. 318-325, 1970.

THOUVEREY, C.; STRZELECKA-KILISZEK, A.; BELCERZAK, M.; BUCHET, R.; PIKULA, S. Matrix vesicles originate from apical membrane microvilli of mineralizing osteoblast-like Saos-2 cells. Journal of Cellular Biochemistry, v. 106, n.1, p. 127 138, 2009.

TIAN, E.; WATANABE, F.; MARTIN, B.; ZANGARI, M. Innate Biomineralization. International Journal of Molecular Sciences, v. 21, n. 14, $p$. 4820, 2020.

TOVANI, C. B.; OLIVEIRA, T. M.; SOARES, M. P.; NASSIF, N.; FUKADA, S. Y.; CIANCAGLINI, P.; ... et al.; RAMOS, A. P. Strontium Calcium Phosphate Nanotubes as Bioinspired Building Blocks for Bone Regeneration. ACS Applied Materials \& Interfaces, v. 12, n. 39, p. 43422-43434, 2020.

TRISTAM-NAGLE, S.; NAGLE, J.F. Lipid bilayers:termodynamics, structure, fluctuations and interactions. Chem. Phys. Lipids, v. 127, p. -14, 2004. 
VESCHI, E.A.; BOLEAN, M.; STRZELECKA-KILISZEK, A.; BANDOROWICZPIKULA, J.; PIKULA, S.; GRANJON, T.; MEBAREK, S.; MAGNE, D.; RAMOS, A.P.; ROSATO, N.; MILLÁN, J.L.; BUCHET, R.; BOTTINI, M.; CIANCAGLINI, P. Localization of Annexin A6 in Matrix Vesicles During Physiological Mineralization. International Journal of Molecular Sciences, v. 21, n. 4, p. 1367, 2020.

WANG, W.; XU, J.; KIRSCH, T. Annexin V and terminal differentiation of growth plate chondrocytes. Exp. Cell Res, v. 305, p. 156 -165, 2005.

WANG, Y.; STRZELECKA-KILISZEK, A.; MANITI, O.; VESCHI, E. A.; BOLEAN, M.; RAMOS, A. P.; MAGNE, D.; BANDOROWICZ-PIKULA, J.; PIKULA, S.; MILLÁN, J. L.; BOTTINI, M.; GOEKJIAN, P.; CIANCAGLINI, P.; BUCHET, R.; TIAN, H.; MEBAREK, S.; HE, X. P.; GRANJON, T. Fluorescence evidence of Annexin A6 translocation across membrane in model matrix vesicles during apatite formation. (Fase final de redação), 2021.

WARNER, G. P.; HUBBARD, H. L.; LLOYD, G. C.; WUTHIER, R. E. Pi- and Cametabolism by matrix vesicle-enriched microsomes prepared from chicken epiphyseal cartilage by isosmotic Percoll densitygradient fractionation, Calcif. Tissue Int., v. 35, p. 327-338, 1983.

WEGE, H.A.; HOLGADO-TERRIZA, J.A.; CABRERIZO-VILCHEZ, M.A. Development of a constant surface pressure penetration Langmuir balance based on axisymmetric drop shape analysis. Journal of Colloid and Interface Science, v. 249, p. 263-273, 2002.

WEGE, H.A.; HOLGADO-TERRIZA, J.A.; GÁLVEZ-RUIZ, M.J.; CABRERIZOVÍLCHEZ, M.A. Development of a new langmuir-type pendant-drop film balance. Colloids and Surfaces B: Biointerfaces, v.12, p.339-349, 1999.

WEI, B.; GUO, C.; LIU, S.; SUN, M. Z. Annexin A4 and cancer, Clinica Chimica Acta, v. 447, p. 72-78, 2015.

WHITMORE, L.; WALLACE, B. A. Protein secondary structure analyses from circular dichroism spectroscopy: methods and reference databases. Biopolymers, v. 89, n. 5, p. 392-400, 2008.

WORCESTER, D. L.; MILLER, R. G.; BRYANT, P. J. Atomic force microscopy of purple membranes. Journal of microscopy, v. 152, n. 3, p. 817-821, 1988.

WU, L. N. Y.; GENGE, B. R.; DUNKELBERGER, D. G.; LEGEROS, R.Z.; CONCANNON, B.; WUTHIER, R. E. Physicochemical characterization of the nucleational core of matrix vesicles. J. Biol. Chem., v. 272, p. 4404-4411, 1997. 
WU, L.N.; YOSHIMORI, T.; GENGE, B. R.; SAUER, G. R.; KIRSCH, T.; ISHIKAWA, Y.; WUTHIER, R.E. Characterization of the nucleational core complex responsible for mineral induction by growth plate cartilage matrix vesicles, J. Biol. Chem., v. 268, p. 25084-25094, 1993.

WUTHIER, R. E. Lipid composition of isolated epiphyseal cartilage cells, membranes and matrix vesicles. Biochimica et Biophysica Acta (BBA)-Lipids and Lipid Metabolism, v. 409, n. 1, p. 128-143, 1975.

WUTHIER, R. E.; LIPSCOMB, G. F. Matrix vesicles: structure, composition, formation and function in calcification. Frontiers in Bioscience, v. 16, p. 2812 2902, 2011.

WUTHIER, R. E.; REGISTER, T. C. Role of alkaline phosphatase, a polifunctional enzyme, in mineralizing tissues. In: "The chemistry and biology of mineralized tissues". (Butler, W.T. ed.) EBSCO Média Inc. Birgmingham, p. 113-124, 1985.

WUTHIER, R.E. Electrolytes of isolated epiphyseal chondrocytes, matrix vesicles, and extracellular fluid. Calcif. Tissue Res., v. 23, p. 125-33, 1977.

WUTHIER, R.E.; CHIN, J.E.; HOLE, J.E.; REGISTER, T.C.; LAURA, Y.H.; ISHIKAWA, Y. Isolation and characterization of calcium accumulating matrix vesicles from chondrocytes of chicken epiphyseal growth plate cartilage in primary culture. Journal of Biological Chemistry, v. 260: p. 15972 - 15979, 1985.

ZEUSCHNER, D.; STOORVOGEL, W.; GERKE, V. Association of annexin 2 with recycling endosomes requires either calcium- or cholesterol-stabilized membrane domains. Eur J Cell Biol, v. 80, n8, p. 499-507, 2001.

ZETASIZER NANO. User manual. Malvern Instruments Ltd, v. 317, n 2.1, 2004.

ZETASIZER NANO. User manual. Malvern Instruments Ltd, v. 485, n 1.1, 2013. 
7. APÊNDICE

7.1 Apêndice A - ARTIGOS PUBLICADOS 


\title{
Localization of Annexin A6 in Matrix Vesicles During Physiological Mineralization
}

\author{
Ekeveliny Amabile Veschi ${ }^{1,+}$, Maytê Bolean ${ }^{1,+}{ }^{+}$Agnieszka Strzelecka-Kiliszek ${ }^{2}$, \\ Joanna Bandorowicz-Pikula ${ }^{2}$, Slawomir Pikula ${ }^{2}$, Thierry Granjon ${ }^{3,4,5,6,7}$, \\ Saida Mebarek ${ }^{3,4,5,6,7}$, David Magne ${ }^{3,4,5,6,7}$, Ana Paula Ramos ${ }^{1}\left(\right.$ C) , Nicola Rosato ${ }^{8}$, \\ José Luis Millán ${ }^{9}$, Rene Buchet ${ }^{3,4,5,6,7}$, Massimo Bottini ${ }^{8,9, *}$ and Pietro Ciancaglini ${ }^{1, *(C)}$ \\ 1 Departamento de Química, Faculdade de Filosofia, Ciências e Letras de Ribeirāo Preto da Universidade \\ de Sāo Paulo (FFCLRP-USP), Ribeirāo Preto, Sāo Paulo 14040-900, Brazil; ekeveliny.veschi@usp.br (E.A.V); \\ maytebolean@usp.br (M.B.); anapr@ffclrp.usp.br (A.P.R.) \\ 2 Nencki Institute of Experimental Biology, 3 Pasteur Street, 02-093 Warsaw, Poland; \\ a.strzelecka-kiliszek@nencki.edu.pl (A.S.K.); j.bandorowicz-pikula@nencki.edu.pl (J.B.-P.); \\ s.pikula@nencki.edu.pl (S.P.) \\ 3 Universite Lyon 1, UFR Chimie Biochimie, CEDEX, 69622 Villeurbanne, France; \\ thierry.granjon@univ-lyon1.fr (T.G.); saida.mebarek@univ-lyon1.fr (S.M.); \\ david.magne@univ-lyon1.fr (D.M.); rene.buchet@univ-lyon1.fr (R.B.) \\ 4 ICBMS UMR 5246 CNRS, CEDEX, 69622 Villeurbanne, France \\ 5 INSA, Lyon, CEDEX, 69622 Villeurbanne, France \\ 6 CPE, Lyon, CEDEX, 69622 Villeurbanne, France \\ 7 Université de Lyon, CEDEX, 69622 Villeurbanne, France \\ 8 Department of Experimental Medicine, University of Rome Tor Vergata, 00133 Rome, Italy; \\ nicola.rosato@uniroma2.it \\ 9 Sanford Burnham Prebys Medical Discovery Institute, La Jolla, CA 92037, USA; millan@sbpdiscovery.org \\ * Correspondence: pietro@ffclrp.usp.br (P.C.); massimo.bottini@uniroma2.it (M.B.) \\ + These authors contributed equally to this paper.
}

Received: 28 December 2019; Accepted: 14 February 2020; Published: 18 February 2020

\begin{abstract}
Annexin A6 (AnxA6) is the largest member of the annexin family of proteins present in matrix vesicles (MVs). MVs are a special class of extracellular vesicles that serve as a nucleation site during cartilage, bone, and mantle dentin mineralization. In this study, we assessed the localization of AnxA6 in the MV membrane bilayer using native MVs and MV biomimetics. Biochemical analyses revealed that AnxA6 in MVs can be divided into three distinct groups. The first group corresponds to $\mathrm{Ca}^{2+}$-bound AnxA6 interacting with the inner leaflet of the MV membrane. The second group corresponds to AnxA6 localized on the surface of the outer leaflet. The third group corresponds to AnxA6 inserted in the membrane's hydrophobic bilayer and co-localized with cholesterol (Chol). Using monolayers and proteoliposomes composed of either dipalmitoylphosphatidylcholine (DPPC) to mimic the outer leaflet of the MV membrane bilayer or a 9:1 DPPC:dipalmitoylphosphatidylserine (DPPS) mixture to mimic the inner leaflet, with and without $\mathrm{Ca}^{2+}$, we confirmed that, in agreement with the biochemical data, AnxA6 interacted differently with the MV membrane. Thermodynamic analyses based on the measurement of surface pressure exclusion $\left(\pi_{e x c}\right)$, enthalpy $(\Delta \mathrm{H})$, and phase transition cooperativity $\left(\Delta t_{1 / 2}\right)$ showed that AnxA6 interacted with DPPC and 9:1 DPPC:DPPS systems and that this interaction increased in the presence of Chol. The selective recruitment of AnxA6 by Chol was observed in MVs as probed by the addition of methyl- $\beta$-cyclodextrin (M $\beta C D$ ). AnxA6-lipid interaction was also $\mathrm{Ca}^{2+}$-dependent, as evidenced by the increase in $\pi_{e x c}$ in negatively charged 9:1 DPPC:DPPS monolayers and the decrease in $\triangle \mathrm{H}$ in 9:1 DPPC:DPPS proteoliposomes caused by the addition of AnxA6 in the presence of $\mathrm{Ca}^{2+}$ compared to DPPC zwitterionic bilayers. The interaction of AnxA6 with DPPC and 9:1 DPPC:DPPS systems was distinct even in the absence of $\mathrm{Ca}^{2+}$ as observed by the larger change in $\Delta t_{1 / 2}$ in 9:1 DPPC:DPPS vesicles as compared to DPPC vesicles. Protrusions on
\end{abstract}




\title{
Langmuir monolayers and proteoliposomes as models of matrix vesicles involved in biomineralization
}

\author{
Ana Paula Ramos ${ }^{1} \cdot$ Mayte Bolean ${ }^{1} \cdot$ Marcos A. E. Cruz ${ }^{1}$. Luiz H. S. Andrilli · Lucas F. B. Nogueira' \\ Heitor G. Sebinelli ' Ana Lara N. dos Santos ${ }^{1}$. Bruno Z. Favarin ${ }^{1}$. Jeferson M. M. Macedo ${ }^{1}$. Ekeveliny A. Veschi ${ }^{1}$. \\ Claudio R. Ferreira ${ }^{1}$ José Luis Millán ${ }^{2} \cdot$ Massimo Bottini $^{2,3} \cdot$ Pietro Ciancaglini' ${ }^{1}$
}

Received: 15 October 2021 / Accepted: 22 October 2021

International Union for Pure and Applied Biophysics (IUPAB) and Springer-Verlag GmbH Germany, part of Springer Nature 2021

\begin{abstract}
Chondrocytes and osteoblasts are able to mineralize the extracellular matrix (ECM) by promoting the nucleation of apatite in the lumen of matrix vesicles (MVs) during endochondral bone formation (Bottini et al. 2018; Plaut et al. 2019). The lipids and proteins present in the membrane of the MVs mediate the interactions of these vesicles with the ECM and regulate the initial mineral deposition and further propagation. Among the proteins, ion transporters control the availability of phosphate and calcium needed for initial apatite precipitation. Phosphatases (orphan phosphatase 1 (PHOSPHO1), ectonucleotide pyrophosphatase/ phosphodiesterase 1 (NPP1), and tissue-nonspecific alkaline phosphatase (TNAP) play a crucial role in controlling the inorganic pyrophosphate/inorganic phosphate ratio that allows MVs-mediated initiation of mineralization. The lipidic microenvironment can serve as binding sites for $\mathrm{Ca}^{2+}$ associated with enzymes and transporters (type III sodiumdependent phosphate transporters (PIT1/2), annexins (specifically AnxA5), and $\mathrm{Na}^{+}, \mathrm{K}^{+}$-ATPase (NKA) to form calcium phosphate complexes (Bolean et al. 2017a; Cruz et al. 2020). This exquisite, highly regulated multistep process can be studied with the aid of simplified membrane models such as Langmuir monolayers, liposomes, and proteoliposomes (Fig. 1).These models are useful for understanding the lipidprotein interactions with emphasis on physicochemical and biochemical processes that trigger mineralization (Andrade et al. 2019; Derradi et al. 2019; Bolean et al. 2015, 2017a, b, 2020; Simão et al. 2010, 2019; Favarin et al. 2017, 2020).
\end{abstract}

Pietro Ciancaglini pietro@ffclrp.usp.br

1 Department of Chemistry, FFCLRP, University of São Paulo, Ribeirão Preto, SP, Brazil

? - d Burnham Prebys, La Jolla, CA, USA

- Reference finder ment of Experimental Medicine, University of Rome
Our group has made a series of advances, based on the use of biomimetic models that have increased the general understanding of the biomineralization process. Among these developments, we highlight the following:

(1) Proteoliposomes composed by different lipids and TNAP propagate mineralization after $48 \mathrm{~h}$ of incubation with ATP as a source of $\mathrm{Pi}$, at saturating conditions, and in the presence of a nucleator (Simão et al. 2019; Favarin et al. 2020). We also found that DMPC:SM proteoliposomes displayed the highest efficiency of substrate hydrolysis, apparent affinity for ATP, and mineral propagation, related to the highest degree of membrane organization (highest $\Delta \mathrm{H}$ of phase transition), among the tested proteoliposomes. Taken together, these data indicated that, in addition to the essential components required for mineralization, such as enzymes, substrates, ions, and lipid bilayers, the degree of packing of lipid bilayers and the presence of sterol can affect both TNAP catalytic efficiency and the supersaturation conditions required to precipitate apatite crystals (Simão et al. 2019, Favarin et al. 2020).

(2) The presence of TNAP in the proteoliposomes did not significantly affect AnxA5-mediated $\mathrm{Ca}^{2+}$ transports. On the other hand, one can observe that the presence of AnxA5 affects significantly the hydrolysis of substrates by TNAP. Admittedly, this proteoliposome system is still incomplete since other proteins are necessary to adequately mimic the MVs in the biomineralization process, such as the protein Pit-1 for example, which may be responsible for the Pi influx into the vesicles (Boelan et al., 2015, 2017a).

(3) An AFM study using proteoliposomes harboring TNAP and AnxA5 provides basic yet crucial information about the structure of lipid-protein microdomains on the surface of MVs that other microscopy techniques 


\section{ASPECTOS QUÍMICOS DA BIOMINERALIZAC̣̃̃O ÓSSEA}

Marcos A.E. Cruz", Claudio R. Ferreiraa, Lucas F. B. Nogueiraa, Luiz H.S. Andrillia, Ana Lara N. dos Santosa ${ }^{a}$, Jeferson M. M. Macedo", Ekeveliny A. Veschi, Bruno Z. Favarin², Heitor G. Sebinelli,, , Mayte Boleanª, Ana Paula Ramos"* e Pietro Ciancaglini" ${ }^{a *,}, \odot$

"Departamento de Química, Faculdade de Filosofia, Ciências e Letras de Ribeirão Preto (FFCLRP) Universidade de São Paulo (USP), 14040-901 Ribeirão Preto - SP, Brasil

Recebido em 00/00/2021; aceito em 00/00/2021; publicado em 14/01/2022

THE CHEMISTRY BEHIND BONE BIOMINERALIZATION. The bone formation process is an example of how both time and nature acted harmonically to pave the path for life as we know. The unique association between calcium phosphate (CaP) and collagen in a single building block, gave rise to one of the most remarkable biomaterials that we know. Our aim in this revision is to provide a brief glance at the different organization levels of the bone tissue, by describing the main their main features. We start with a brief discussion regarding the thermodynamic conditions for mineral formation and how living organisms surpass them. Then we present collagen, the major organic component of bone, in the light of its hierarchical organization as well as its association to CaP crystals. The mechanisms that control both mineral formation and the association with the organic phase are further presented, in which cells and other components of the extracellular matrix, such as matrix vesicles and noncollagenous proteins, become agents of bone construction. Finally, we underline the difficulty of studying the complex process of bone mineralization and present liposomes, proteoliposomes, and Langmuir monolayers as biomimetic approaches to this end.

Keywords: bone mineralization, collagen, calcium phosphate, matrix vesicles 


\title{
Lipid microenvironment affects the ability of proteoliposomes harboring TNAP to induce mineralization without nucleators
}

\author{
Ana Maria Sper Simão ${ }^{1}$ Maytê Bolean ${ }^{1} \oplus$ - Bruno Zoccaratto Favarin ${ }^{1} \cdot$ Ekeveliny Amabile Veschi ${ }^{1}$. \\ Camila Bussola Tovani ${ }^{1}$ - Ana Paula Ramos ${ }^{1}$ - Massimo Bottini ${ }^{2,3} \cdot$ Rene Buchet ${ }^{4,5,6,7,8}$. José Luis Millán ${ }^{3}$. \\ Pietro Ciancaglini ${ }^{1}[$ [
}

Received: 30 July 2018 / Accepted: 19 September 2018

๑ The Japanese Society for Bone and Mineral Research and Springer Japan KK, part of Springer Nature 2018

\begin{abstract}
Tissue-nonspecific alkaline phosphatase (TNAP), a glycosylphosphatidylinositol-anchored ectoenzyme present on the membrane of matrix vesicles (MVs), hydrolyzes the mineralization inhibitor inorganic pyrophosphate as well as ATP to generate the inorganic phosphate needed for apatite formation. Herein, we used proteoliposomes harboring TNAP as MV biomimetics with or without nucleators of mineral formation (amorphous calcium phosphate and complexes with phosphatidylserine) to assess the role of the MVs' membrane lipid composition on TNAP activity by means of turbidity assay and FTIR analysis. We found that TNAP-proteoliposomes have the ability to induce mineralization even in the absence of mineral nucleators. We also found that the addition of cholesterol or sphingomyelin to TNAP-proteoliposomes composed of 1,2-dipalmitoyl-snglycero-3-phosphocholine reduced the ability of TNAP to induce biomineralization. Our results suggest that the lipid microenvironment is essential for the induction and propagation of minerals mediated by TNAP.
\end{abstract}

Keywords Biomineralization $\cdot$ Proteoliposome $\cdot$ Alkaline phosphatase $\cdot$ Matrix vesicles $\cdot$ Nucleational core

Ana Maria Sper Simão and Maytê Bolean contributed equally to this work.

$\triangle$ Pietro Ciancaglini

pietro@ffclrp.usp.br

1 Departamento de Química, Faculdade de Filosofia, Ciências e Letras de Ribeirão Preto da Universidade de São Paulo (FFCLRP-USP), Av. Bandeirantes 3900, Ribeirão Preto, SP 14040-901, Brazil

2 Department of Experimental Medicine and Surgery, University of Rome Tor Vergata, 00133 Rome, Italy

3 Sanford Burnham Prebys Medical Discovery Institute, La Jolla, CA 92037, USA

4 UFR Chimie Biochimie, Universite Lyon 1 , 69622 Villeurbanne Cedex, France

5 ICBMS, UMR 5246, CNRS, 69622 Villeurbanne Cedex, France

6 INSA, Lyon, 69622 Villeurbanne Cedex, France

7 CPE, Lyon, 69622 Villeurbanne Cedex, France

8 Universite de Lyon, 69622 Villeurbanne Cedex, France

\section{Introduction}

During bone formation, osteoblasts or chondrocytes produce and mineralize the extracellular matrix (ECM) [1]. The formation of apatite is initiated in the lumen of matrix vesicles (MVs) and has been described to depend on the presence of a nucleator, the nucleational core (NC), in the lumen of MVs $[2,3]$. The components of the NC, the amorphous calcium phosphate (ACP) in association with phosphatidylserine (PS), result in calcium-phosphate-lipid complexes (PS-CPLXs). Further accumulation of $\mathrm{Ca}^{2+}$ and inorganic phosphate $\left(\mathrm{P}_{\mathrm{i}}\right)$ in MVs can lead to the growth of apatite crystals, which then propagate on the ECM and continue to grow onto collagenous fibers, forming bone tissues. Tissue-nonspecific alkaline phosphatase (TNAP, E.C. 3.1.3.1) $[4,5]$ is a glycosylphosphatidylinositol (GPI)-anchored protein present on the plasma membrane of osteoblasts and chondrocytes, and also on the surface of MVs [6]. TNAP provides $\mathrm{P}_{\mathrm{i}}$ needed for apatite crystallization by hydrolyzing phosphomonoesters [7]. Among various substrates, TNAP catalyzes the hydrolysis of pyrophosphate $\left(\mathrm{PP}_{\mathrm{i}}\right)$, a mineralization inhibitor [8], thus facilitating the formation of apatite crystals [5, 9-11]. Adequate local concentrations of extracellular $\mathrm{PP}_{\mathrm{i}}$, originating from the hydrolysis 


\title{
Biophysical aspects of biomineralization
}

\author{
Maytê Bolean ${ }^{1} \cdot$ Ana M. S. Simão ${ }^{1} \cdot$ Marina B. Barioni $^{1} \cdot$ Bruno Z. Favarin $^{1}$. \\ Heitor G. Sebinelli ${ }^{1}$ - Ekeveliny A. Veschi ${ }^{1}$. Tatiane A. B. Janku ${ }^{1}$ - Massimo Bottini ${ }^{2,3}$. \\ Marc F. Hoylaerts ${ }^{4}$. Rosangela Itri ${ }^{5}$. José L. Millán ${ }^{6}$ - Pietro Ciancaglini ${ }^{1}$
}

Received: 22 June 2017 /Accepted: 4 August 2017 /Published online: 29 August 2017

(C) International Union for Pure and Applied Biophysics (IUPAB) and Springer-Verlag GmbH Germany 2017

\begin{abstract}
During the process of endochondral bone formation, chondrocytes and osteoblasts mineralize their extracellular matrix (ECM) by promoting the synthesis of hydroxyapatite (HA) seed crystals in the sheltered interior of membranelimited matrix vesicles (MVs). Several lipid and proteins present in the membrane of the MVs mediate the interactions of MVs with the ECM and regulate the initial mineral deposition and posterior propagation. Among the proteins of MV membranes, ion transporters control the availability of phosphate and calcium needed for initial HA deposition. Phosphatases (orphan phosphatase 1, ectonucleotide pyrophosphatase/ phosphodiesterase 1 and tissue-nonspecific alkaline phosphatase) play a crucial role in controlling the inorganic pyrophosphate/inorganic phosphate ratio that allows MV-
\end{abstract}

This article is part of a Special Issue on 'Latin America' edited by Pietro Ciancaglini and Rosangela Itri.

$\triangle$ Maytê Bolean

maytebolean @usp.br

$\triangle$ Pietro Ciancaglini

pietro@ frclp.usp.br

1 Depto. Química, Faculdade de Filosofia, Ciências e Letras de Riberião Preto (FFCLRP), Universidade de Săo Paulo, Av. Bandeirantes, 3900, Ribeiria Preto, SP 14040-901, Brazil

2 Department of Experimental Medicine and Surgery, University of Rome Tor Vergata, Rome, Italy

3 Inflammatory and Infectious Disease Center, Sanford Bumham Prebys Medical Discovery Institute, La Jol ha, CA, USA

4 Department of Cardiovascular Sciences, Center for Molecular and Vascular Biology, University of Leuven, Leuven, Belgium

5 Depto. Física Aplicada, Instituto de Física, Universidade de São Paulo, São Paulo, SP, Brazil

6 Sanford Bumham Prebys Medical Discovery Institute, La Jolla, CA, USA mediated initiation of mineralization. The lipidic microenvironment can help in the nucleation process of first crystals and also plays a crucial physiological role in the function of MVassociated enzymes and transporters (type III sodiumdependent phosphate transporters, annexins and $\mathrm{Na}^{+} / \mathrm{K}^{+}$ ATPase). The whole process is mediated and regulated by the action of several molecules and steps, which make the process complex and highly regulated. Liposomes and proteoliposomes, as models of biological membranes, facilitate the understanding of lipid-protein interactions with emphasis on the properties of physicochemical and biochemical processes. In this review, we discuss the use of proteoliposomes as multiple protein carrier systems intended to mimic the various functions of MVs during the initiation and propagation of mineral growth in the course of biomineralization. We focus on studies applying biophysical tools to characterize the biomimetic models in order to gain an understanding of the importance of lipid-protein and lipid-lipid interfaces throughout the process.

Keywords Lipid microenvironment - Biomineralization . Matrix vesicles $\cdot$ Liposome Proteoliposome $\cdot$ Hydroxyapatite

\section{Mineralization process and the biogenesis of matrix vesicles}

Mineralization of cartilage and bone occurs by a series of physicochemical and biochemical processes that together facilitate the deposition of calcium phosphate. The deposited calcium phosphate is subsequently converted into hydroxyapatite (HA) $\left[\mathrm{Ca}_{10}\left(\mathrm{PO}_{4}\right)_{6}(\mathrm{OH})_{2}\right]$ in specific areas of the extracellular matrix (ECM). Various experiments have revealed the presence of HA crystals both inside and outside collagen fibrils in the ECM (McNally et al. 2012) and also within the 